\title{
VIBRATION STUDY OF THE APS MAGNET SUPPORT ASSEMBLIES
}

\author{
by \\ M.W. Wambsganss, J.A. Jendrzejczyk, and S.S. Chen \\ Materials and Components Technology Division \\ Argonne National Laboratory
}

APP 271992

\section{BACKGROUND}

Stability of the positron closed orbit is a requirement for successful operation of the Advanced Photon Source. The fact that vibration of the storage ring quadrupole magnets can lead to distortion of the positron closed orbit and to potentially unacceptable beam emittance growth provides the motivation for the subject studies. Low frequency vibrations $(<10-20 \mathrm{~Hz})$ can be controlled with steering magnets using feedback systems, provided the vibration amplitudes are within the dynamic range of the controllers. High frequency $(>10-20 \mathrm{~Hz}$ ) vibration amplitudes, on the other hand, are out of the range of the controller and, therefore, must be limited to ensure that the emittance growth will not exceed a prescribed value.

Vibration criteria were developed based on the requirement that emittance growth be limited to 10 percent. Recognizing that the quadrupole magnets have the most significant effect, three different scenarios were considered: (1) vibration of a single quadrupole within the storage ring, (2) random vibration of all the quadrupoles in the ring, and (3) the hypothetical case of a plane wave sweeping across the site and the quadrupoles following the motion of the plane wave. The maximum allowable peak vibration amplitudes corresponding to these three vibration scenarios are given in Table 1 . The criteria associated with the passage of a plane wave is dependent on wavelength, or, alternatively, on frequency given the wave speed. The wave speed used in Table 1 is that measured as a part of the geotechnical investigation at the APS site.

From Table 1, it can be seen that the most stringent criteria are those associated with random vibration of all the storage ring quadrupoles. As such, these criteria will be assumed as the vibration criteria to be met for vibration r.mplitudes in the frequency range $>10-20 \mathrm{~Hz}$. In the low frequency region, the criterion is that the amplitudes must be within the dynamic range of the feedback control system. 


\section{DISCLAIMER}

This report was prepared as an account of work sponsored by an agency of the United States Government. Neither the United States Government nor any agency thereof, nor any of their employees, makes any warranty, express or implied, or assumes any legal liability or responsibility for the accuracy, completeness, or usefulness of any information, apparatus, product, or process disclosed, or represents that its use would not infringe privately owned rights. Reference herein to any specific cornmercial product, process, or service by trade name, trademark, manufacturer, or otherwise does not necessarily constitute or imply its endorsement, recommendation, or favoring by the United States Government or any agency thereof. The views and opinions of authors expressed herein do not necessarily state or reflect those of the United States Government or any agency thereof. 
Table 1. Vibration criteria: maximum allowable vibration amplitudes

\begin{tabular}{|c|c|c|}
\hline Vibration Type & $\left(\delta_{\mathrm{m}}\right)_{\mathrm{H}}, \mu \mathrm{m}$ & $\left(\delta_{\mathrm{m}}\right)_{\mathrm{V}}, \mu \mathrm{m}$ \\
\hline Single Quadrupole & $2: 2$ & 1.29 \\
\hline Random (all quadrupoles) & 0.34 & 0.12 \\
\hline \multicolumn{3}{|c|}{ Plane Wave $(v=306 \mathrm{~m} / \mathrm{s}, \mathrm{f}$ in $\mathrm{Hz})$} \\
\hline $\begin{aligned} & f<2.2 \\
2.2< & \mathrm{f}<4.6 \\
4.6<\mathrm{f} & <7.7 \\
7.7< & \mathrm{f}<13.5 \\
& \mathrm{f}>13.5\end{aligned}$ & $\begin{array}{c}16.1 \\
16.1 \\
16.1 \\
16.1-0.90 \\
0.90\end{array}$ & $\begin{array}{c}4.4 \\
4.4-0.28 \\
0.28 \\
0.28 \\
0.28\end{array}$ \\
\hline
\end{tabular}

$\left(\delta_{\mathrm{m}}\right)_{\mathrm{H}}$ and $\left(\delta_{\mathrm{m}}\right)_{\mathrm{V}}$ are peak horizontal and vertical components, respectively, of magnet vibration.

The technical approach followed is illustrated in flow diagram format in Fig. 1. As illustrated in Fig. 1, the major thrust of the studies is to estimate magnet vibration to internal excitation sources and floor motion, to assess the estimated response relative to the vibration criteria, and, based on the assessment to make a decision as to the way to proceed, that is, proceed with design and construction or redesign.

As illustrated in Fig. 1, vibration of the quadrupole magnets will be determined by the dynamic characteristics (natural frequencies, modes, and damping) of the magnet/girder/support assemblies and the excitation sources. Internal excitation sources include the coolant flow in header and return piping and energization of the power supplies. The magnet support system will also respond to motion of the experimental hall floor slab, in particular, the storage ring basemat.

As shown in Fig. 1, vibration of the floor slabs will be determined by the design of the experimental hall and foundation, the soil properties at the site, external excitation in the form of ground motion due to natural and/or cultural scurces, and internal (to the experimental hall) excitation associated with pumps, compressors, HVAC equipment, and the like. Program elements relating to the motion of the experimental hall floor slab and storage ring basemat, and to design to minimize floor motion, have been addressed and reported [1-11]. The results of these earlier investigations, including preliminary analyses of the magnet support assemblies [12, 13], are summarized in the following. 


\section{VIBRATION STUDIES IN SUPPORT OF 7-GeV APS}

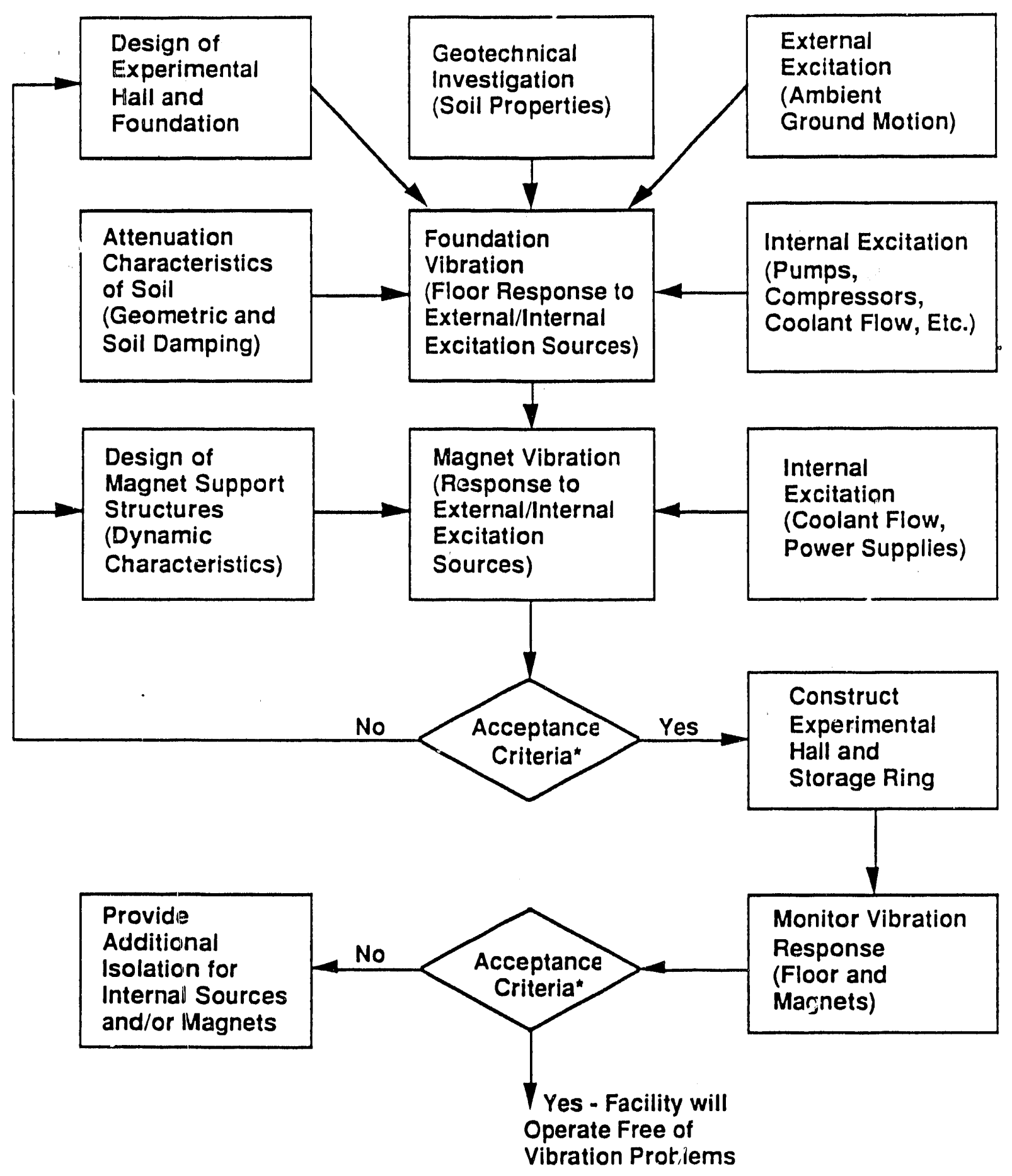

"Vibration acceptance criteria: for $f>10-20 \mathrm{~Hz}$; peak vertical amplitude $<0.12 \mu \mathrm{m}$, peak horizontal amplitude $<0.34 \mu \mathrm{m}$

Fig. 1. Technical Approach 


\section{SUMAMARY OF PREVIOUS INVESTIGATIONS}

A geotechnical investigation including 28 borings at the original site [1], supplemented with additional borings at the new site (shifted approximately 270 feet south and 100 feet west) [2] was completed. Field testing, crosshole seismic testing, and laboratory testing were performed. Among other things, the results provided information on foundation bearing capacities and settlement. It was concluded that bearing soils existing at design subgrade level are generally suitable (competent and stable) for support of the storage ring basemat and experimental hall floor slab on grade. Results from the crosshole seismic testing gave information on shear and compressional wave speeds which, in turn, allowed computation of soil modulus values; such information is needed for soil/foundation interaction analyses. These results supplemented earlier surface measurements of shear wave velocities [3].

Sources of ground motion can be classified as ambient and cultural. Ambient sources include natural disturbances such as microseismic tremors. Examples of cultural sources include road and rail traffic and reciprocating machinery in nearby buildings. Surveys of ground motion were made in the vicinity of Building 335 [4, 5], as well as at the APS site [6,7]. At the APS site, six simultaneous measurements were made on what would correspond to the circumference of the storage ring. Continuous recordings of acceleration-time data were performed over a 24-hour period in May 1988 [6]. Results of these measurements indicated relatively large amplitude response $(>0.05 \mathrm{~mm} \mathrm{rms})$ at select frequencies (18 and $60 \mathrm{~Hz}$ ) at two measurement locations. These measurements were followed by continuous monitoring, over the period July 1988 to January 1990, for further indications of the large amplitude response [7]. With one exception, no further indications were found.

Conclusions from the ground motion measurement program can be summarized as follows:

- From a vibrations standpoint, the selected APS site is "quiet" and wellsuited for construction of the APS. (Note - independent measurements by the A-E's vibration consultant confirmed this finding [8].)

- Disturbances associated with road traffic can be controlled by maintaining smooth road suriaces and enforcing speed limits.

- "Distance" can be effectively used to isolate potential excitation sources associated, for example, with the utility building. 
A soil/foundation interaction analysis was performed to develop an understanding of the dynamic characteristics, in particular, resonant frequencies and damping, to be expected with the slab on grade construction [9]. Equivalent lumped parameter modelling based on elastic half space theory was used, with the soil shear modulus and density as obtained from the geotechnical investigation. The modelling was evaluated using available test data on large foundations, and shown to be generally applicable. The significant conclusion from the analysis is that the large plan dimensions of the APS storage ring basemat and experimental hall floor slabs result in very large damping values, which, in turn, implies that any dynamic magnification factors will be small (negligible). As a consequence, amplification of ground motion as a result of the soil/foundation interaction dynamics is not a corcern. Conservatively, the floor can be assumed to follow the motion of the ground. However, experience suggests that with large slabs the floor motion will actually be smaller than the ground motion due, among other things, to "waveform averaging" [10].

It should be noted that if the floor slabs were supported on caissons, as suggested in a value engineering proposal, the large damping values could not be assured for the requisite contact between the concrete slabs and soil could not be assured. As a result, a potential for dynamic amplification of ground motion would exist with that support configuration. The analysis then serves to confirm the decision to support the storage ring basemat and experimental hall floor slabs on grade.

To gain insight into the vibration levels that might be expected at an accelerator facility located at Argonne, a vibration survey was performed at the Intense Pulsed Neutron Source (IPNS) Facility [11]. The survey included measurements of experimental hall floor vibraition at several locations, vibration of the floor at the base of the magnets, and magnet vibration. The vibration measurements were made with various equipment in operation and not operating. In the frequency range of 10 to $250 \mathrm{~Hz}$, measured vibration levels were in the range of 0.02 to $0.08 \mu \mathrm{m} \mathrm{rms}$. Among other things the results of the survey led to the conclusions that (1) the magnet/support structure can provide dynamic amplification of the floor motion, and (2) energizing the quadrupole magnets results in an increase, by a factor greater than 2 , in vibration level.

Preliminary dynamic analyses of the magnet support assemblies were performed and reported [12-13]. The major results and insights derived as a consequence of the analyses were as follows:

- In the lowest modes, the flexibility of the jack screw/pedestal supports plays the dominant rol! in determining the dynamic behavior of the system; as a consequence, the girder can be considered as a rigid beam. 
- The largest uncertainty in the analyses is the estimation of the flexibilities (effective spring constants) of the jack screw/pedestal supports.

- Once the flexibilities of the jack screw/pedestal supports have been established, mathematical modelling can be used to perform parameter studies to determine optimal design and positioning of the supports to achieve desired dynamic behavior of the system.

It was recommended that construction and vibration testing of a prototypic magnet/girder/support system be given high priority.

\section{OBJECTIVES}

The study reported herein was focused on the magnet support assemblies which essentially consists of a girder mounted on three jack screw supports. The objectives of the study are to (1) understand and characterize the dynamics of the magnet support assemblies, (2) evaluate two different support configurations, (3) evaluate nominal response to floor motion and flow through coolant header and return piping as a means of gaining insights relative to expected displacements, and (4) provide data and an information base for designing magnet support assemblies to avoid vibrations that may be detrimental to the operation of the APS.

\section{TEST DESCRIPTION}

Test article. The test article is the prototype APS storage ring girder section 3, shown schematically in Fig. 2. The girder is essentially a box beam formed by 12 -in. I-beams and 0.75 -in. steel plates. However, it should be noted that there are complexities introduced by lateral stiffeners, a cutout section, and a stepped section. As illustrated in Fig. 2, the girder is mounted on jack screws which, in turn, are supported on flanged cylinders that are bolted to the floor. The jack screw assemblies are positioned by a pipe frame and held in contact with the girder by turnbuckles between the girder and pipe frame. The magnets are supported from the girder on individual jack screws. As illustrated in Fig. 3, two different support configurations, designated configurations $A$ and $B$, were considered.

The actual magnets were not available for testing. Therefore, concrete s. $^{\mathrm{L}}$ ielding blocks wero used to simulate the masses of the magnets. In Fig. 4, locations of the centers of mass of the simulated magnets (shielding blocks), with reference to the end of the girder, are given. The shielding blocks are shown 


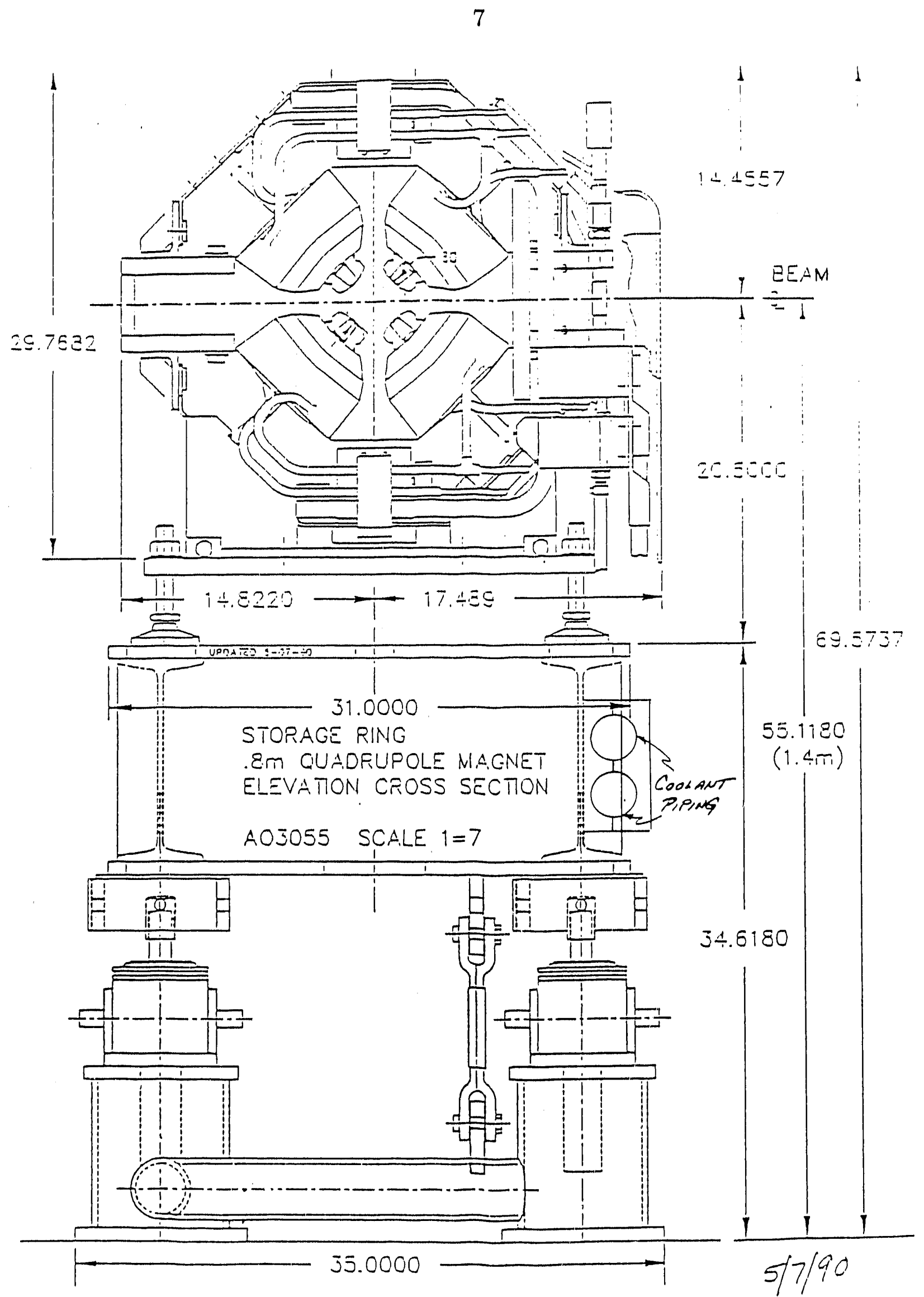

Fig. 2. APS storage ring magnet support assembly 


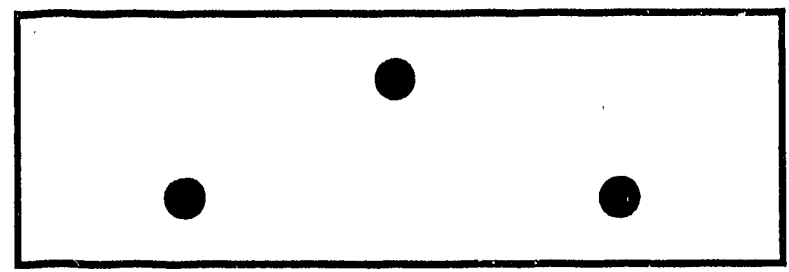

Configuration A

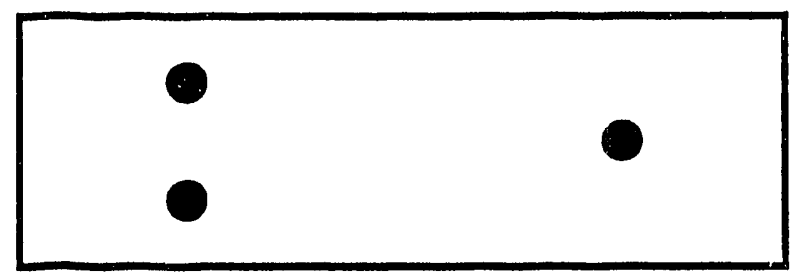

Configuration B

Fig. 3. Support configurations evaluated 


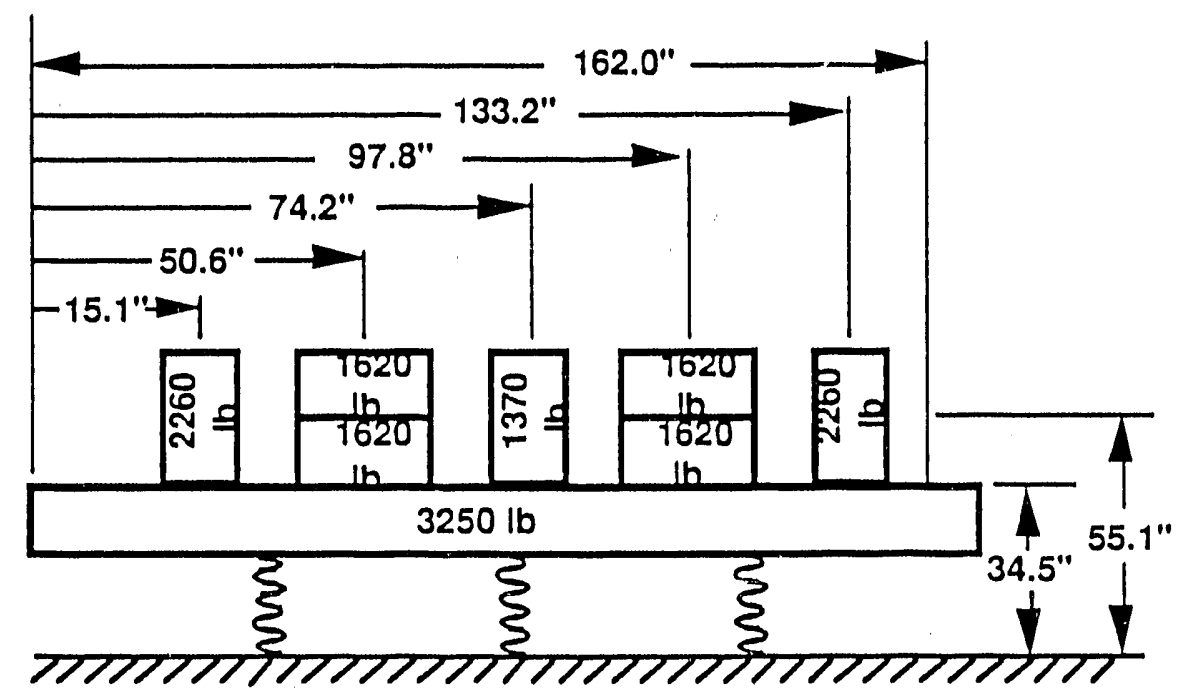

Fig. 4. Dimensions and weights of magnet support assembly 
positioned on the girder in the photograph of Fig. 5. In Table 2, a comparison is made between the estimated magnet weights and the corresponding weights of the shielding blocks used to simulate the magnets. As shown in Table 2, the simulation of individual magnet masses is within -14 to +7 percent of estimated weights; overall the simulation is within 2 percent.

In the actual design, cooling water for the magnets and power supplies is provided by a coolant flow header attached to the girder. Return flow is through a return pipe also mounted to the girder in parallel with the header. In the vibration tests to evaluate coolant flow as an excitation source, the header and return piping are simulated with 2-1/2 in. diameter copper pipes. The pipes are mounted to the girder as illustrated in Fig. 2. It should be noted that in testing there is an overhanging U-bend pipe section at one end of the girder. which is nonprototypic. The design flow rate is approximately $100 \mathrm{gpm}$.

The actual design will also have two parallel copper bus bars and power supplies hung from the girders. The total weight of the power supplies is approximately $180 \mathrm{~kg}$. The bus bars and power supplies are not simulated in the subject tests.

Table 2. Component simulation

\begin{tabular}{|c|c|c|c|}
\hline Component & $\begin{array}{l}\text { Estimated } \\
\text { Weight (lbs) }\end{array}$ & $\begin{array}{l}\text { Simulation } \\
\text { (lbs) }\end{array}$ & $\begin{array}{c}\text { Deviation } \\
(\%) \\
\end{array}$ \\
\hline $0.5 \mathrm{~m}$ Quadrupole (2) & 2619 & 2260 & -14 \\
\hline $0.6 \mathrm{~m}$ Quadrupole (2) & 3104 & 3240 & 4 \\
\hline Sextupole & $\underline{1279}$ & 1370 & 7 \\
\hline Total Magnets & 12,725 & 12,370 & -3 \\
\hline \multirow[t]{2}{*}{ Girder } & 3,250 & 3,250 & $=$ \\
\hline & 15,975 & 15,620 & -2 \\
\hline
\end{tabular}

Test matrix. The tests were performed in Bldg. 335 high-bay to allow ready access to vibration data acquisition and processing equipment and computing facilities. The thickness of the high-bay floor slab is estimated to be approximately 7 in. The jack screw supports were bolted to the concrete floor using $3 / 4 \mathrm{in}$. bolts. 


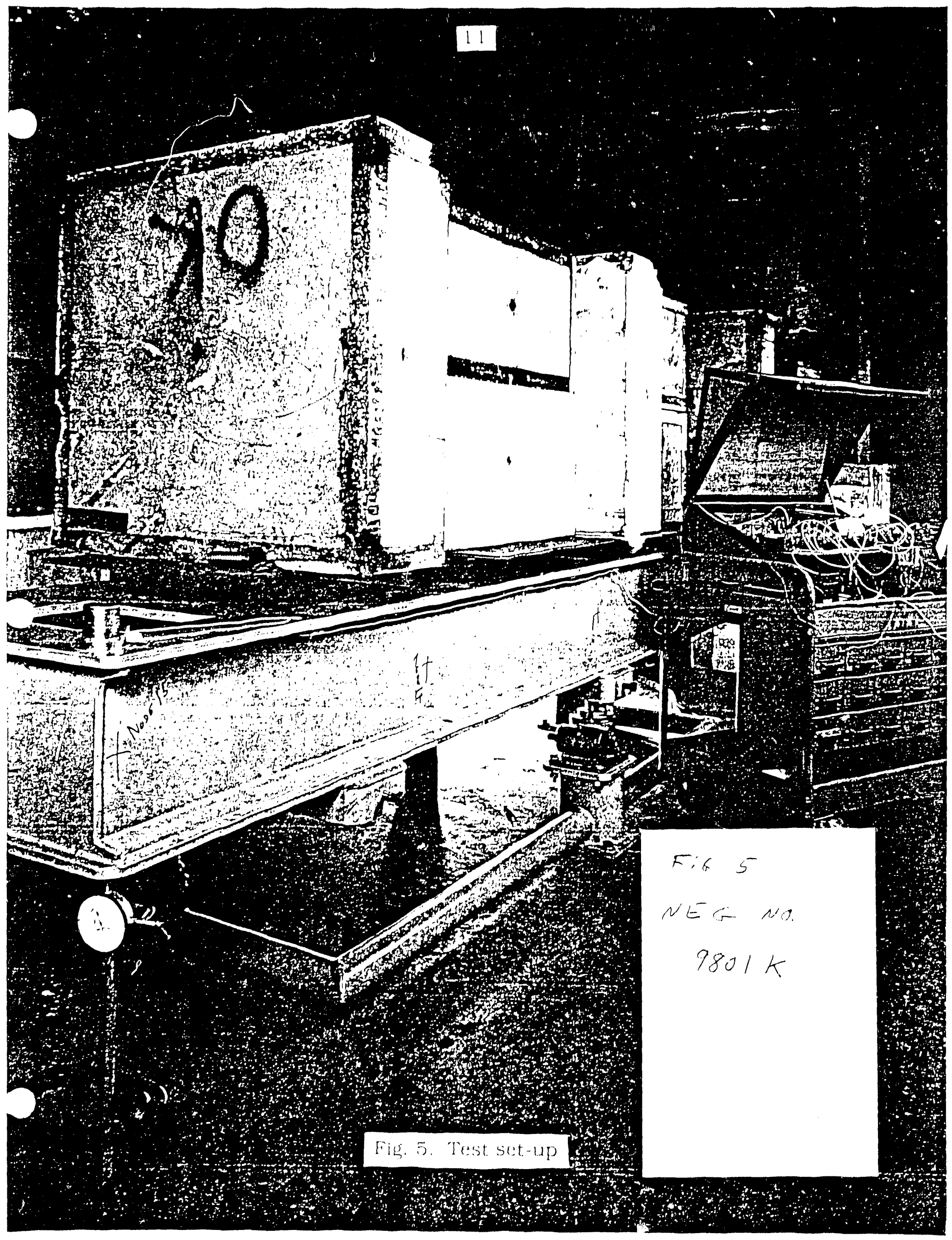


A series of tests, as documented in Table 3, were performed. In Table 3, configurations $A$ and $B$ refer to the jack screw support arrangements shown in Fig. 3, "w/o magnets" refers to the girder alone, "w/ magnets" refers to the girder with shielding blocks used to simulate the magnet masses, and jack screw keyed is used to make a distinction from earlier tests in which the jack screws were not keyed; designations relative to the coolant pipe will be explained below. Only Test A was performed with the turnbuckles loose; in all other tests the turnbuckles were tight. The design distance rom the floor to the top of the girder is nominally 34-1/2 in. With the exception of Test C', all tests were performed with the girder level and at that nominal height; Test $C^{\prime}$ was performed with the jack screws raised 1-1/2 in., as representative of the maximum travei expected.

Table 3. Vibration tests

\section{Test $\quad$ Description}

A Configruration A; w/o "magnets"; turnbuckles loose

$A^{\prime}$ configuration $A$; w/o "magnets"

B Omitted

C Configuration A; w/"magnets"

$C^{\prime} \quad$ Configuration A; w/"magnets"; jack screws raised 1-1/2 in.

D Configuration B; w/o "magnets"

E Configuration $B$; w/"magnets"

$E^{\prime} \quad$ Configuration $B$; w/"magnets"; coolant flow with pipe overhangs unrestrained

F Configuration A; w/"magnets"; jack screw keyed; coolant flow with pipe overhangs unrestrained

G Configuration A; w/"magnets"; jack screw keyed; coolant flow with pipe overhangs restrained

$\mathrm{H}$ Configuration A; w/"magnets"; jack screw keyed

I Configuration A; w/"magnets"; jack screw keyed; coolant flow with pipe decoupled from girder 


\section{APPROACH}

For each of the two support configurations ( $A$ and $B$ in Fig. 3), the technical approach involved:

(a) determination of the dynamic characteristics of the magnet support assembly by testing, using modal analysis techniques, and by analysis, using finite element analysis techniques, and comparison of results determined by the two methods, and

(b) measurement of response (displacement amplitudes) to simulated coolant flow excitation.

For support configuration $B$, measurement of response (displacement amplitudes) to both ambient floor motion and to forced floor motion were also performed.

Modal analysis - experimental. Modal analysis was performed using a HP model 9300 Fast Fourier Transform (FFT) Analyzer together with SDRC TDAS software [14]. The test procedure involved defining a series of nodal points on the structure that will allow definition of rigid body, bending, and torsional modes of the girder/support assembly. The nodal positions are given in Fig. 6. Accelerometers were positioned at two vertical nodes (1 and 5) and one horizontal node (11); the accelerometer located at node 5 can be seen in Fig. 5 . Impact excitation of the girder was achieved by applying hammer blows at the various nodes using a hammer with a built-in force transducer. The resulting force and acceleration data, in the form of frequency response functions, are input to the SDRC software package. Invoking the reciprocity principle which is valid for linear systems, the SDRC program is then used to compute the natural vibration modes and associated values of frequency and damping. A typical rigid body mode, torsional mode and bending mode are shown in Figs. 7 - 9, respectively.

Modal analysis was performed as a part of all the test runs described in Table 3, with the exception of the coolant flow test runs (Tests E', F, G, and I). The test plan called for maintaining the proper center of mass with respect to the floor surface, viz. $1.4 \mathrm{~m}$ (55.1 in.). To accomplish this, the blocks were mounted on individual steel plates each supported from the girder on three standoffs which simulated the tripod arrangement of the individual magnet jack screw supports. The steel plate arrangement, however, was not prototypic and it was found that they contributed additional vibration modes that coupled with the motion of the girder making it difficult to interpret the data. Consequently, to eliminate the extraneous modes, the blocks were placed directly on the girder with the result that the centers of mass are $\sim 3$ in. lower than prototypic. This will not have a 


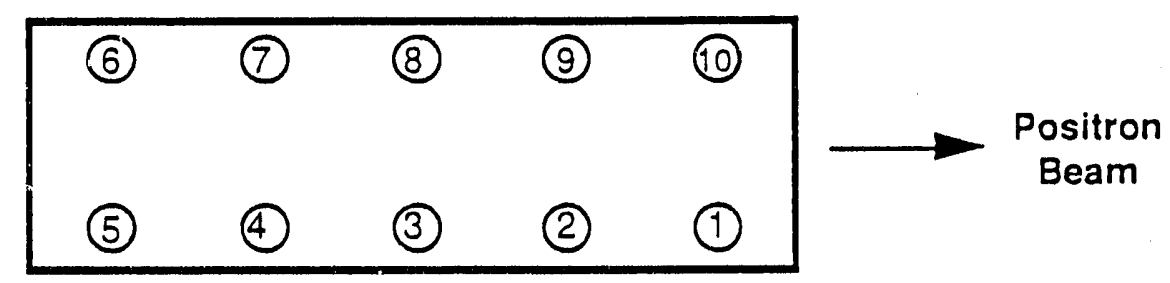

In-plarie (vertical) excitation modes
(5)
(4)
(3)
(12)
(11)

Out-of-plane (horizontal) excitation modes

Fig. 6. Impact excitation nodes 


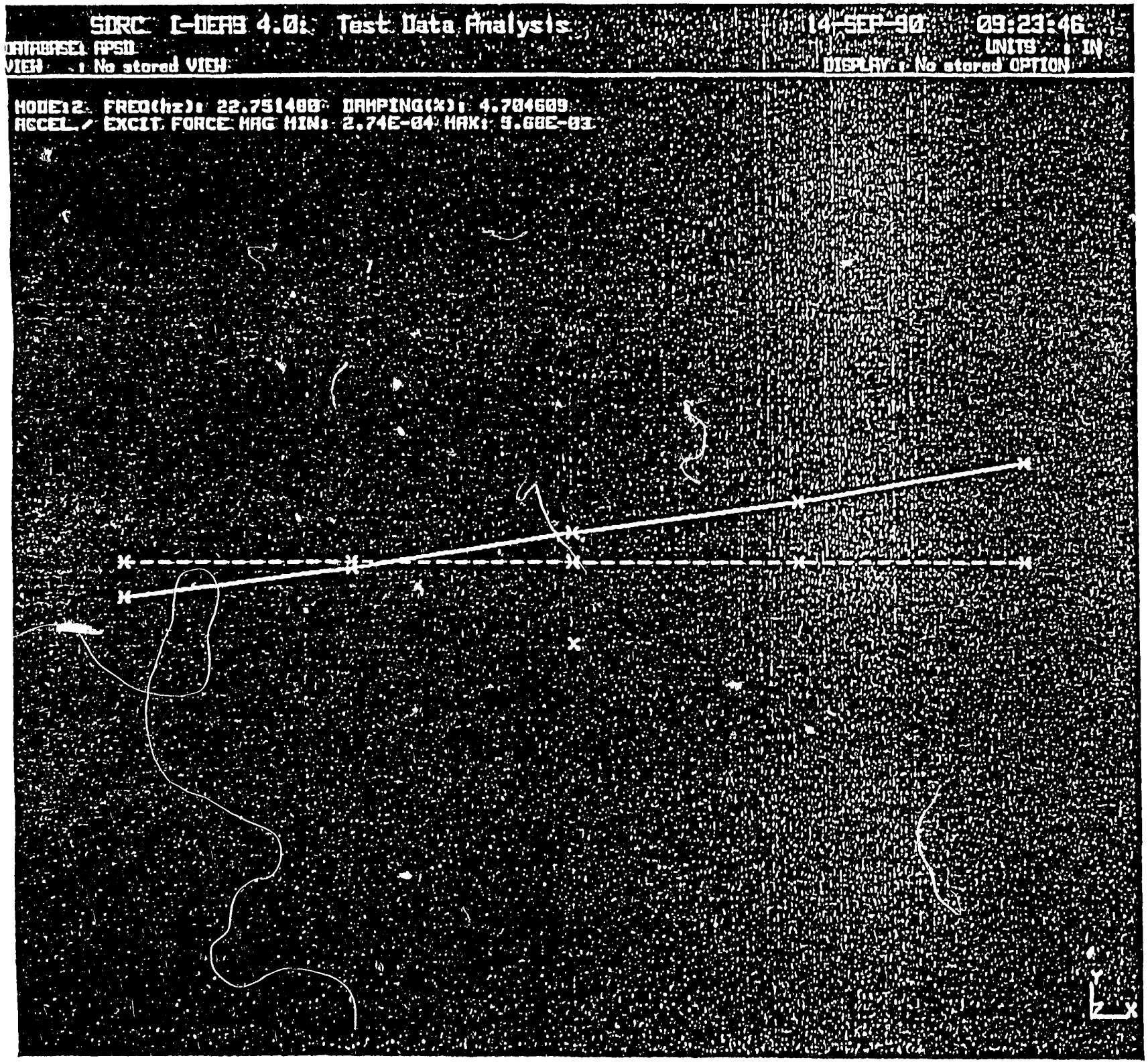

Fig. 7. Rigid body mode, Test D, Configuration B w/o "magnets" 


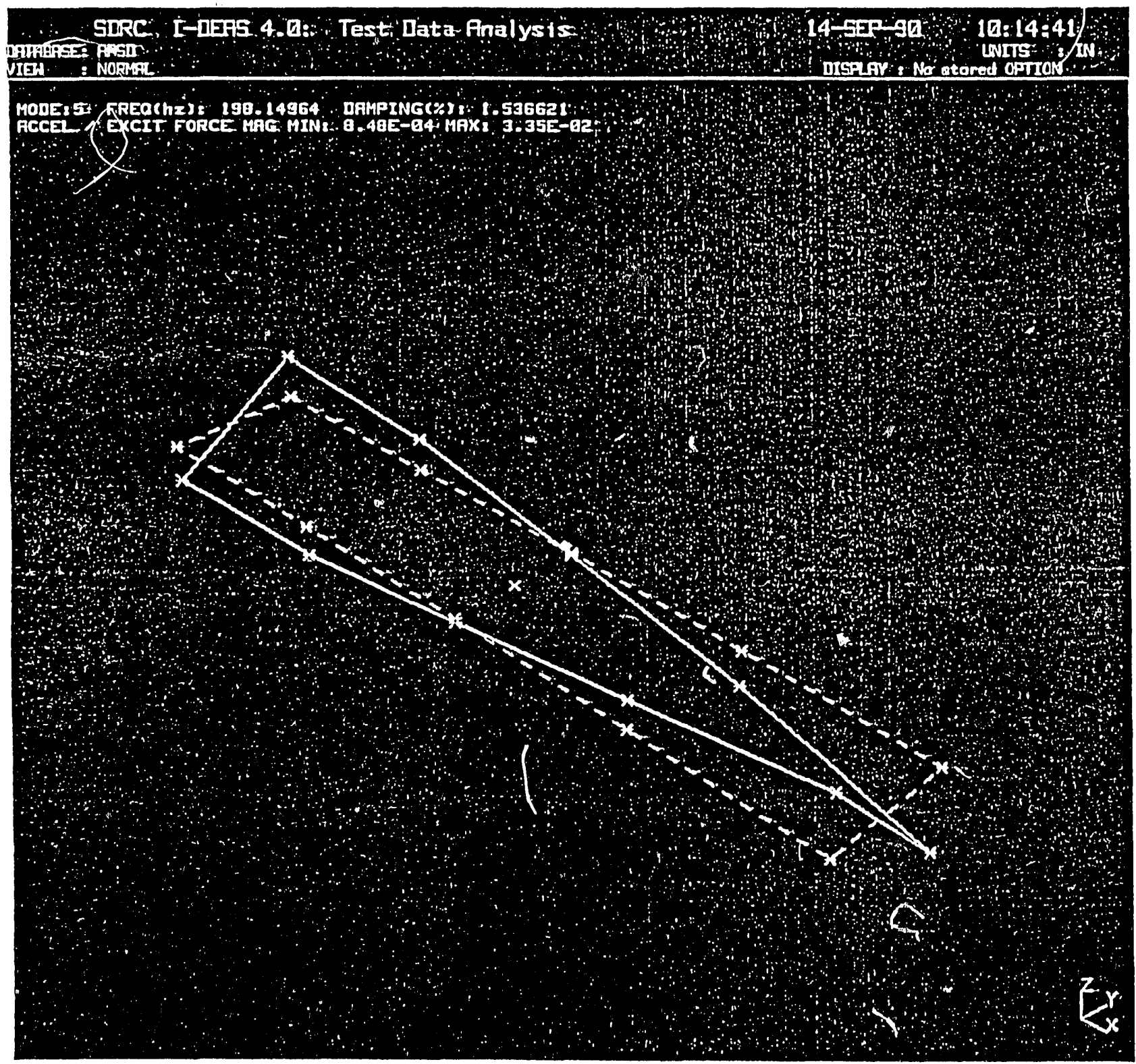

Fig. 8. Torsional mode, Test $\mathrm{D}$, Configuration B w/o "magnets" 


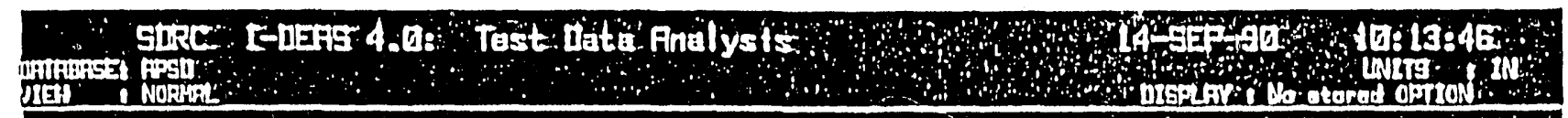

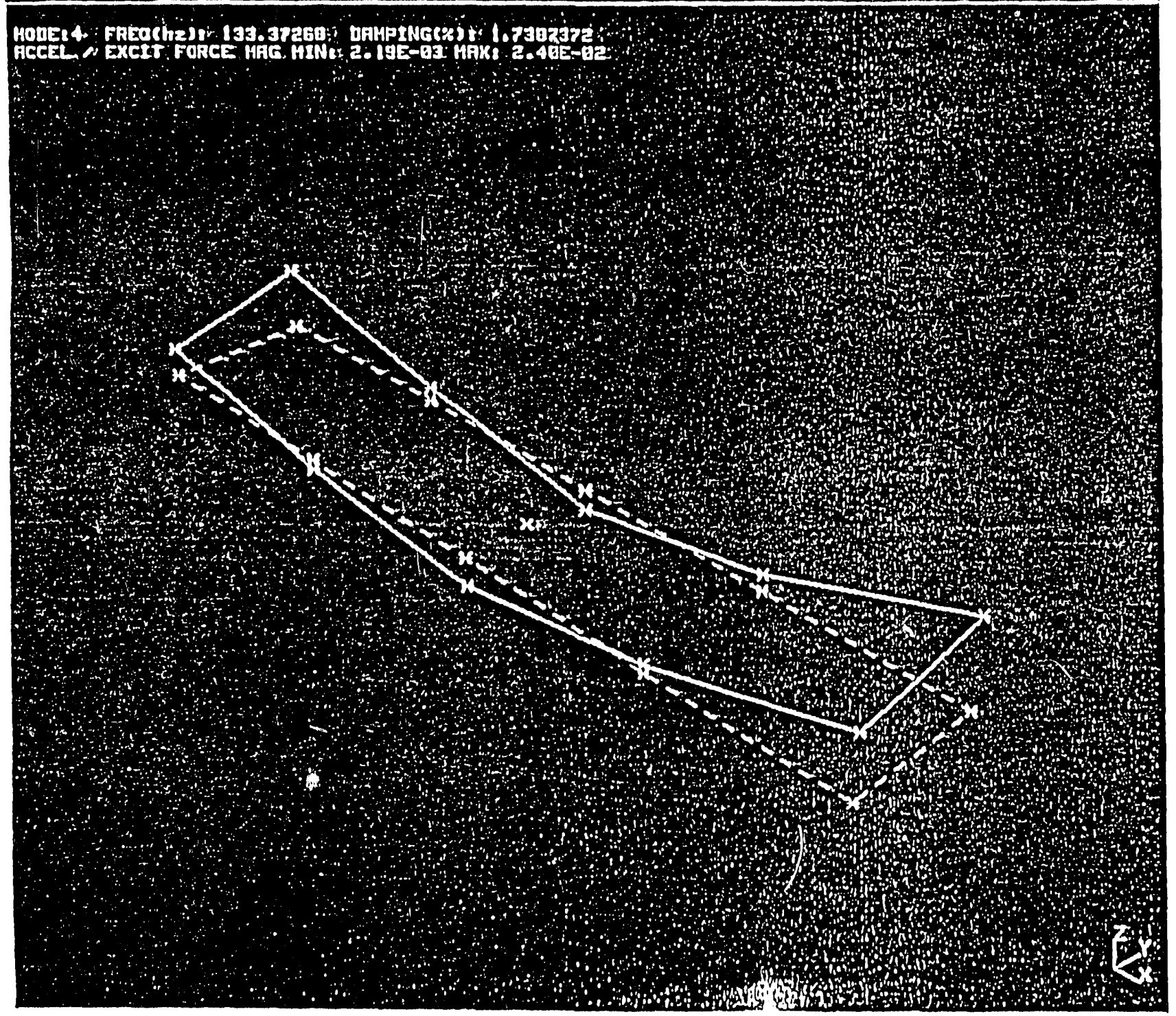

Fig. 9. Bending mode, Test D, Configuration B w/o "magnets" 
significant effect on the results and, more importantly, on the conclusions drawn from the study.

Modal analysis - theoretical. The finite element code MSC/PAL [15] was used to model the magnet support structure system and to predict the normal modes and frequencies. The girder was modelled as a uniform beam; this neglects the lateral stiffeners, and cut-out and stepped sections. The jack screws were modelled as linear springs acting in both the in-plane (vertical) and out-ofplane (horizontal) directions; it was assumed that the set of spring constants (inplane and out-of-plane) is the same for all three jack screws. The magnets are modelled as point masses, thus neglecting rotatory inertia effects. While there are many simplifications and assumptions in the model, perhaps the greatest uncertainty is associated with the choice of spring constants for the jack screws.

To evaluate the modelling, the experimentally determined owest rigid body mode frequencies were used to back-calculate effective linear spring constants (inplane and out-of-plane) that would give the measured results. Attempts were also made to experimentally measure the in-plane spring constant directly. The constants thus determined were then used in the calculation of higher mode frequencies and the theoretical and experimental results compared.

Response measurements. Direct girder/magnet response measurements were made with ambient floor motion as input and with the floor force excited in the vertical direction using a small, 100-lb electrodynamic exciter and random excitation. Accelerometer signals were electronically double-integrated to obtain displacement. Since low frequency "noise" is inherent in such integration processes, displacement values are accurate only for frequencies greater than 5 $\mathrm{Hz}$; for frequencies less than $5 \mathrm{~Hz}$, displacement results should be considered conservative as they contain noise contributions from the integration process.

Girder/magnet response measurements to coolant flow excitation were made with the header and return piping simulated as discussed above. The design water flow rate is approximately $100 \mathrm{gpm}$. Tests were performed at flow rates more than 2 times greater than design flow. The water pump was particularly noisy and vibrations associated with the pump could readily be "felt" at the test site. As a consequence, the response measurements were conservative as they included the pump-induced noise as background. To obtain a quantitative measure of the pump-induced noise, the pipes were de-coupled from the girder, the pump operated over the same flow range, and response measurements made. The quantitative measurement of background noise can be used in interpretation of the flow-induced response data. 


\section{RESULTS AND DISCUSSION}

Modal analysis - experimental. While simple frequency response analysis allows one to identify characteristic frequencies associated with a dynamic system, modal analysis allows one to identify the mode shape, and thereby also the basic type of mode (rigid body, torsional, or bending), and provides an estimate of the damping associated with each particular mode. Again, typical results representing an out-of-plane rigid body mode, a torsional mode, and an inplane girder bending mode are given in Figs. 7 - 9, respectively.

Test $\mathrm{E}$ (configuration $\mathrm{B}$ - with magnets) can be considered representative of the r.odal testing performed. The modal test results form Test $\mathrm{E}$ are given in the Appendix. The modal frequencies and associated damping values obtained from Test $\mathrm{E}$ are given in Table 4. The damping is typically highest for the lower modes. For the higher modes, damping is on the order of $1-2$ percent. Modal damping is of interest as it directly determines the magnification factor $Q$ associated with a given mode. $Q$ is inversely proportional to two times the damping factor $(Q=1 / 2 \zeta)$; in Table 4 magnification factors based on measured damping values are also list $ə \mathrm{~d}$.

Table 4. Modal frequencies $\left(f_{n}\right)$, damping $\left(\zeta_{n}\right)$, and magnification factors $\left(Q_{n}\right)$ from Test $\mathrm{E}$ (configuration $\mathrm{B}$ - with magnets)

\begin{tabular}{|c|c|c|c|c|c|}
\hline \multicolumn{3}{|c|}{ Out-of-Plane Excitation } & \multicolumn{3}{|c|}{ In-Plane Excitation } \\
\hline$f_{n}(H z)$ & $\zeta_{n}(\%)$ & $Q_{n}$ & $f_{n}(\mathrm{~Hz})$ & $\zeta_{n}(\%)$ & $Q_{n}$ \\
\hline 5.0 & 33.5 & 1.5 & 26.8 & 4.6 & 10.9 \\
\hline 8.3 & 1.7 .2 & 2.9 & 36.8 & 5.8 & 8.6 \\
\hline 13.3 & 4.8 & 10.4 & 54.0 & 3.6 & 13.9 \\
\hline 26.7 & 3.7 & 13.5 & 58.1 & 2.1 & 23.8 \\
\hline 53.7 & 2.8 & 17.9 & 87.6 & 1.8 & 27.8 \\
\hline 255.1 & 2.3 & 21.7 & 179.4 & 1.7 & 29.4 \\
\hline 344.5 & 1.4 & 35.7 & 186.4 & 2.0 & 25.0 \\
\hline \multirow{8}{*}{361.2} & 3.7 & 13.5 & 199.3 & 1.8 & 27.8 \\
\hline & & & 209.6 & 1.8 & 27.8 \\
\hline & & & 221.4 & 1.4 & 35.7 \\
\hline & & & 285.0 & 2.2 & 22.7 \\
\hline & & & 325.3 & 0.7 & 71.4 \\
\hline & & & 342.7 & 1.5 & 33.3 \\
\hline & & & 350.7 & 1.5 & 33.3 \\
\hline & & & 369.2 & 1.3 & 38.5 \\
\hline
\end{tabular}


Among other things, the modal testing served to confirm the results of the preliminary modelling. In particular, it demonstrated that the lower vibrotion modes, which are the modes of most concern, were rigid body modes governed by the flexibility of the jack screw/pedestal supports, and that the higher modes were girder bending modes and torsional modes.

Modal testing results, with and without the girder loaded, and with the turnbuckles loose, indicated that the jack screws were highly nonlinear in the sense that the effective spring constant was a function of load. To investigate this further, a feature test was performed in which the load versus deflection curve given in Fig. 10 was generated. The effective spring constant can be taken as the slope of the curve in the vicinity of a given load; the nonlinearity is readily apparent. This result aided in interpretation of modal analysis results obtained with the turnbuckles loose. However, with the turnbuckles tightened, as they will be in the field, a preload is applied to the jack screws and the deviation in spring constant for the girder unloaded and loaded is not as significant. Nevertheless, because of the inherent complexity of the jack screw assemblies, it should be expected that the effective spring constants and damping will vary anong the different supports.

One of the secondary objectives of the study was to assess the effect of the turnbuckles (being loose or tightened) on the dynamic characteristics of the support assembly. The test results showed that because of the magnitude of the loading associated with the magnets, there are only slight differences in dynamic behavior between the tests with and without the turnbuckles tightened.

Testing with the jack screws extended, that is, raised 1.5 in. to simulate the maximum expected range of travel, also revealed only slight differences in the dynamic characteristics. As a consequence, the fact that the shaft extension of the jack screws may vary from support location to support location and/or from magnet section to magnet section, due to inherent unevenness in the basemat, should not be a cause for concern relative to it having a significant effect on dynamic characteristics.

Modal analysis - theoretical. The finite element analysis was applied using experimental data for the lowest mode frequency to back-calculate effective linear spring constants with the following results:

$$
\begin{array}{ll}
\text { in-plane: } & 5.5 \times 10^{6} \mathrm{~kg} / \mathrm{m} \\
\text { out-of-plane: } & 3.5 \times 10^{5} \mathrm{~kg} / \mathrm{m}
\end{array}
$$

These values were subsequently used to compute the natural frequencies and modes. 


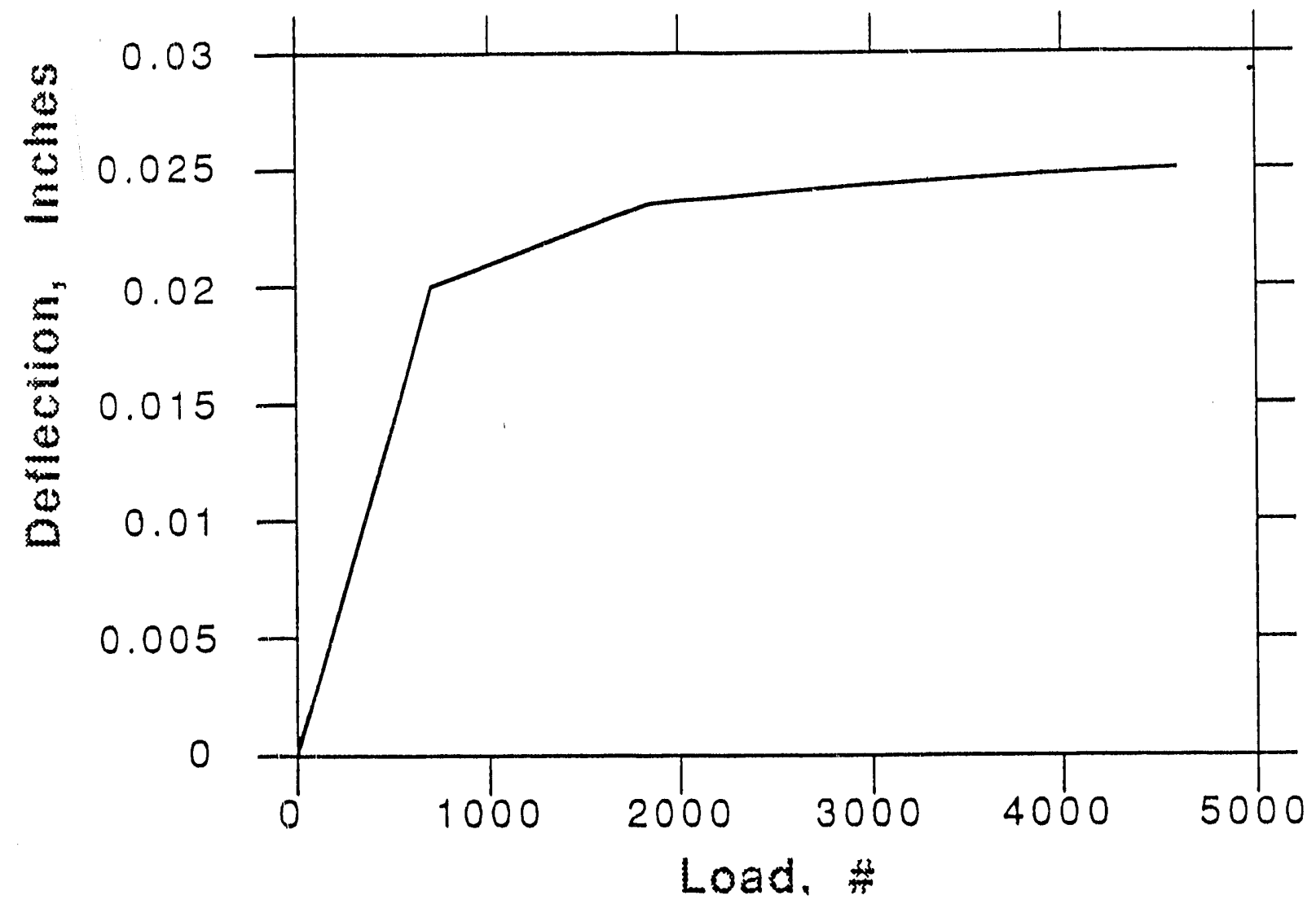

Fig. 10. Deflection of jack screw as a function of load 
The theoretically determined natural modes can be divided into three' groups: out-of-plane (horizontal) modes, in-plane (vertical) modes, and axial (longitudinal) modes. The frequencies of the lowest fifteen modes are given in Table 5 for configuration B without magnets (Test D) and in Table 6 for configuration $B$ with magnets (Test $E$ ). Corresponding mode shapes determined from the theoretical models are given in Figs. 11 and 12 . It can readily be observed from these figures that the lower modes are rigid body modes in which the girder is effectively rigid and simply acts as a mass.

Table 5. Natural frequencies $(\mathrm{Hz})$ Test $\mathrm{D}$ : configuration $\mathrm{B}$ - without magnets

\begin{tabular}{|c|c|c|c|c|c|}
\hline \multicolumn{2}{|c|}{ Out-of-Plane Mode } & \multicolumn{2}{|c|}{ In-Plane Mode } & \multicolumn{2}{|c|}{ Axial Mode } \\
\hline Theory & Experiment & Theory & Experiment & Theory & Experiment \\
\hline 12.6 & 12.6 & 49.6 & 63.5 & 14.8 & \\
\hline 18.3 & 22.7 & 71.2 & & 666.5 & \\
\hline 64.0 & & 138.3 & 132.0 & & \\
\hline 212.7 & 212.7 & 355.9 & 358.0 & & \\
\hline 419.9 & & 656.6 & & & \\
\hline 521.6 & 393.0 & & & & \\
\hline 833.0 & & & & & \\
\hline 907.3 & & & & & \\
\hline
\end{tabular}

Table 6. Natural frequencies $(\mathrm{Hz})$ Test $\mathrm{E}$ : configuration B - with magnets

\begin{tabular}{|c|c|c|c|c|c|}
\hline \multicolumn{2}{|c|}{ Out-of-Plane Mode } & \multicolumn{2}{|c|}{ In-Plane Mode } & \multicolumn{2}{|c|}{ Axial Mode } \\
\hline Theory & Experiment & Theory & Experiment & Theory & Experiment \\
\hline 5.7 & 5.0 & 21.2 & & 6.1 & \\
\hline 7.8 & 8.3 & 29.6 & 36.8 & 284.8 & \\
\hline 62.4 & 53.6 & 67.0 & 87.6 & & \\
\hline 103.2 & & 165.5 & & & \\
\hline 241.5 & 361 & 396.2 & & & \\
\hline 419.5 & & 485.8 & & & \\
\hline 539.6 & & & & & \\
\hline
\end{tabular}

Similar calculations have been performed for configuration A. Analytical results are given in Table 7, for the girder alone, and in Table 8 for the girder with magnets. 

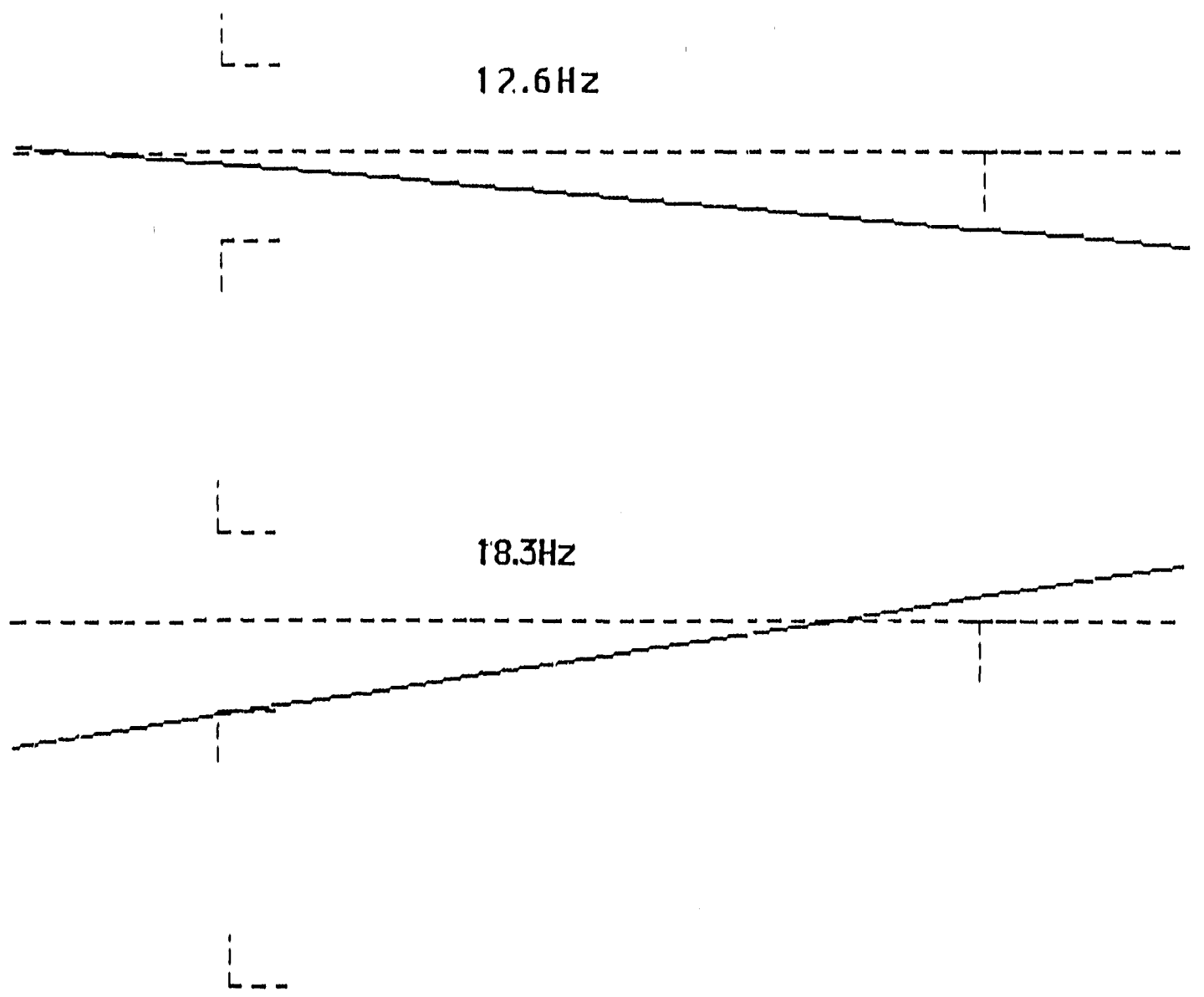

\section{$64.0 \mathrm{~Hz}$}
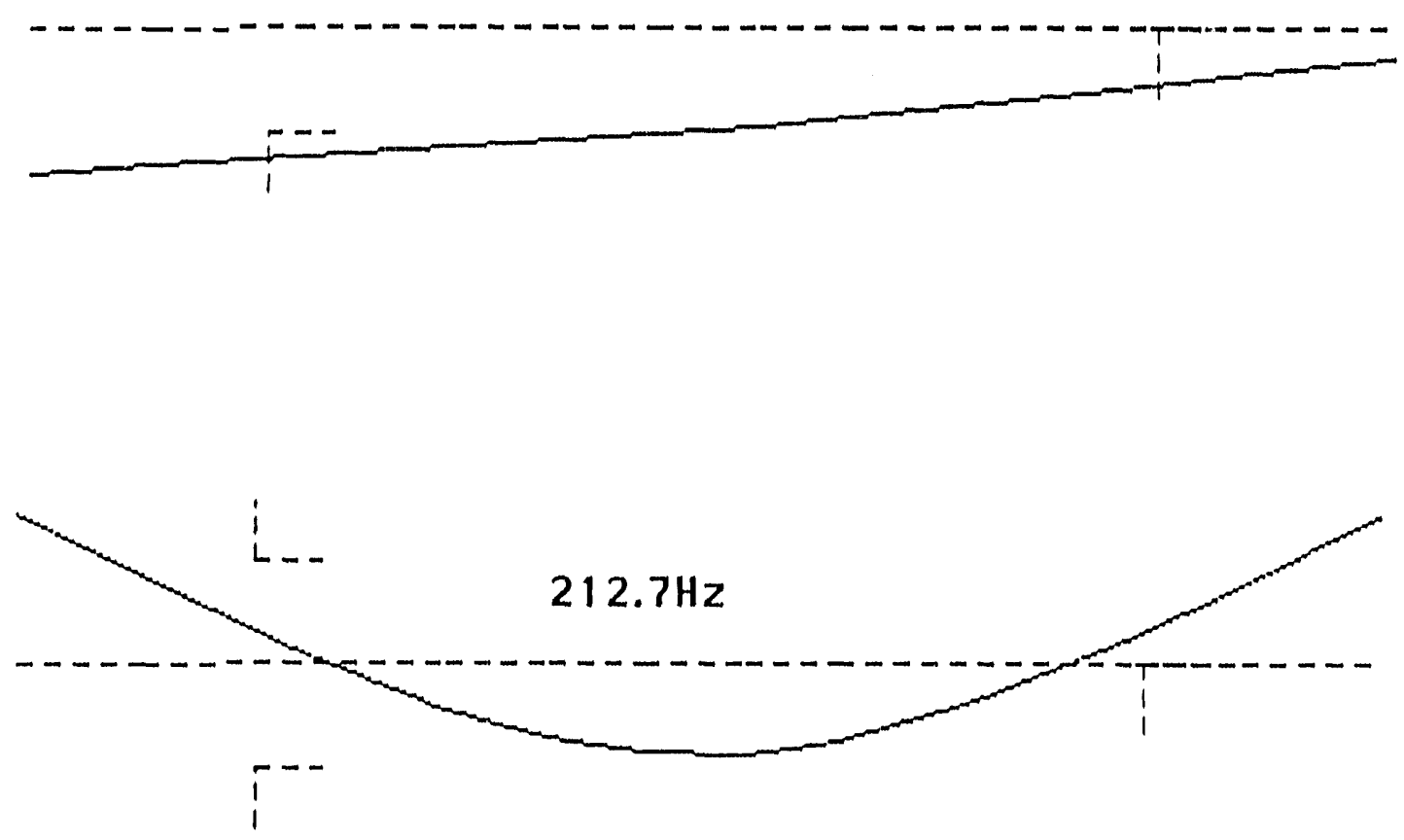

Fig. 11a. Out-of-plane modes: configuration B - without magnets 

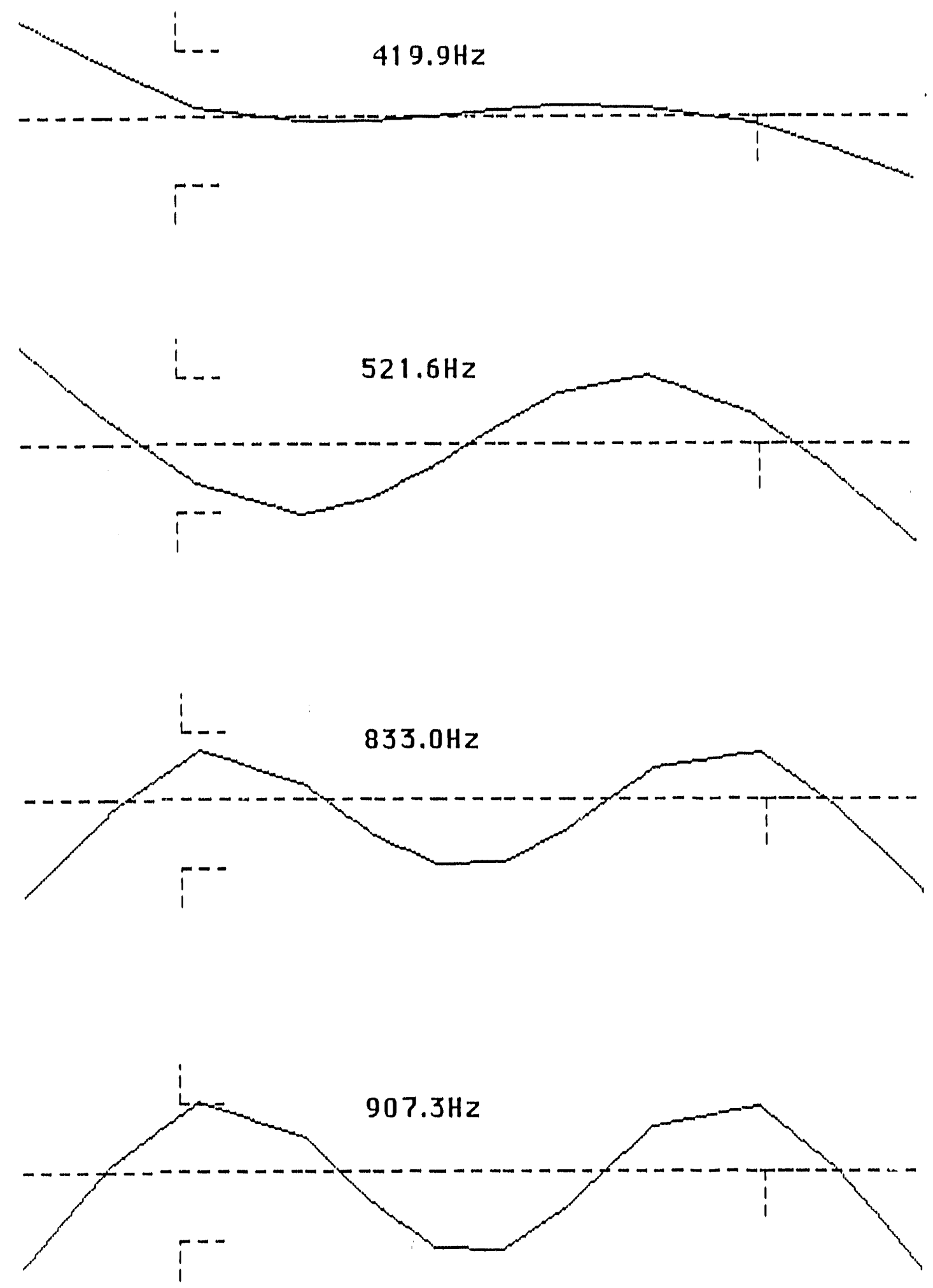

Fig. 11b. Out-of-plane modes: configuration B - without magnets 


\section{$49.6 \mathrm{~Hz}$}
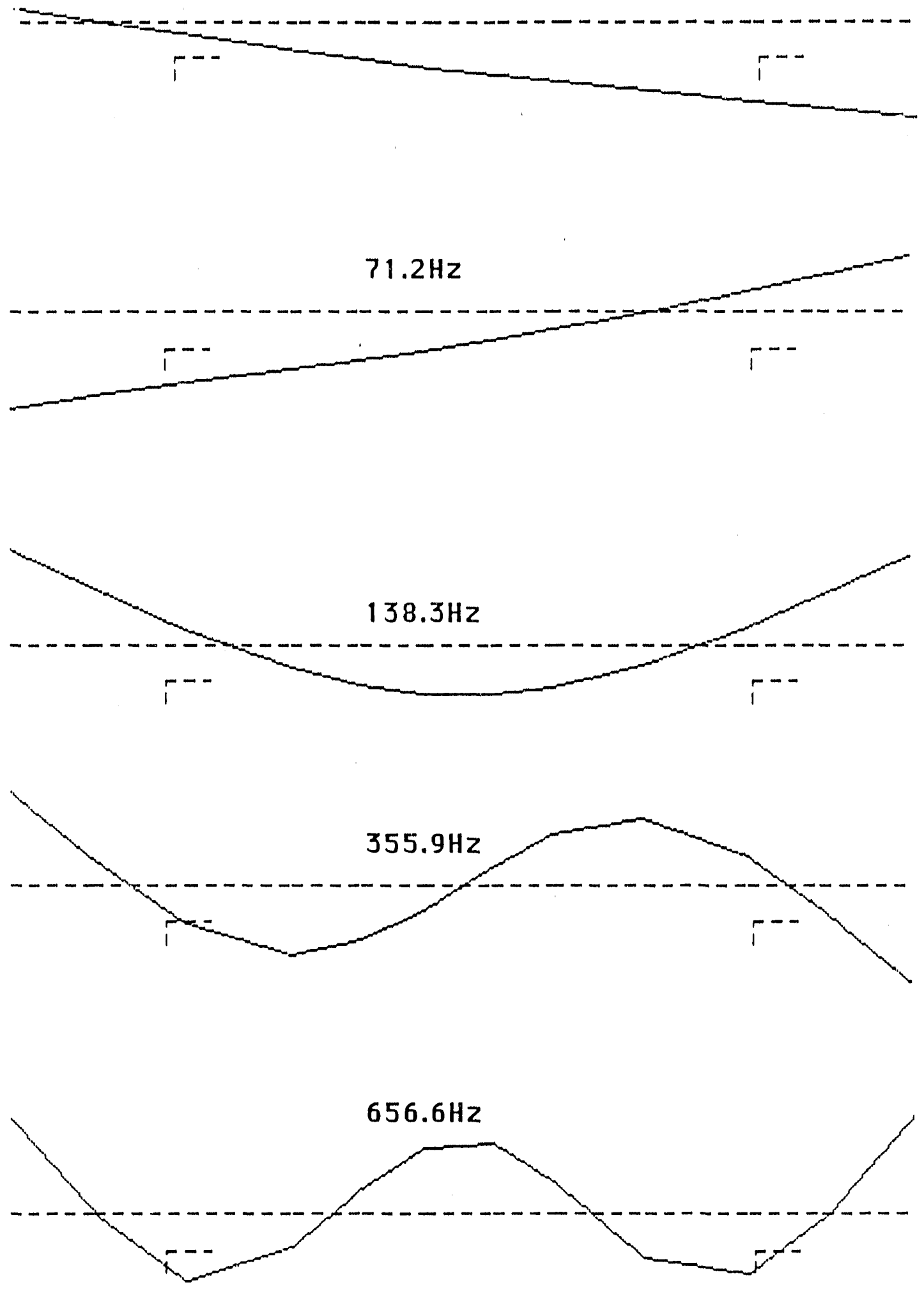

Fig. 11c. In-plane modes: configuration B - without magnets 
$5.7 \mathrm{~Hz}$
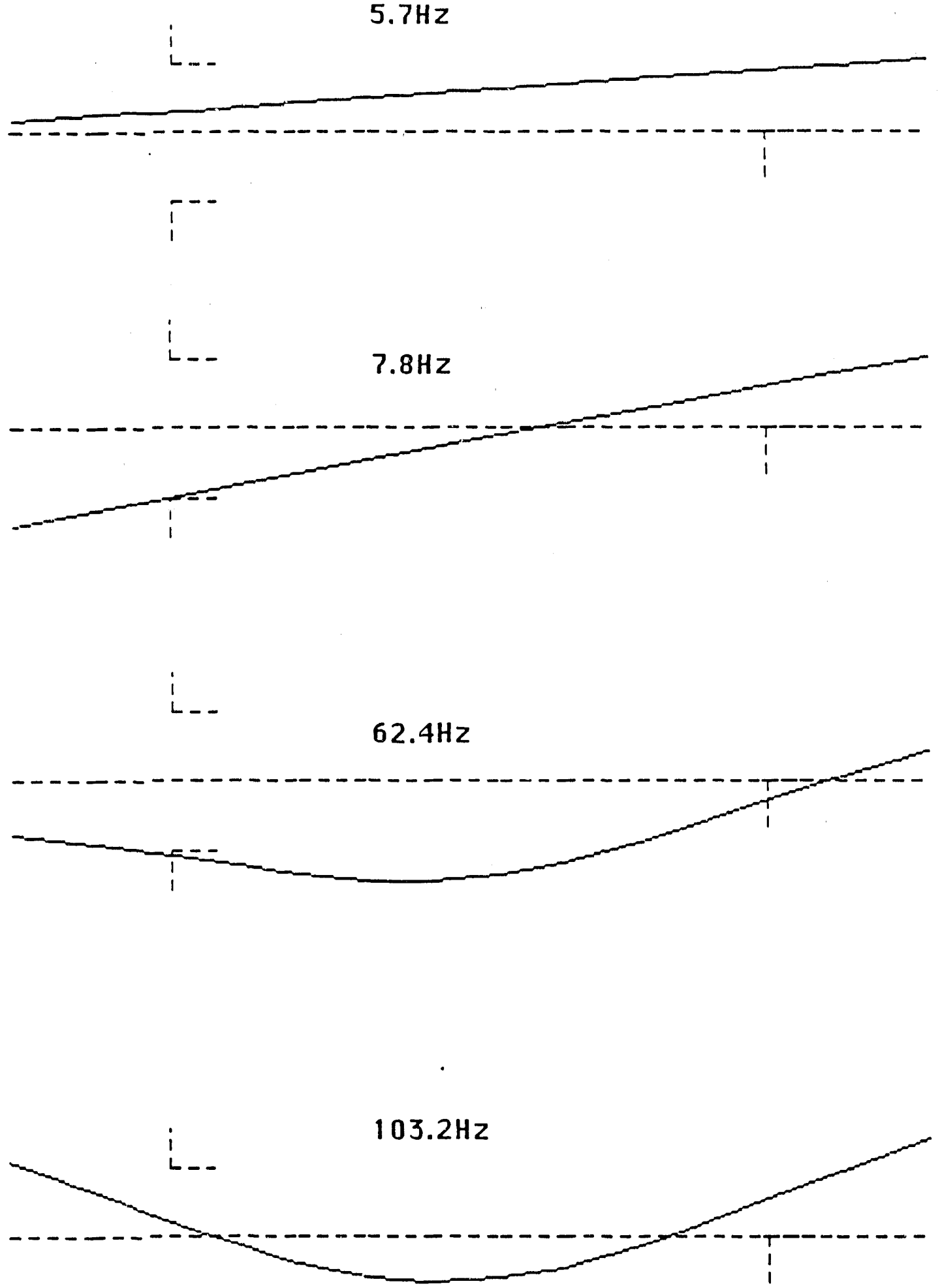

$i^{--}$

Fig. 12a. Out-of-plane modes: configuration B - with magnets 

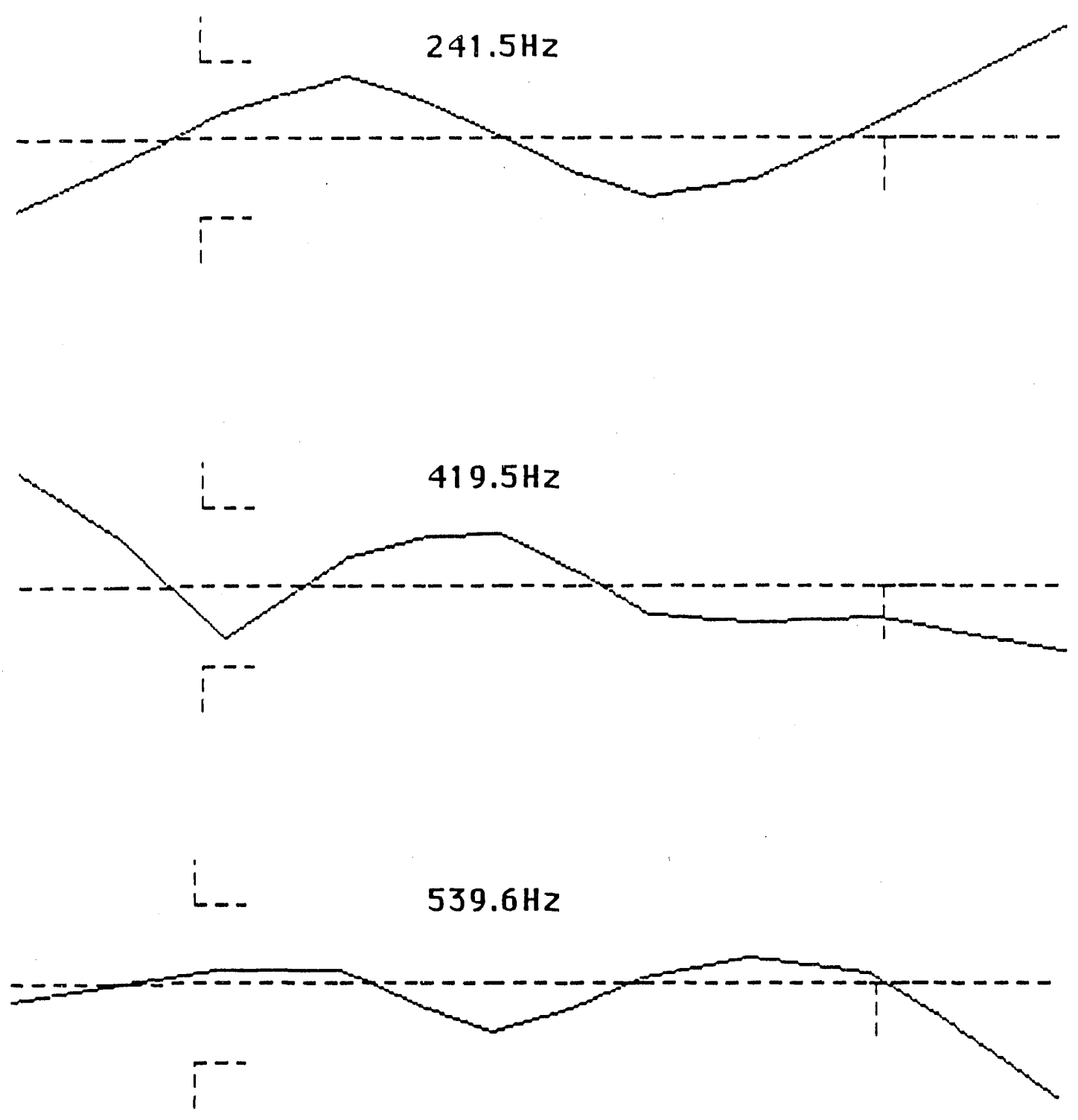

Fig. 12b. Out-of-F'ane modes: configuration B - with magnets 


\section{$21.2 \mathrm{~Hz}$}
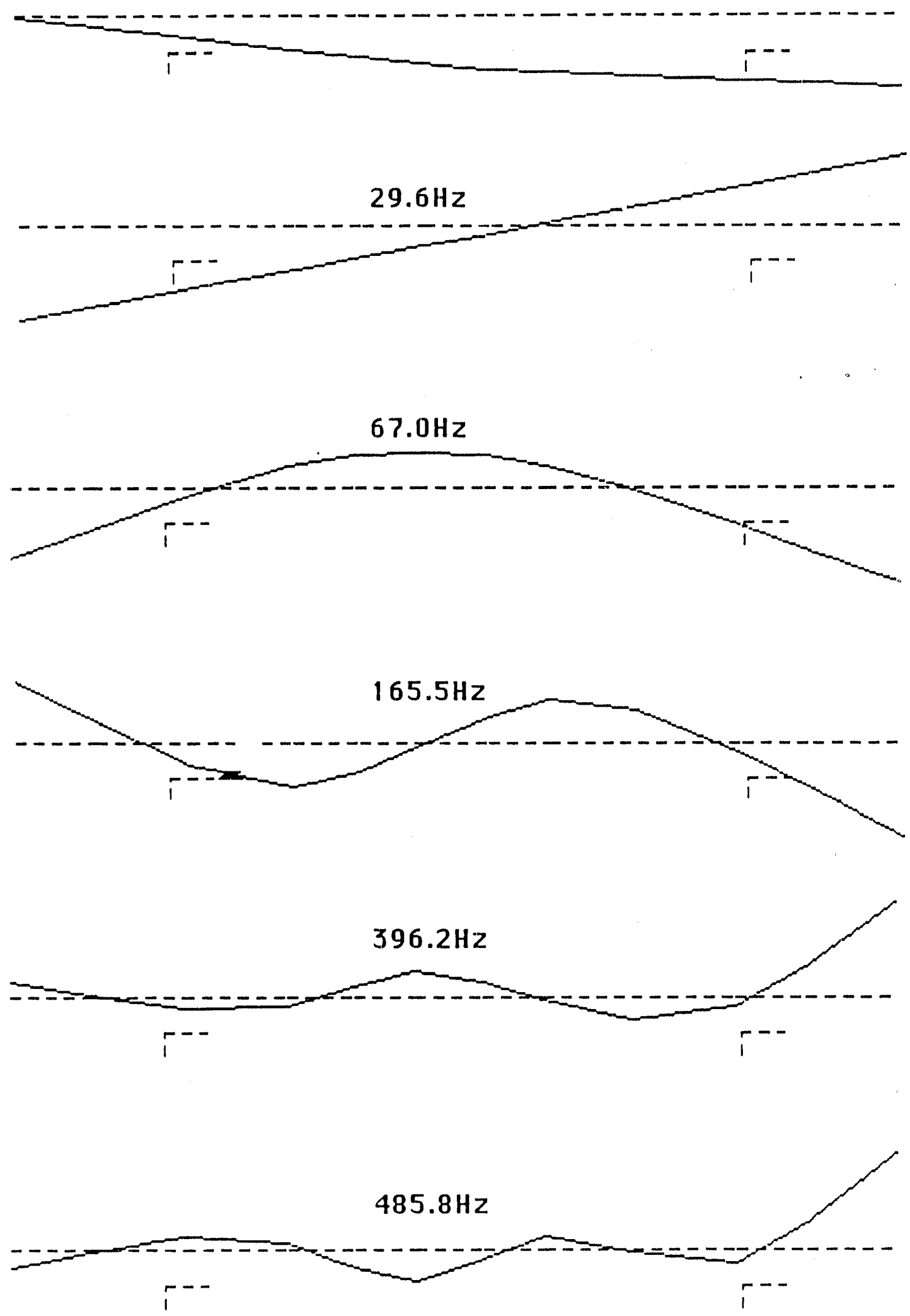

Fig. 12c. In-plane modes: configuration B - with magnets 
Table 7. Natural frequencies $(\mathrm{Hz})$ Test $\mathrm{A}$ : configuration $\mathrm{A}$ - without magnets

\begin{tabular}{|c|c|c|c|c|c|}
\hline \multicolumn{2}{|c|}{ Out-of-Plane Mode } & \multicolumn{2}{|c|}{ In-Plane Mode } & \multicolumn{2}{|c|}{ Axial Mode } \\
\hline Theory & Experiment & Theory & Experiment & Theory & Experiment \\
\hline 13.6 & & 50.6 & & 657 & \\
\hline 14.6 & 16 & 52.8 & 54 & 666 & \\
\hline 15.2 & & 80.1 & & & \\
\hline 213 & & 145 & 137 & & \\
\hline 522 & & 355 & 308 & & \\
\hline 836 & & 420 & & & \\
\hline 907 & & & & & \\
\hline
\end{tabular}

Table 8. Natural frequencies $(\mathrm{Hz})$ Test $\mathrm{C}$ : configuration A - with magnets

\begin{tabular}{|c|c|c|c|c|c|}
\hline \multicolumn{2}{|c|}{ Out-of-Plane Mode } & \multicolumn{2}{|c|}{ In-Plane Mode } & \multicolumn{2}{|c|}{ Axial Mode } \\
\hline Theory & Experiment & Theory & Experiment & Theory & Experiment \\
\hline 5.7 & & 21.6 & & 285 & \\
\hline 6.1 & & 25.1 & & 538 & \\
\hline 6.8 & & 60.8 & & & \\
\hline 103 & & 85.8 & 94 & & \\
\hline 241 & 309 & 165 & & & \\
\hline & & 397 & & & \\
\hline & & 420 & & & \\
\hline & & 486 & & & \\
\hline
\end{tabular}

Corresponding experimental results are also given in Tables $5-8$, as available. From a comparison with the theoretically determined values one can get a feel for the ability of this simplified modeling to predict actual dynamic behavior; recall that the spring constant is chosen to match results for the lowest mode. In making the comparison, one will note that not all of the theoretical modes are represented by an experimental mode. The lack of experimental data is due to the fact that certain modes are difficult to excite using the particular method. Based on the experimental data that are available for comparison, it can be concluded, in light of the complexity of the system, that the modeling does a reasonable job in predicting the overall dynamic behavior of the system. Any lack of agreement can be attributed to the following: (1) in the analytical models, the magnets are considered as point masses, (2) the girder is considered to be a uniform beam, and (3) all supports are considered to be identical. Some of these 
restrictions can be removed in the future if there is a need to model the magnet support assembly in more detail.

As to be expected, the primary effect of the magnets is to lower the natural frequencies. As an example, one can compare the frequencies given in Table 5 with those of Table 6, and those given in Table 7 with those of Table 8 . Among other things, the lower mode frequencies are reduced by a factor slightly greater than two; the higher mode frequencies are also reduced.

An objective of the investigation is to compare the two jack screw support configurations relative to their dynamic characteristics, viz., natural frequencies and modes. Based on the reasonable agreement between the theoretical predictions and experimental results, it was decided to use the results from the computer model in making this comparison. An advantage in this approach is that the same basic model is used for each support configuration. The results are given in Table 9, which allows for a direct comparison of the two support configurations. From Table 9, one is lead to conclude that the particular support configuration does not have a strong effect on the dynamics of the support structure. It should be recognized, as shown in Tables $5-8$, that the theoretical predictions can be expected to differ from the actual frequencies by as much as 25 to 33 percent. However, this fact does not change the basic conclusion.

Table 9. Normal mode solutions (natural frequencies, $\mathrm{Hz}$ )

\begin{tabular}{cc}
\hline Configuration A & Configuration B \\
\hline $5.75(\mathrm{o})$ & $5.66(\mathrm{o})$ \\
$6.09(\mathrm{o})$ & $6.11(\mathrm{o})$ \\
$6.81(\mathrm{o})$ & $7.81(\mathrm{o})$ \\
$21.6(\mathrm{i})$ & $21.2(\mathrm{i})$ \\
$25.1(\mathrm{i})$ & $29.6(\mathrm{i})$ \\
$60.8(\mathrm{i})$ & $62.4(\mathrm{o})$ \\
$85.8(\mathrm{i})$ & $67.0(\mathrm{i})$ \\
$103.3(\mathrm{o})$ & $103.3(\mathrm{c})$ \\
$165.5(\mathrm{i})$ & $165.5(\mathrm{i})$ \\
$241.5(\mathrm{o})$ & $241.5(\mathrm{o})$ \\
$284.8(\mathrm{o})$ & $284.8(\mathrm{o})$ \\
$397.0(\mathrm{i})$ & $396.2(\mathrm{i})$ \\
\hline
\end{tabular}

(o) out-of-plane mode

(i) in-plane mode 
Response measurements. While the primary objective of the test program was to develop an understanding of the dynamic behavior of the storage ring magnet support assemblies; the test set up provided an opportunity to gain insights into the response of the magnets/girder to floor motion and coolant flow excitation. The response of the support assembly to floor motion was studied as a part of Test E: support configuration B - with magnets.

The response to ambient floor motion in Bldg. 335 was measured in the vertical and horizontal orientations and simultaneous measurements were made on the girder. The results given in Table 10 are averaged RMS displacements over a 60 -s time period and frequency range $10-100 \mathrm{~Hz}$. The results indicate an amplification factor of approximately two between floor and girder motion. Nevertheless, the displacements measured on the girder are still within the APS vibration criteria. They are also in general agreement with similar measurements made at the IPNS Facility.

Table 10. Response ( $\mu \mathrm{m}$ RMS) to ambient floor motion (10 $-100 \mathrm{~Hz}$ range)

Horizontal Vertical

$\begin{array}{lll}\text { Floor } & 0.012 & 0.018\end{array}$

$\begin{array}{lll}\text { Girder* } & 0.032 & 0.034\end{array}$

* Horizontal displacement is measured at node 11; vertical displacement is measured at node 1

The data shown in Fig. 13 represent an attempt to force excite floor motion with an electrodynamic exciter and random excitation, and to evaluate the resultant response of the magnet support assembly. Vertical and horizontal displacements in $\mu \mathrm{m}$ RMS are given on the ordinate; the abscissa is representative of the input to the exciter. The zero excitation level corresponds to ambient floor motion. From the ambient excitation level to the highest excitation level it was possible to achieve an increase of slightly more than 1.5. The response of the girder at node 1 (vertical) to the floor excitation of Fig. 13 is given in Fig. 14.

In Fig. 14, the broad band $(5-100 \mathrm{~Hz}$ ) response is of particular interest. It can be observed to follow the general trend of the floor motion with an overall amplification factor in the range 1.4 to 1.8. At the highest excitation levels, the girder response approaches the APS vibration criteria $(0.12 \mu \mathrm{m}$ vertical) if one considers that the criteria are based on peak amplitudes and the measurements 


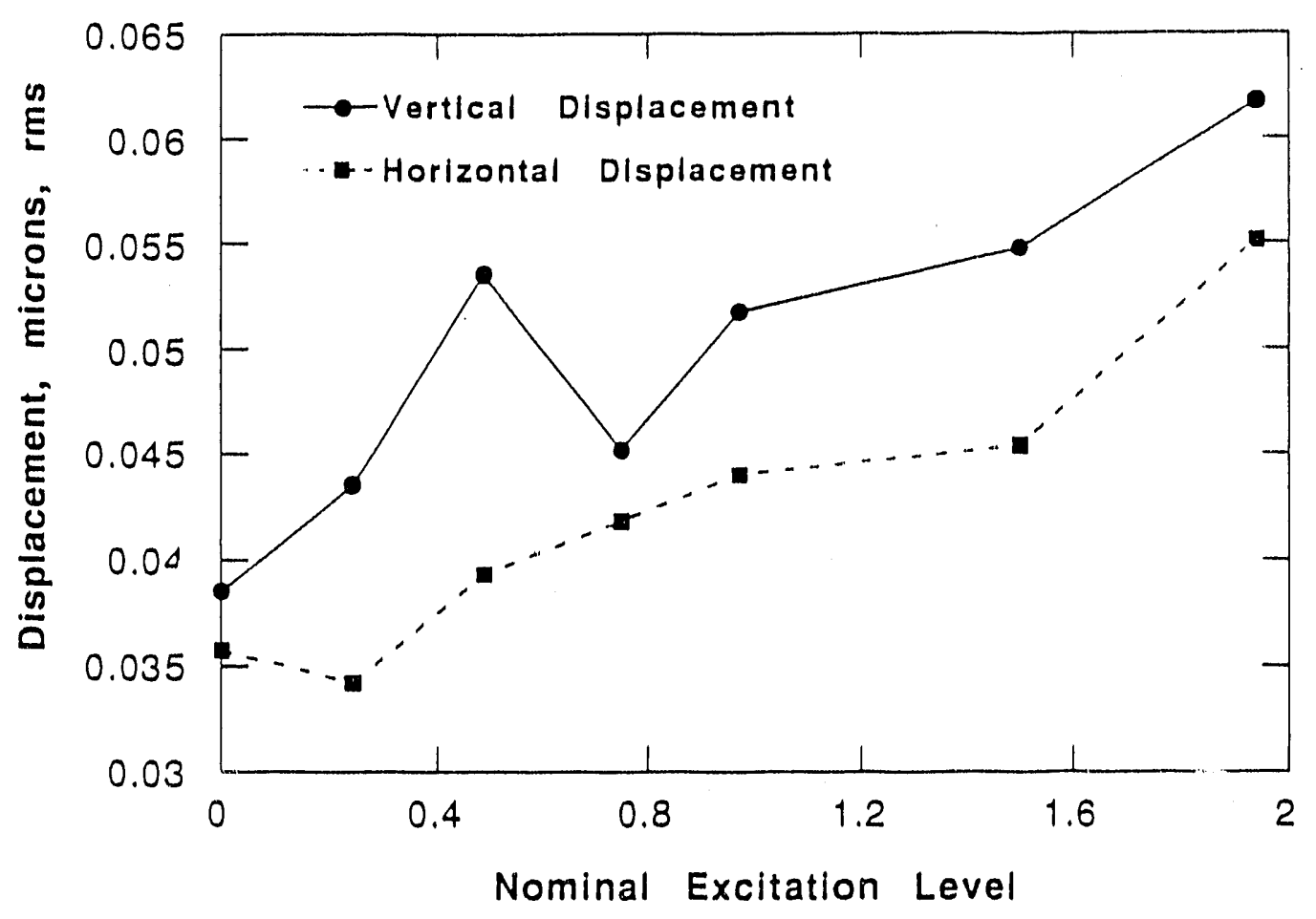

Fig. 13. Force excited floor motion

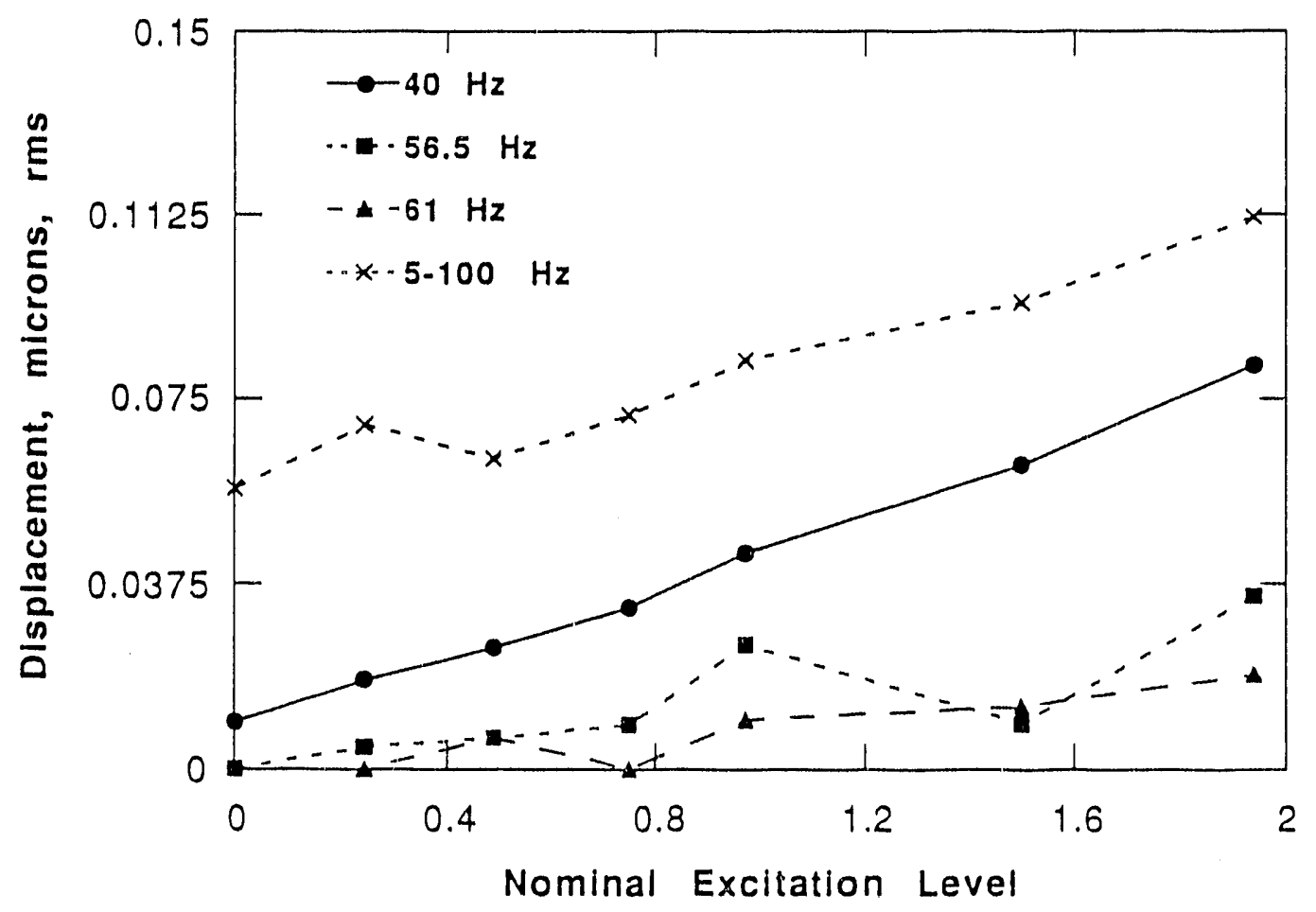

Fig. 14. Response of girder (vertical at node 1) to floor motion 
are RMS values. In this particular test run, peaks in the frequency response spectra were observed at frequencies of $40,56.5$, and $61 \mathrm{~Hz}$. The specific contribution to the overall response from each of these frequency components is also given on Fig. 14.

The response data given in Table 10 and the zero excitation level results in Figs. 13 and 14 correspond to the conditions governing the ambient motion of the Bldg. 335 hi-bay floor (the particular soil-foundation interaction dynamics and internal/external excitation sources) and the prototypic girder support system with the magnets simulated with concrete blocks. It is reasonable to assume these data are representative of what one might expect in the APS storage ring. However, one must also recognize that there will be differences in the actual APS storage ring response, as ambient floor motion will be different (hopefilly, less as the experimental hall is designed to minimize vibrations) and the actual magnets and their individual supports will form dynamic subsystems that can couple with the dynamics of the girder and its supports to alter overall vibration characteristics and response to floor motion.

A series of tests (Tests $E^{\prime}, F, G$, and I in Table 3) were performed with the objective to gain insights into the effects of coolant flow through the coolant header and return piping on response. Measurements were made on the girder in the vertical (node 1) and horizontal (node 11) directions, in the horizontal direction near the top of the concrete block simulating the $0.6 \mathrm{~m}$ quadrupole, and in the vertical direction near the inlet on the pipe simulating the coolant flow header.

RMS displacement response in the frequency ranges $5-100 \mathrm{~Hz}, 15-100 \mathrm{~Hz}$, and $20-100 \mathrm{~Hz}$, are given in Figs. 15a, 15b, and 15c, respectively, from Test $\mathrm{E}^{\prime}$ (configuration B - with magnets), and in Figs. 16a, 16b, and 16c, respectively, from Test $\mathrm{F}$ (configuration A - with magnets). From these curves one can conclude that the majority of the energy is in the low frequency range involving the lower vibration modes. The fact that the response does not show a monotonic increase with flow rate can be attributed at least in part to the way in which the flow facility was operated. The response measured on the inlet pipe is consistently the highest. This can be attributed to the flexibility of the piping which is nonprototypic.

To evaluate the effect of pipe flexibility, the pipe overhangs on either end of the girder were restrained and Test $G$ (configuration A - with magnets) was performed. The results are given in Fig. 17. A comparison of the $5-100 \mathrm{~Hz}$ data (which includes the natural frequency of the unrestrained pipe) of Figs. 16a and $17 a$, reveals, as suspected, that the pipe response is lower with the pipe restrained. 


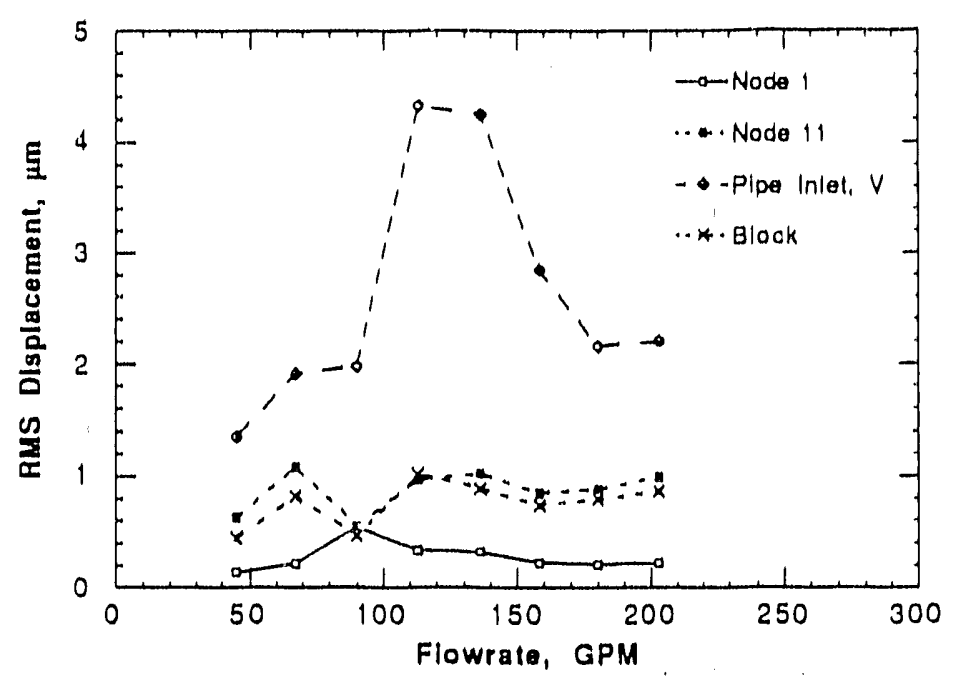

a) $5-100 \mathrm{~Hz}$ range

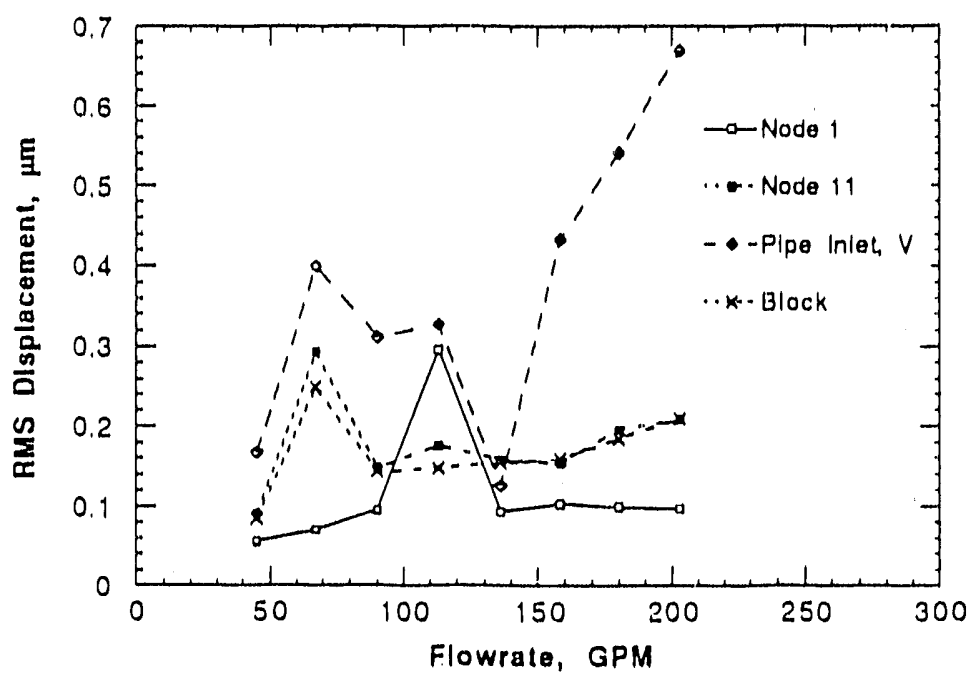

b) $15-100 \mathrm{~Hz}$ range

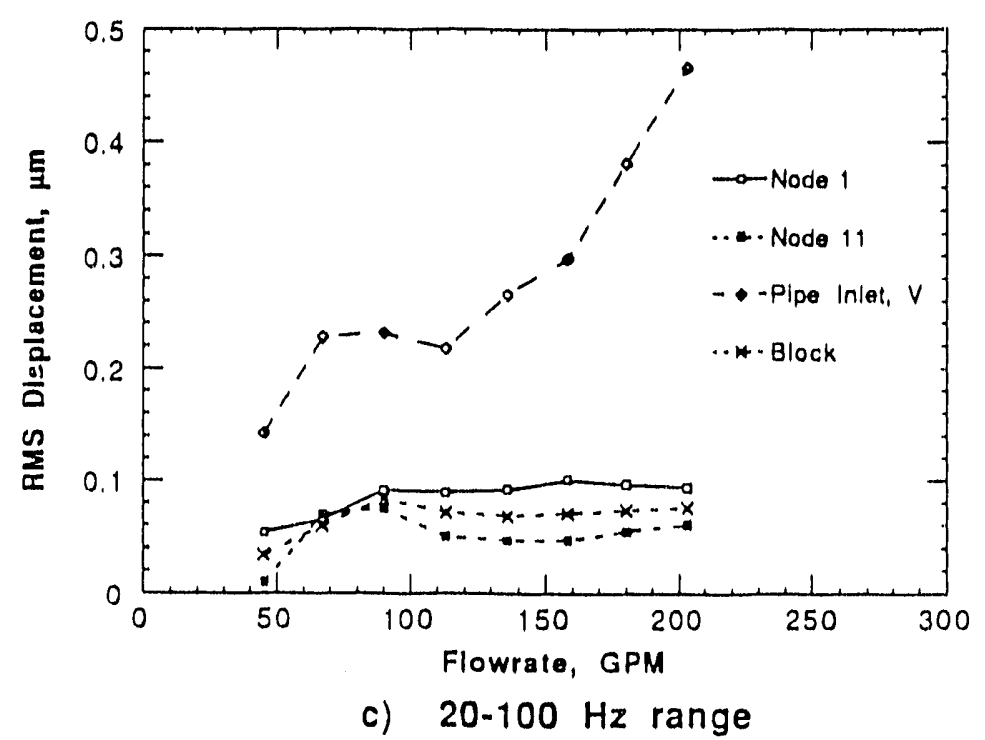

Fig. 15. Response to coolant flow excitation and pump noise (Test E'). Node 1 . vertical on girder; Node 11 - horizontal on girder; pipe inlet, $V$ - vertical on pipe; block - horizontal on simulated $0.6 \mathrm{~m}$ quadrupole 


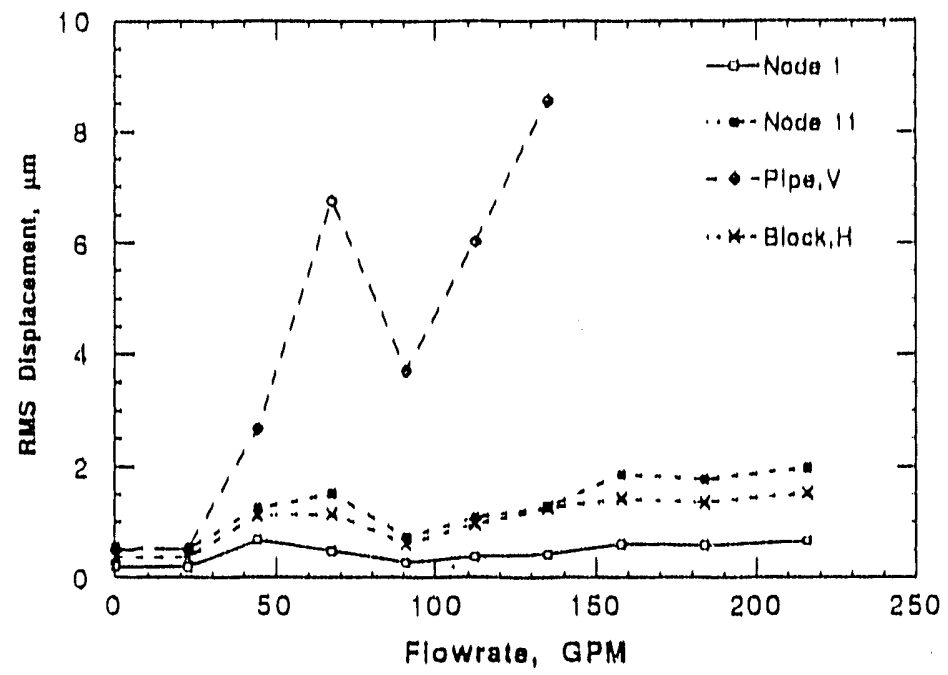

a) 5-100 $\mathrm{Hz}$ rainge

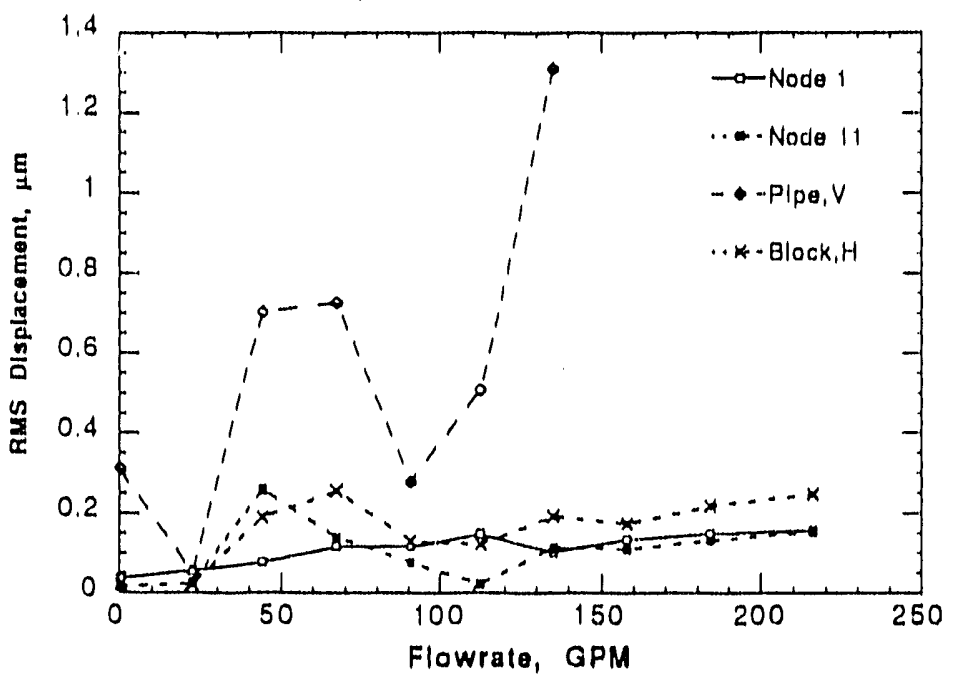

b) $15-100 \mathrm{~Hz}$ range

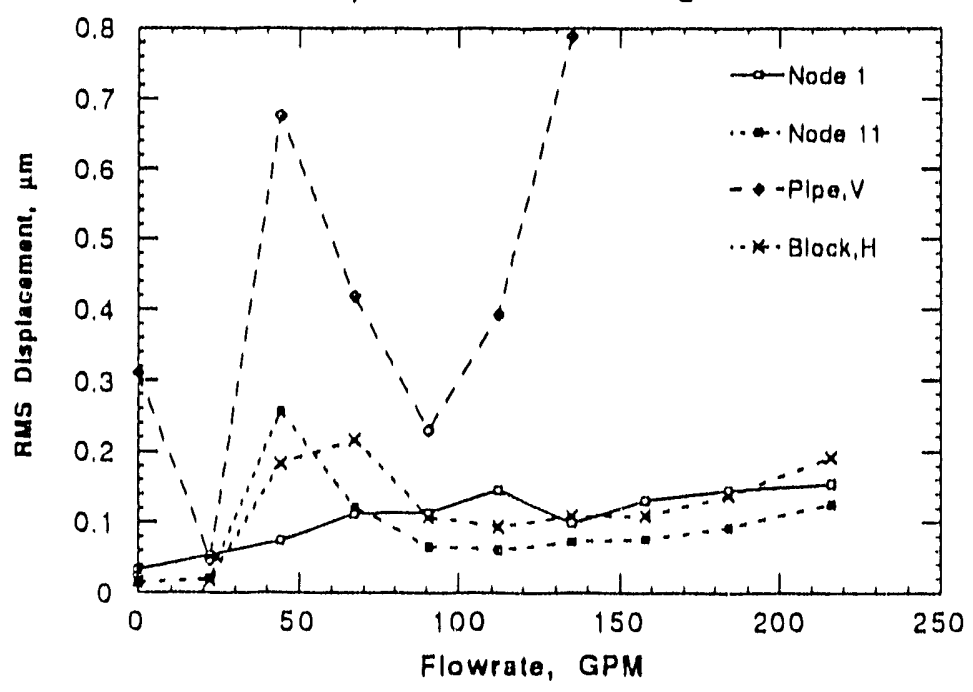

C) $20.100 \mathrm{~Hz}$ range

Fig. 16. Response to coolant flow excitation and pump noise (Test F). Node 1 vertical on girder; Node 11 - horizontal on girder; pipe, V - vertical on pipe; block, $\mathrm{H}$ - horizontal on simulated $0.6 \mathrm{~m}$ quadrupole 


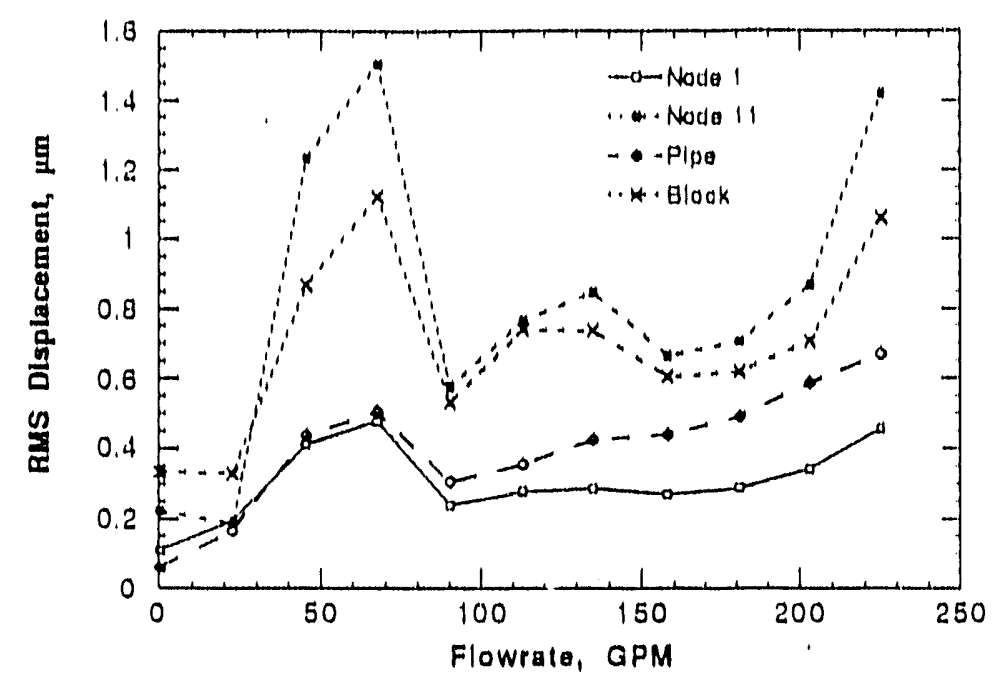

a) 5-100 $\mathrm{Hz}$ range

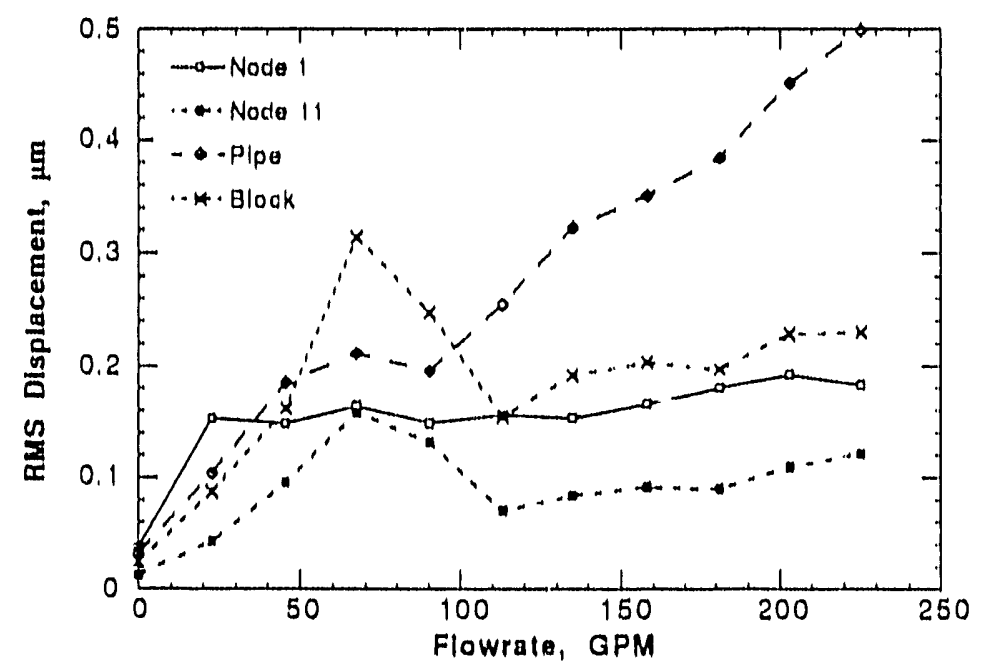

b) $15-100 \mathrm{~Hz}$ range

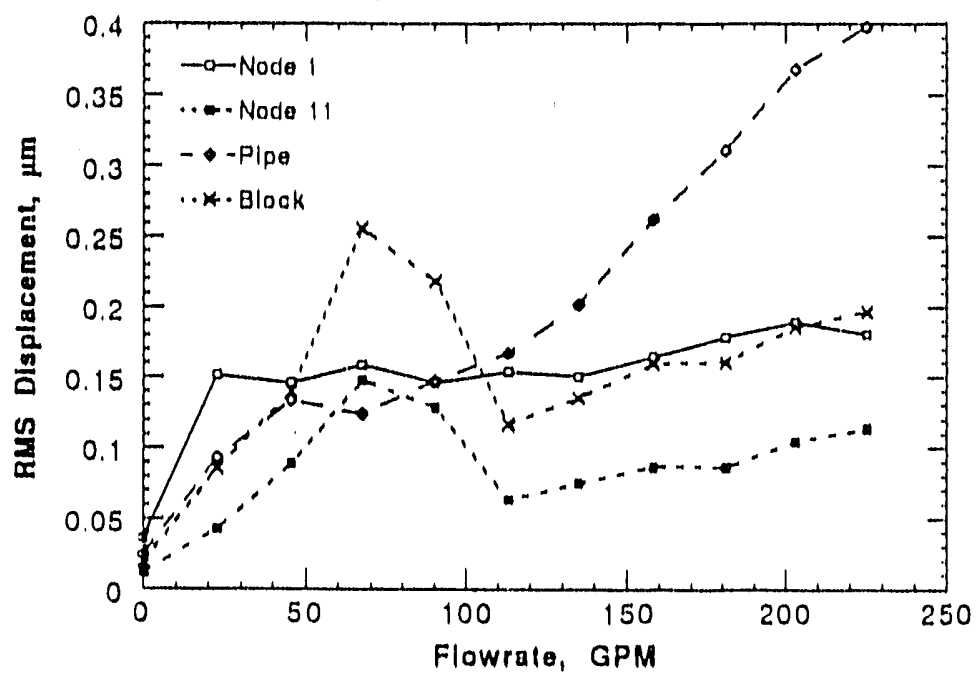

c) $20-100 \mathrm{~Hz}$ range

Fig. 17. Response to coolant flow excitation and pump noise (Test G). Node 1 vertical on girder; Node 11 - horizontal on girder; pipe - vertical on pipe; block - horizontal on simulated $0.6 \mathrm{~m}$ quadrumnls 
Finally, as discussed above, the water pump was determined to be particularly noisy, from a structural-borne vibration standpoint, as vibrations could readily be "felt" at the test site. To obtain a quantitative measure of pump noise, the piping was de-coupled from the girder and Test I (configuration A * with magnets) was performed with the results given in Fig. 18. In Fig. 18, the vertical and horizontal motion of the floor is given together with vertical motion of the girder (node 1) and horizontal motion near the top of the concrete block simulating the $0.6 \mathrm{~m}$ quadrupole. A comparison of these results with the data of Figs. 15 - 17, leads one to conclude that the structurally-borne pump noise represents a considerable portion of the measured response. This, of course, is not prototypic, but it does serve to indicate the types of problems that can be encountered if equipment, is not properly vibration-isolated. If the background noise is subtracted from the response given in Figs. $15-17$, the resulting response is within the APS vibration criteria for frequencies greater than $15 \mathrm{~Hz}$.

\section{SUMMMARY AND CONCLUDING REMARKS}

Both the tests and analyses serve to demonstrate that the girder is sufficiently stiff with respect to the jack screw assemblies that the lower frequency rigid body modes and the higher frequency bending and torsional modes can be considered independently. For a linear system, the number of vibration modes is equal to the number of degrees of freedom If the magnet/girder assembly is assumed to behave as a rigid body on spring supports, it would have six degrees of freedom. Therefore, one would expect six rigid body modes; the finite element analysis bears this out.

The test results do not always yield six rigid body modes. The reason for this is that some modes are inherently more difficult to excite. It follows that the modes that are excited are dependent on the particular excitation method and point of application used.

The lower frequency rigid body modes are controlled by the flexibility of the individual jack screws. Modal testing supplemented with feature tests demonstrated that the jack screws are nonlinear in the sense that the effective spring constants are functions of the applied load. However, for a given load and small motions it is reasonable to assume linearity. Also, once the turnbuckles are tightened, the load versus deflection curve is in an asymptotic range in which it is reasonable to assume that the spring constants are independent of load.

As discussed above, in performing the analysis one of the greatest uncertainties is related to the value to assume for the effective spring constants for the jack screws. These values are of critical importance as they directly 


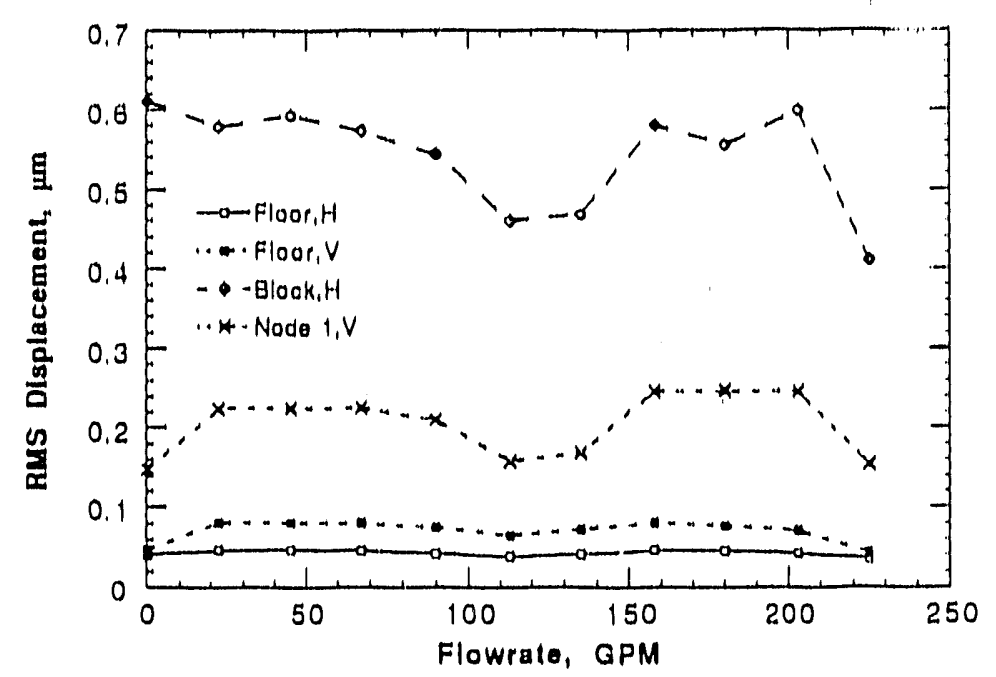

a) 5-100 $\mathrm{Hz}$ range

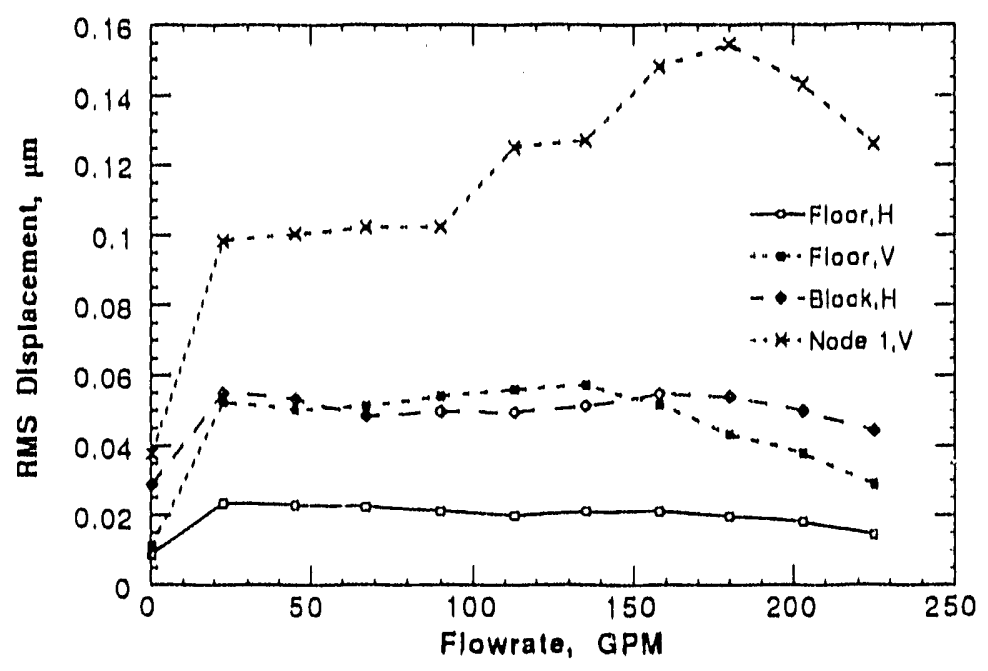

b) $15-100 \mathrm{~Hz}$ range

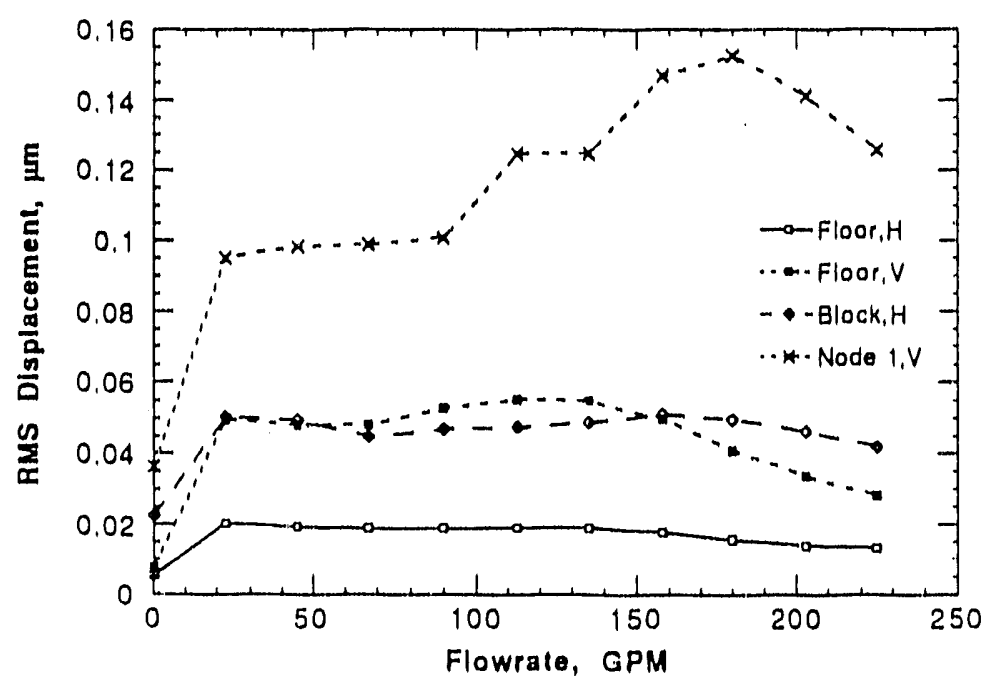

c) $20-100 \mathrm{~Hz}$ range

Fig. 18. Response to coolant flow excitation and pump noise (Test G). Floor, H horizontal on floor; Floor, V - vertical on floor; block, $\mathrm{H}$ - horizontal on simulated $0.6 \mathrm{~m}$ quadrupole; Node $1, \mathrm{~V}$ - vertical on girder 
determine the lower frequency rigid body modes. The approach taken was to use the experimental results and to back-calculate values for the two (in-plane and out-of-plane) spring constants that would give good agreement with the finite element calculations.

In the analysis it is assumed that all three jack screws have the same set of spring constants. In real life it can be assumed that the values will vary amorg the different jack screws; among other things, the extension of the jack screws will vary somewhat as the floor will not be perfectly level. Differences in spring constants are expected to account for some of the disagreement between analysis and test results.

An objective of the study was to compare the two jack screw support configurations illustrated in Fig. 3. It was demonstrated that the finite element analysis, with experimentally based values for jack screw spring constants, does a reasonable job of predicting natural frequencies and modes. Since it was deemed important to use the same method for the comparison, it was decided to use the finite element method. The results indicate only slight differences in the lower frequency rigid body modes and essentially no differences in the higher bending modes; torsional modes are not calculated. Based on the comparison it can be concluded that from a vibrations standpoint there is no preferred configuration when considering the two. However, from an overall design standpoint, configuration $\mathrm{A}$ is preferred as it allows for easier installation of the bus bars.

Tests demonstrated that the vibration of an unrestrained U-bend pipe overhang could couple with the magnet/girder system with the result that a contribution at the resonant frequency of the U-bend pipe overhang is present in the response of the overall system. The U-bend pipe overhang is analogous in many respects to the power supplies that are hung from the girder. As with the pipe overhang, a low frequency mode, in this case associated with the power supply support structures, could couple with the magnet/girder system and contribute to the overall response.

The test results show that floor motion is magnified by the dynamics of the magnet/support assemblies; tests at the IPNS facility also led to this conclusion.

The dominant responses to ambient floor motion and coolant flow are in the lower modes $(<15 \mathrm{~Hz})$. It is in this frequency range that vibrations can be controlled using feedback systems with steering magnets. However, it must be kept in mind that the vibration amplitudes in this frequency range must be within the dynamic range of the controllers. It remains to define the dynamic range of 
the controllers and the corresponding maximum limit on low frequency vibration amplitudes that can be corrected.

In the frequency range $15-100 \mathrm{~Hz}$ response to floor motion is within the APS criteria. Similarly, accounting for background noise associated with pump operation, response to coolant flow (up to two times design flow rate of $100 \mathrm{gpm}$ ) is also within the criteria.

A frequency of $\sim 8.1 \mathrm{~Hz}$ was detected on many of the response measurements. The tests were performed in the Bldg. 335 high-bay, and it is of interest to note that responses at approximately this frequency were measured in earlier vibratinn tests in the vicinity of the building, including ground motion measurements [4,5]. The $8.1 \mathrm{~Hz}$ signal seems to be a "site" or "building" frequency with unknown origin. While one would not expect to see this particular frequency at the APS site, it does not seem unreasonable to expect that a similar "site" frequency, inherent in the overall design and siting, may be associated with the APS site and experimental hall. A further basis for this conclusion is the fact that similar site-related frequencies were also identified as the result of measurements made in Bldgs 360 and 378. Perhaps coincidentally, these frequencies were also approximately $8 \mathrm{~Hz}$.

The reasonable agreement between analysis and test results using testbased effective jack screw spring constants suggests that the finite element method can be used as an effective design tool, for example, in the performance of parameter studies.

$\Lambda s$ evidenced by the high frequencies associated with the bending modes of the girder in both the in-plane and out-of-plane directions, the girder itself is sufficiently stiff as a structural member. Displacement response at these high frequencies due to internal and/or external excitation sources will be very small and well within the APS vibration criteria. Again, the lower modes, which are the rigid body modes, are the modes of most concern, since displacemient response will be the largest in these modes. As the lower modes are controiled by the flexibility of the jack screws, it is important to note that the lower mode frequencies can be shifted, as necessary, by redesign of the jack screws. In this regard, the subject analyses and tests demonstrated that with three jack screw supports, the two spatial configurations tested exhibited only slight differences in the lower rigid body mode frequencies. However, other spacings and/or arrangements could be evaluated as design constraints, for example, on mounting power supplies and bus bars, allow.

The tests were performed with the magnet masses simulated, but not the magnet supports, which, for most magnets, consists of a flat plate on a tripod 
arrangement of three smaller jack screws. The magnets and their individual supports will then form their own dynamic systems each with its own set of normal modes and frequencies which have the potential to couple with the dynamics of the girder and its support assemblies. The potential for magnification of girder (magnet base) motion is inherent in such coupled systems.

Also of potential concern, and not studied in the subject investigation, is the vibration of the vacuum chamber. The vacuum chamber is supported from the girder by one stiff and two flexible (in the axial, or positron beam, direction) supports; the flexible supports are required to allow for changes in length due to differential thermal expansion that are, in turn, accommodated in a flexible bellow. The concern is related to the fact that the vacuum chamber is the support for the buttons that serve as sensors for the beam position monitors. Vibratory motion of the vacuum tube with respect to the magnets could compromise the operation of the associated feedback control system.

To minimize magnification of floor motion, and to minimize potential coupling with the individual magnet support assemblies and vacuum chamber supports, one would like to have the girder support assemblies be as stiff as possible. From a vibrations standpoint then, the ideal situation would be to effectively eliminate the jack screws, as they represent the most flexible member. One way to do this, would be to support the girder on concrete piers. This would serve to eliminate the inherent flexibility of the girder support assemblies. The practicality of this approach would have to be assessed.

\section{FUTURE WORK}

A clarification of the vibration criteria and the establishment of an upper limit on low frequency $(<1.0-20 \mathrm{~Hz}$ ) vibration amplitudes to ensure that they are within the dynamic range of the controllers are required. In particular, with regard to criteria, the allowable amplitudes based on the requirement that emittance growth be limited to 10 percent are, for the scenario of random vibration of all the storage ring quadrupoles, $0.34 \mu \mathrm{m}$ peak in the horizontal direction and $0.12 \mu \mathrm{m}$ peak in the vertical direction. It should be noted that these are peak values. In our vibration studies the measurement results are typically reported in terms of $R M S$ values. In terms of RMS values, the vibration criteria would be as given in Table 11; in the case of random motion, it is assumed Gaussian such that the peak value can be taken as approximately equal to $3 \sigma$. The characteristics of the measured response (for example, whether sinusoidal or random) and the interpretation of the vibration criteria can obviously influence the conclusions drawn from the study. 
Table 11. Vibration criteria: allowable vibration amplitudes $(\mu \mathrm{m})$

\begin{tabular}{lcccc} 
& Peak & & $\begin{array}{c}\text { RMS } \\
\text { (Sinusoidal) }\end{array}$ & $\begin{array}{c}\text { RMS } \\
\text { (Random) }\end{array}$ \\
\cline { 2 - 2 } & 0.12 & & 0.085 & 0.04 \\
Vertical: & 0.34 & & 0.24 & 0.11
\end{tabular}

The subject study provided valuable insights into the dynamic characteristics of the magnet/girder/support assemblies, and, in particular, the importance of the flexibility of the jack screws as they control the lower rigid body mode frequencies. However, as noted in the discussion, the study did not include the effects of the dynamics of individual magnet support assemblies, the bus bars and power supply racks, and the vacuum chamber supports. Each has the potential to couple with the dynamics of the girder/support assemblies and to result in motion magnification. Also, vibratory motion of the vacuum chamber can adversely effect the operation of the beam position monitoring system.

Future work will include an ongoing vibration measurement program to characterize the dynamics of these subsystems and to evaluate dynamic coupling with the girder/support assembly. Information and data will be made available to the Mechanical Design and Accelerator Physics Groups and, as required, recommendations will be made relative to the need to redesign to avoid potential problems.

Also, having established nominal values for the in-plane and out-of-plane effective spring constants for the jack screw/pedestal supports, the finite element analysis code will be used to estimate the dynamic characteristics of the other two magnet sections, assuming such information is of interest. Here, it should be noted that of the five magnet sections comprising one sector of the storage ring, two are repeating, such that there are only three unique sections.

\section{ACKNOWLEDGMENTS}

The authors gratefully acknowledge the assistance of R.K. Smith and R.N. Lanham in the set-up and conduct of the testing program, the contributions of M.G. Srinivasan in the application of the modal analysis software, and the cooperation of A. Passi in providing the girder assembly and concrete shielding blocks and overall co-ordination with the APS project. 


\section{REFERENCES}

1. "Subsurface Exploration and Geotechnical Engineering Evaluation for Proposed 7-GeV Advanced Photon Source (APS)," Final Report, STS Project No. 25229, STS Consultants, Northbrook, IL, May 20, 1988

2. "Title II - Subsurface Exploration and Geotechnical Engineering Evaluation for Proposed 7-GeV Advanced Photon Source (APS)," Final Report, STS Project No. 25229-B, STS Consultants, Northbrook, IL, April 30, 1990

3. Jendrzejczyk, J.A., and Wambsganss, M.W., "Surface Measurements of Shear Wave Velocity at the 7-GeV APS Site," LS-129, December 1987

4. Jendrzejczyk, J.A., and Smith, R.K., "Building-Soil Vibration Coupling," LS79, January 1987

5. Jendrzejczyk, J.A., Wambsganss, M.W., and Smith, R.K., "Ambient Ground Motion Measurements at Argonne National Laboratory over Extended Time Periods," LS-111, March 1988

6. Jendrzejczyk, J.A., Nagy, Z., and Smith, R.K., "Ambient Ground Motion at the 7-GeV A.PS Site at Argonne National Laboratory over Extended Time Periods," LS-136, December 1988

7. Jendrzejczyk, J.A., Wambsganss, M.W., and Smith, R.K., "Surveillance of $18 \mathrm{~Hz}$ and $60 \mathrm{~Hz}$ Components of Ground Motion at the APS Site," APS/IN/VIB/90-1, March 1990

8. Amick, H., and Gordon, C.G., "Site Vibration Survey - Advanced Photon Source - Argonne National Laboratory," Report No. 18, Acentech Inc., August 1989

9. Wambsganss, M.W., "Dynamic Analysis of the 7-GeV APS Experiment Hall Foundation based on Equivalent Lumped Parameter Modeling," APS/IN/VIB/89-1, January 1989

10. Amick, H., Acentech Inc., personal communication, November 13, 1990

11. Jendrzejczyk, J.A., Smith, R.K., and Wambsganss, M.W., "Vibration Survey of IPNS Beam Line Magnets and Experiment Hall," LS-89, April 1987 
12. Wambsganss, M.W., "Preliminary Dyramic Analysis of Conceptual Design of Magnet/Support System for the APS Storage Ring," APS/IN/VIB/89-2, June 1988 (Rev. May 1989)

13. Chen, S.S., and Wambsganss, M.W., "Vibration Analysis of A.PS Magnet/Support Systems based on the Finite Element Method," APS/IN/VIB/89-3, March 1989

14. I-DEAS Tdas. Test Data Analysis User's Guide, Structural Dynamics Research Corporation, 1988.

15. MSC/PAL. "Stress and Vibration Analysis," Users' Manual, Apple Macintosh Version, The MacNeal-Schwendler Corp. 


\section{APPENDIX}

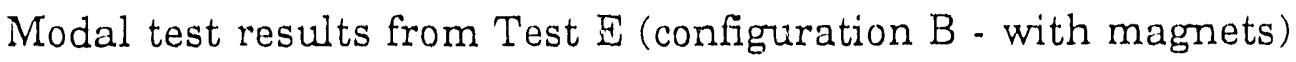


Out-of-Plane (Horizontal) Excitation 


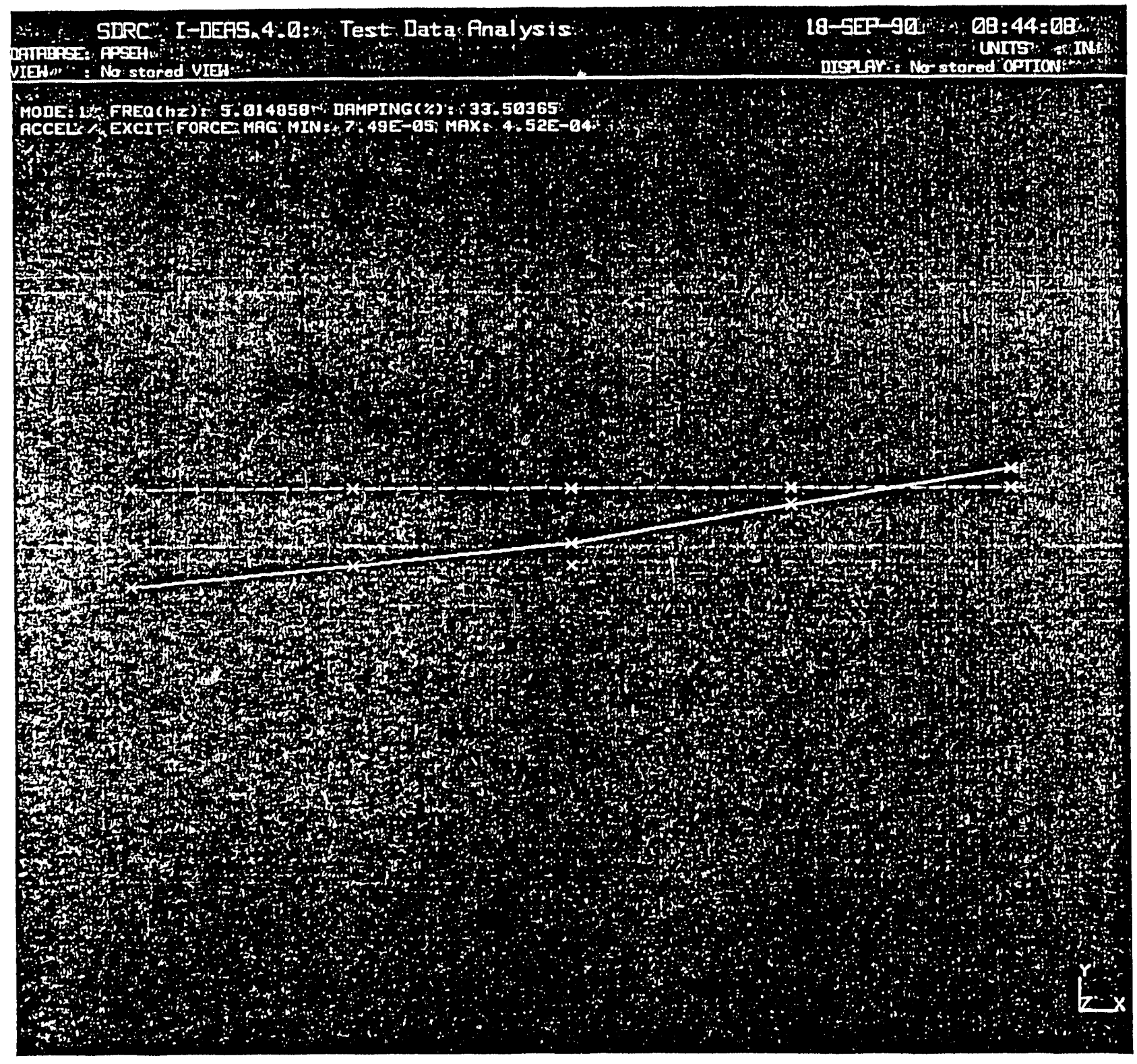




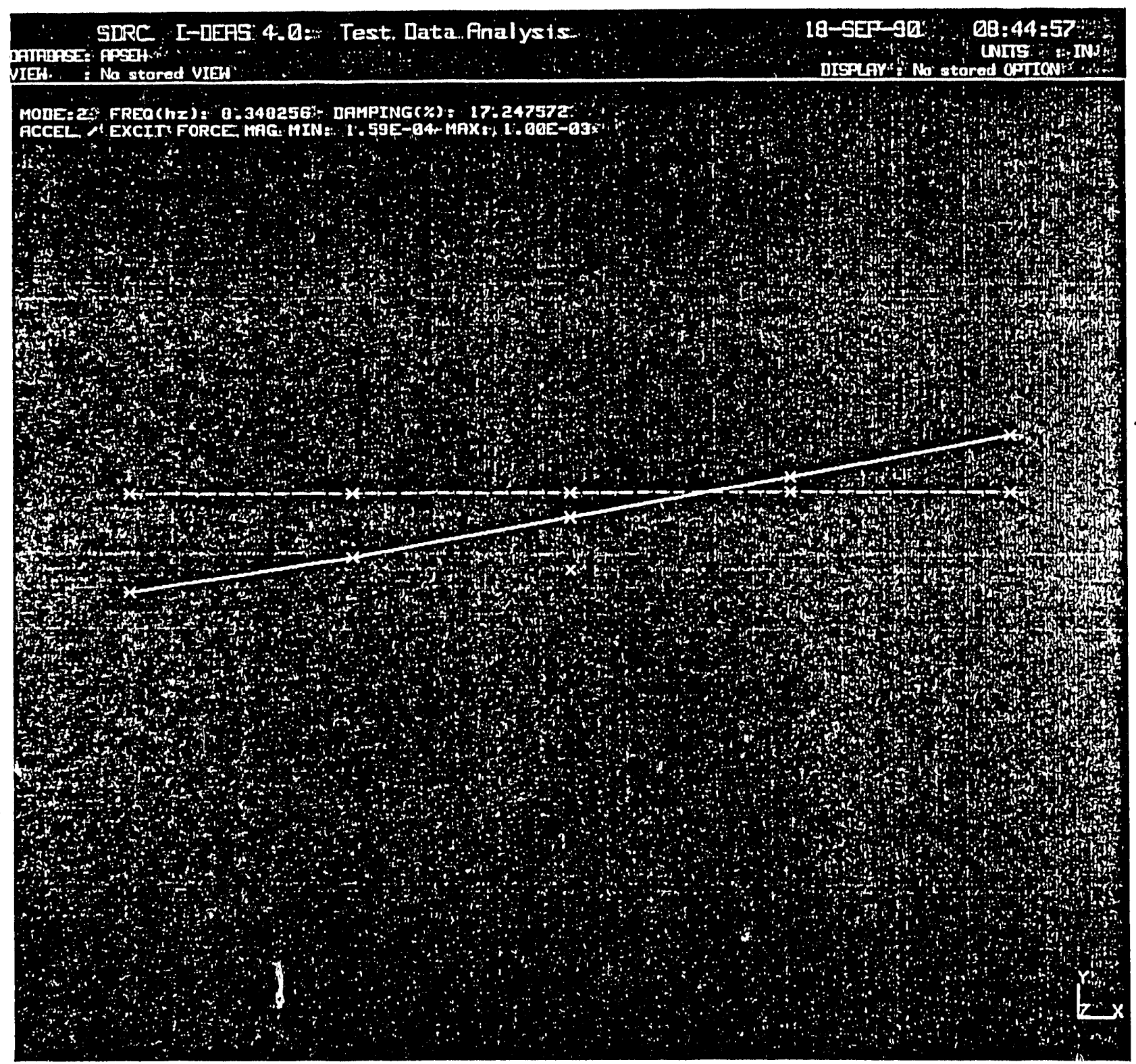




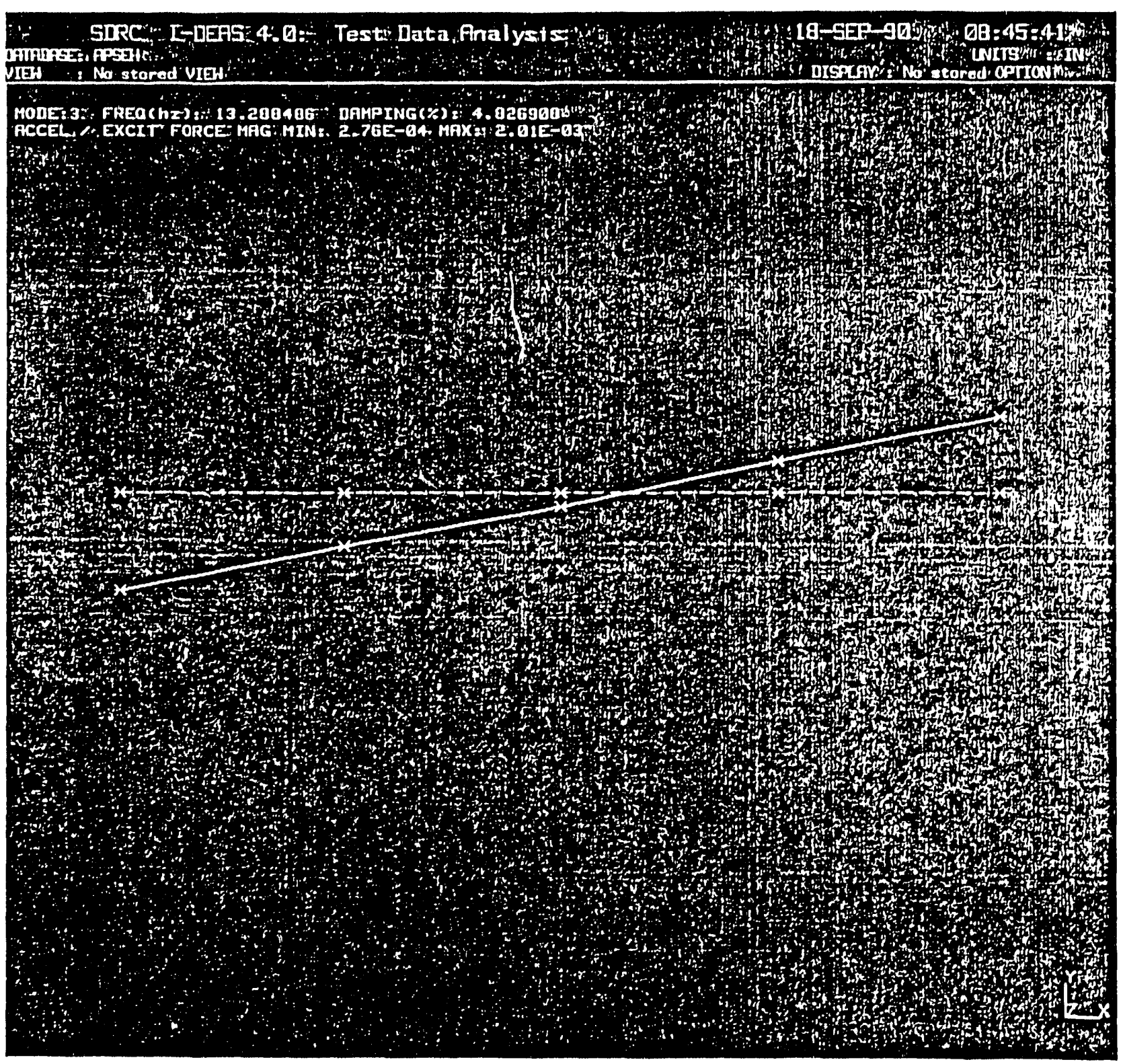




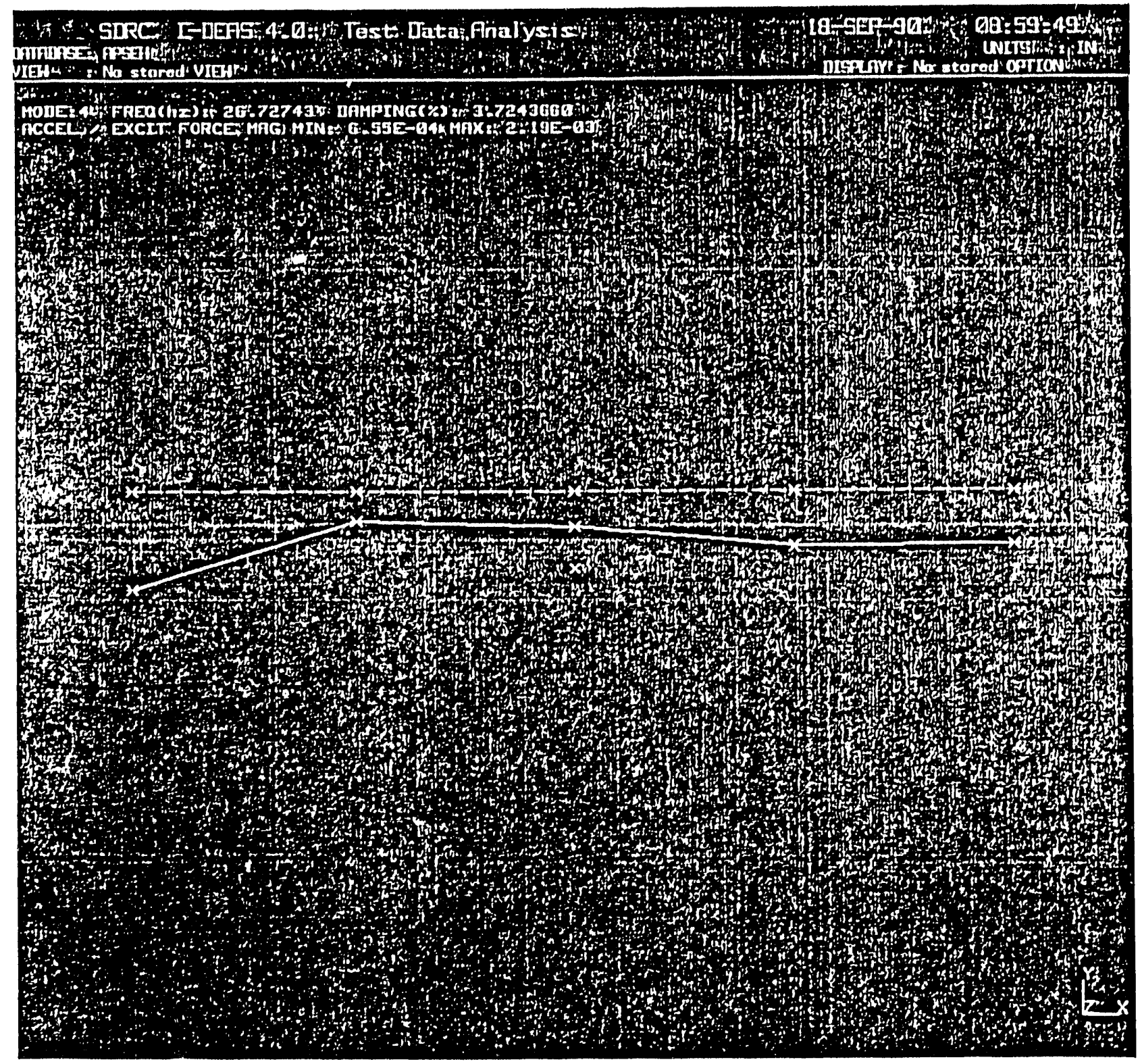




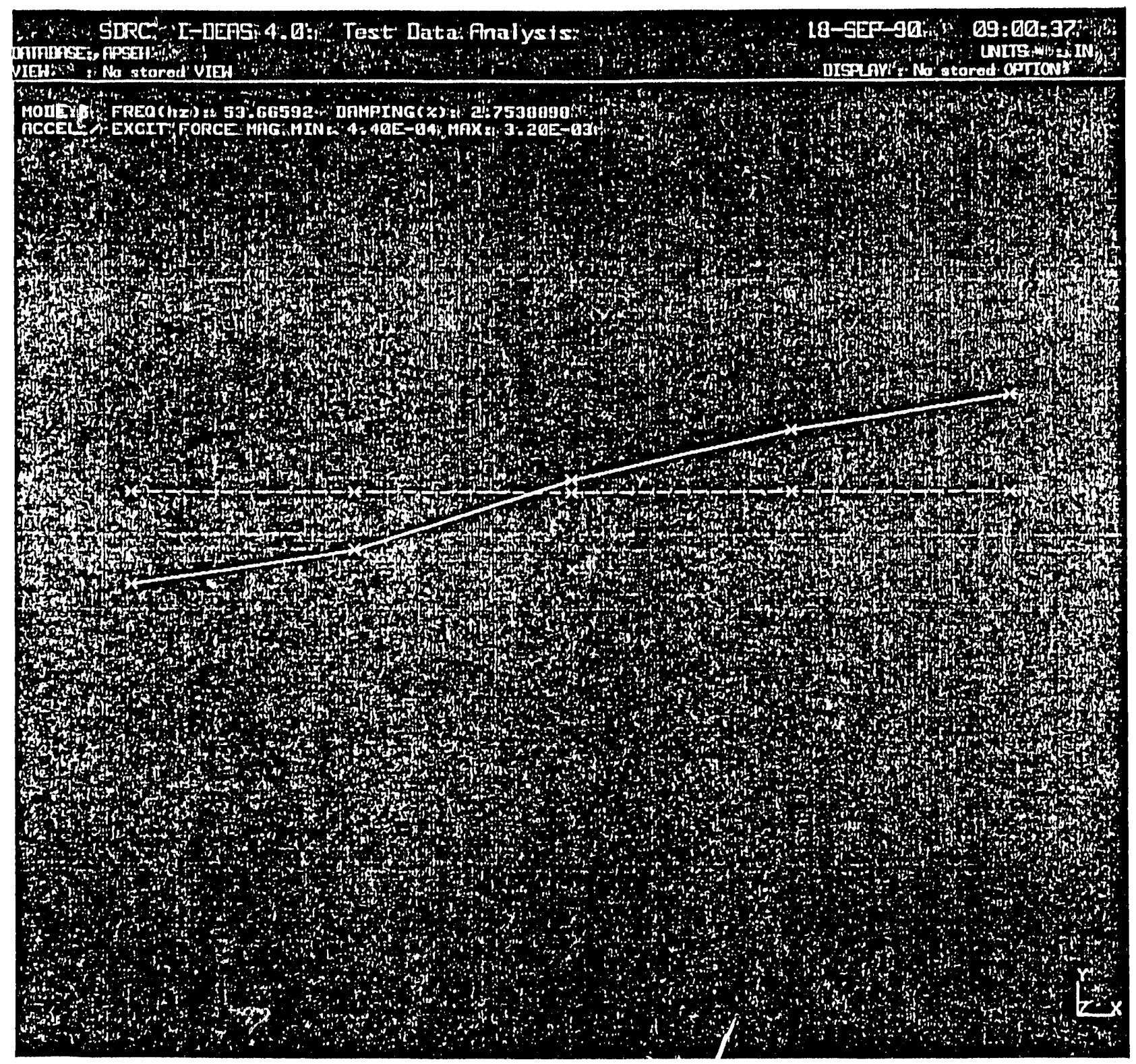




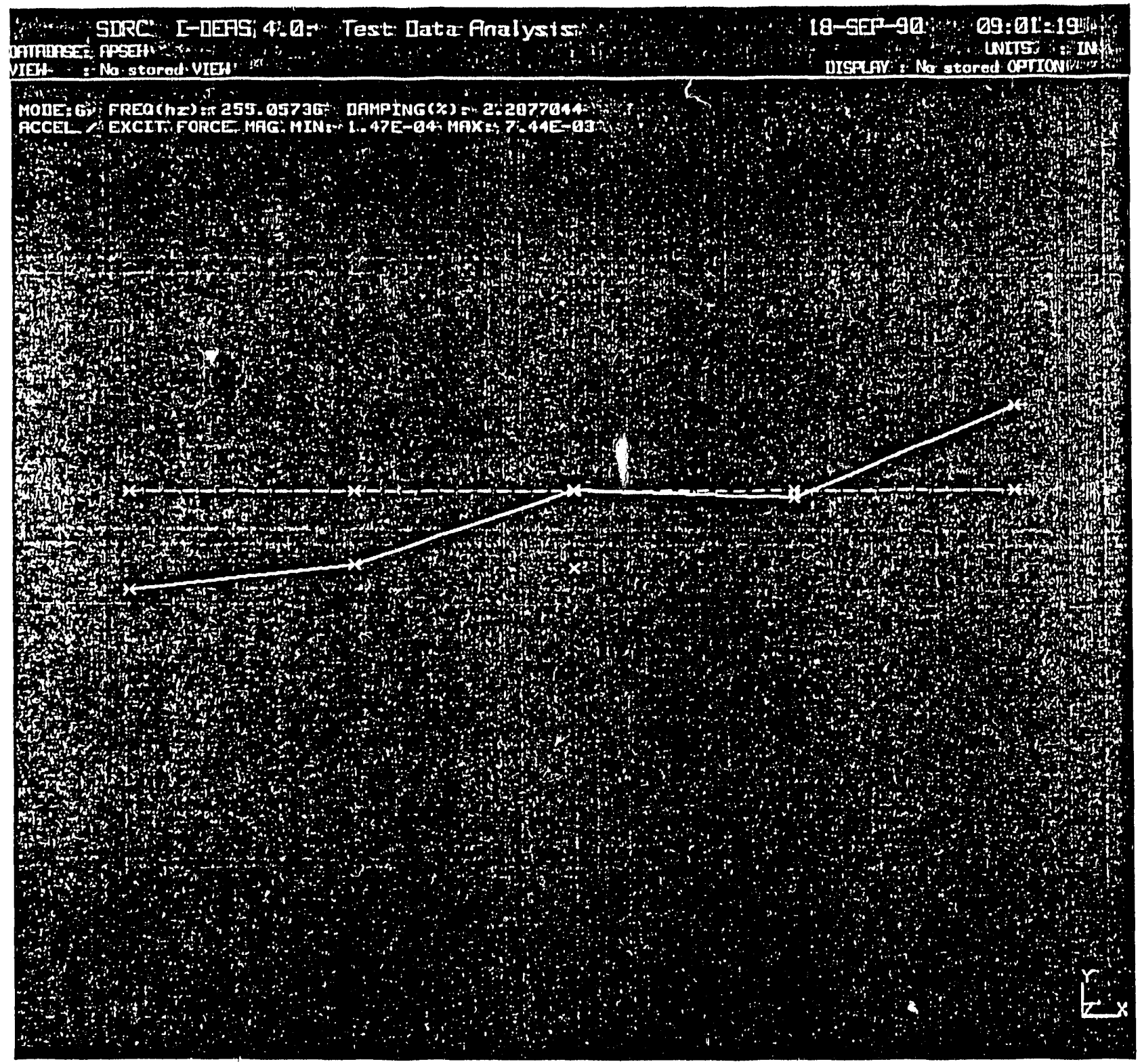




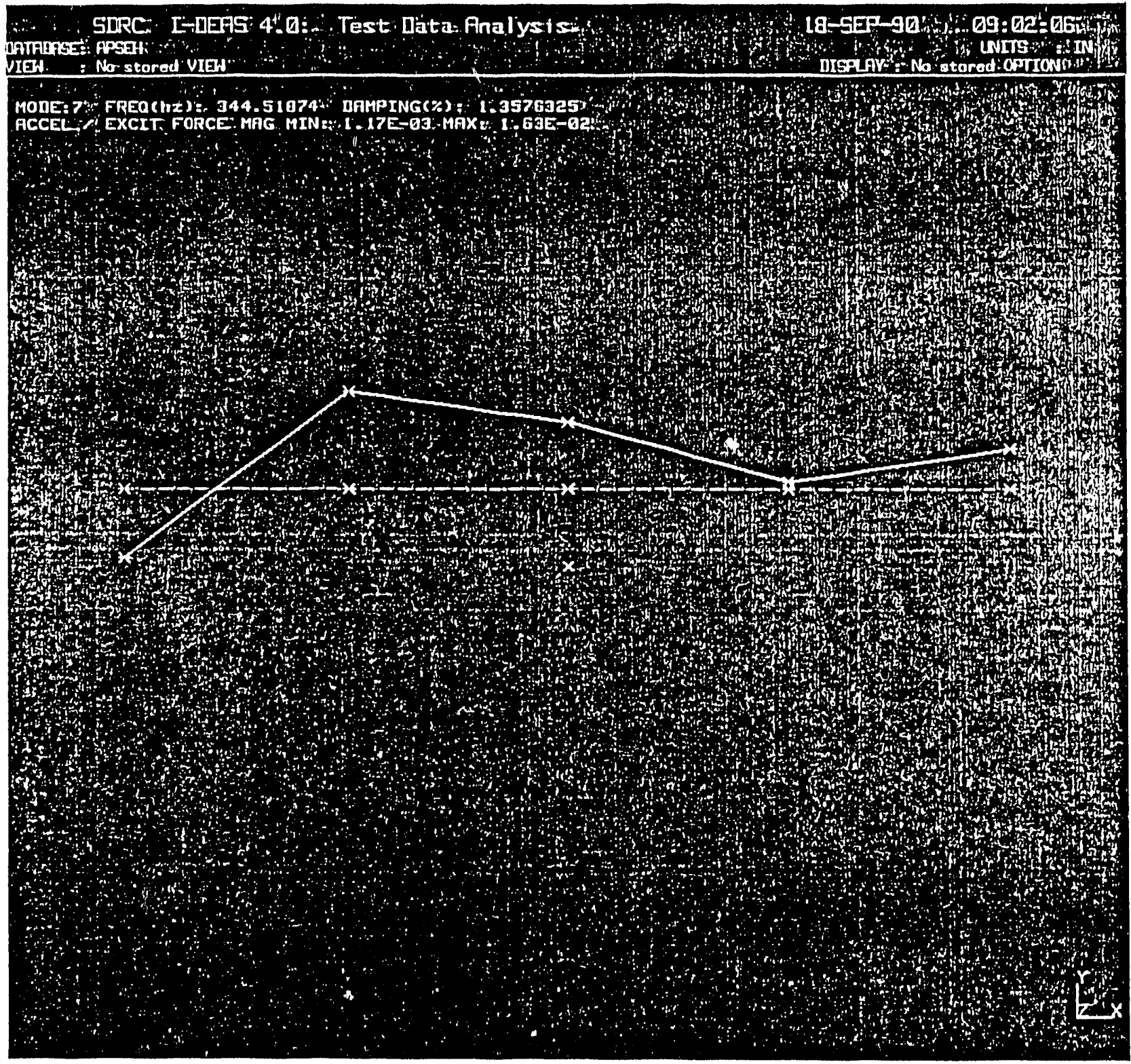




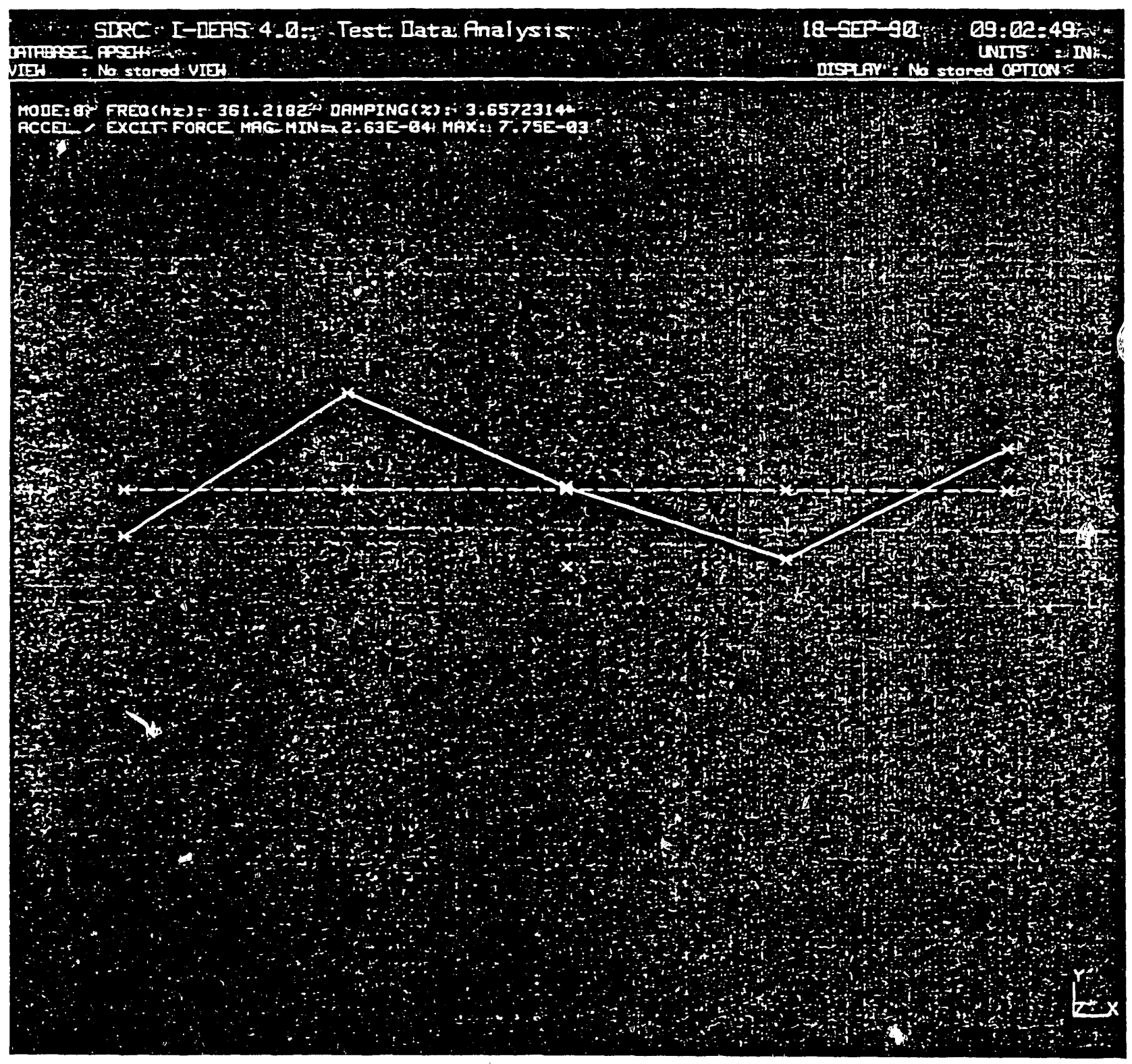


In-Plane (Vertical) Excitation 


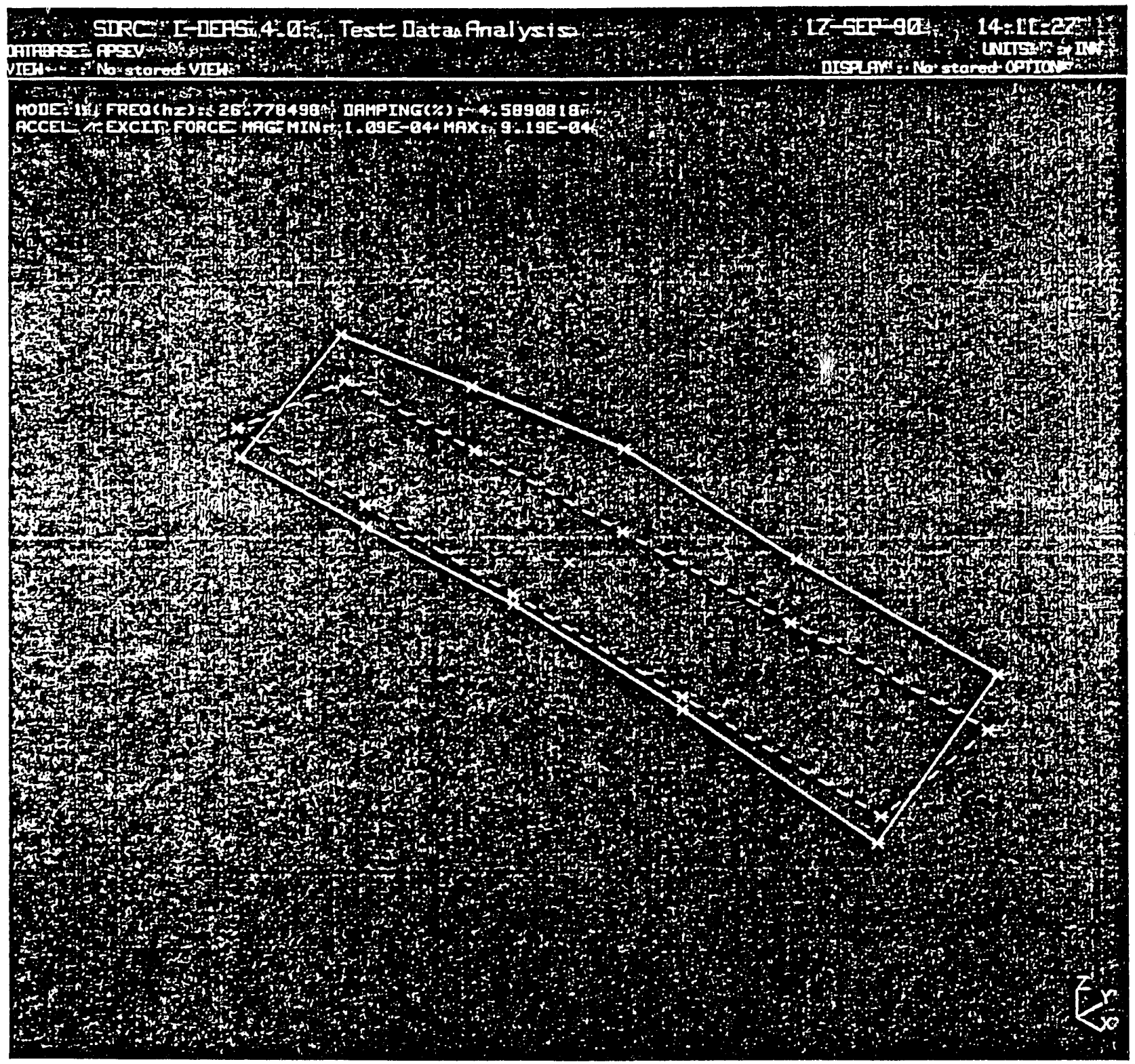




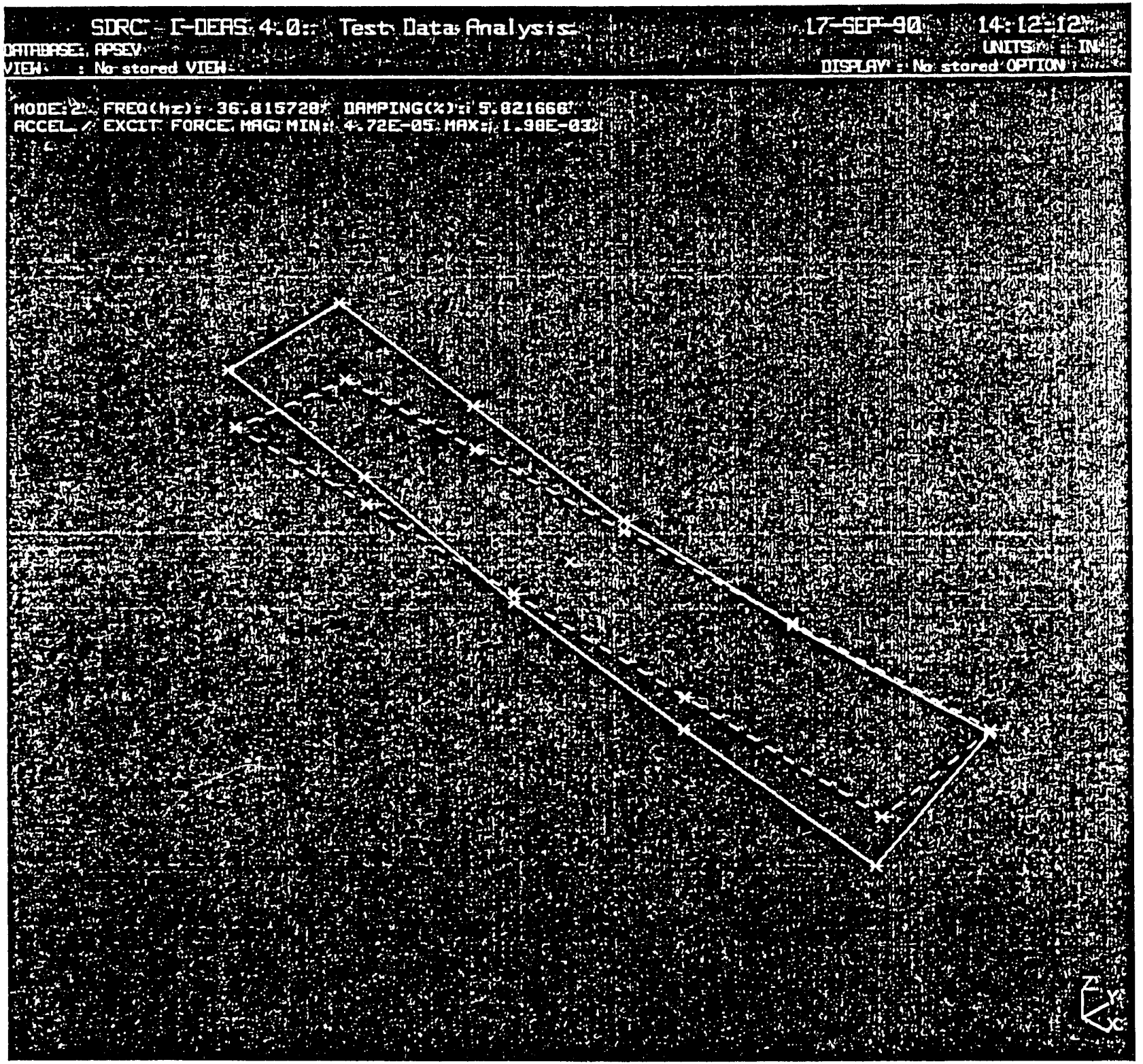




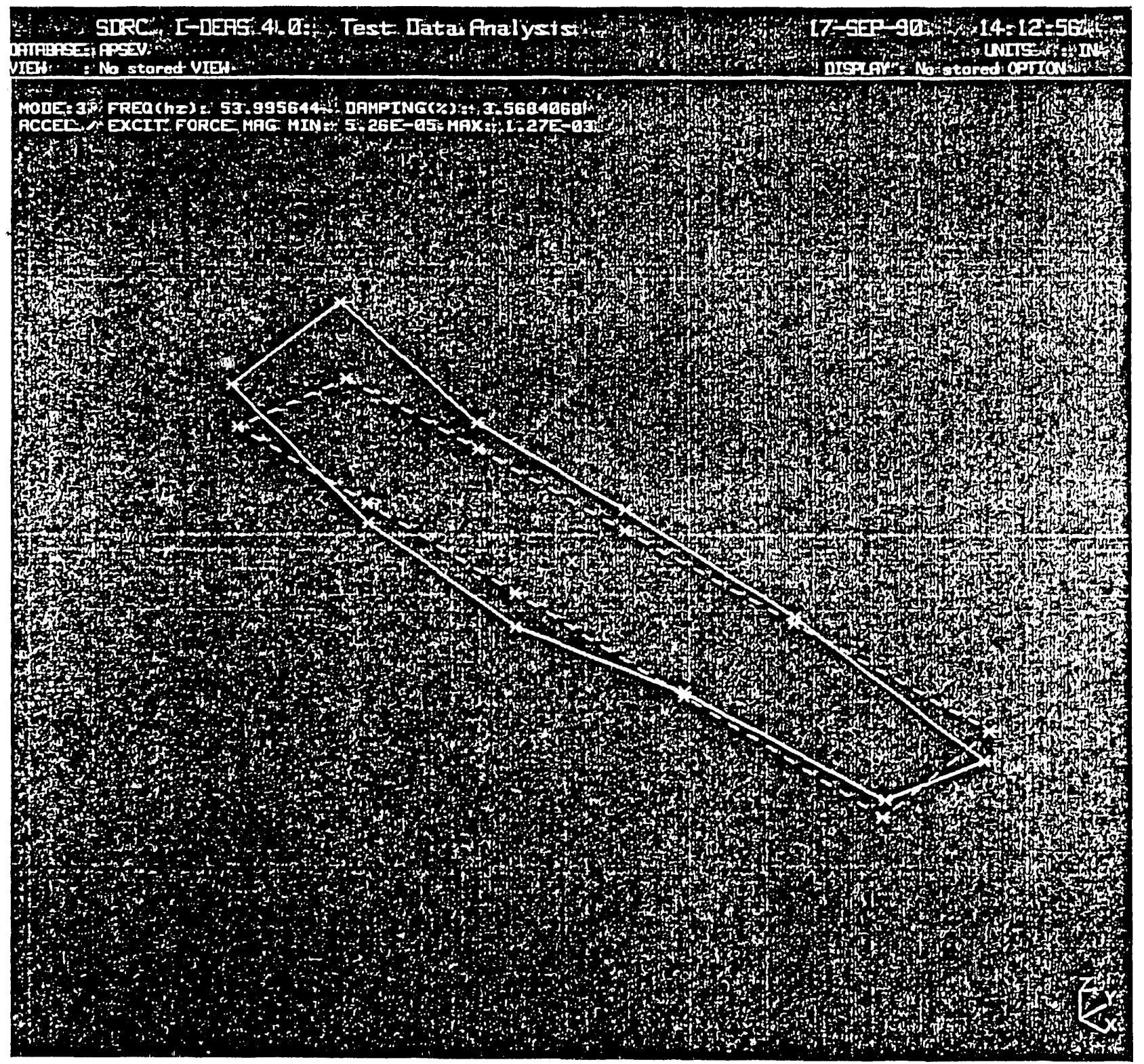




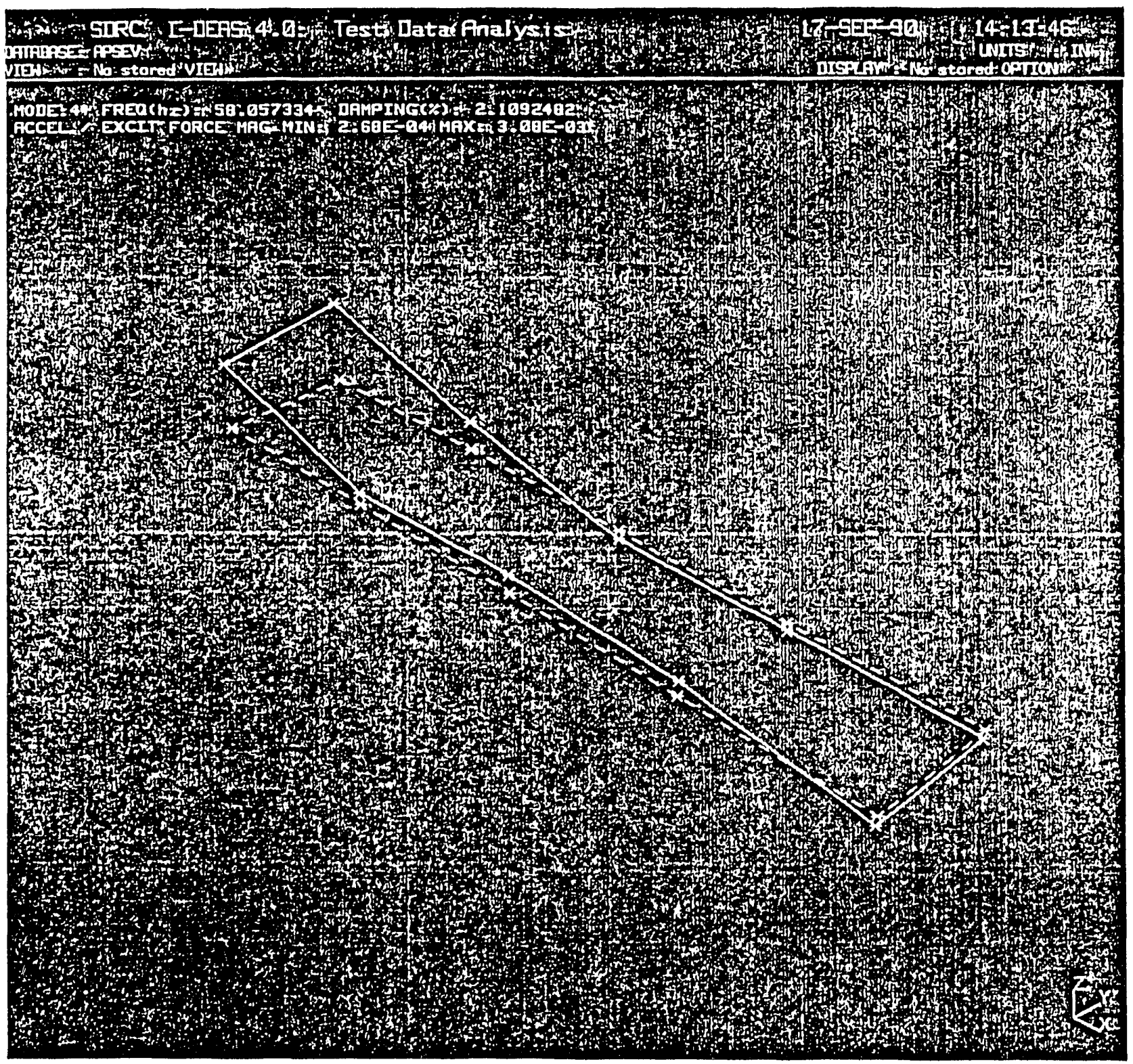




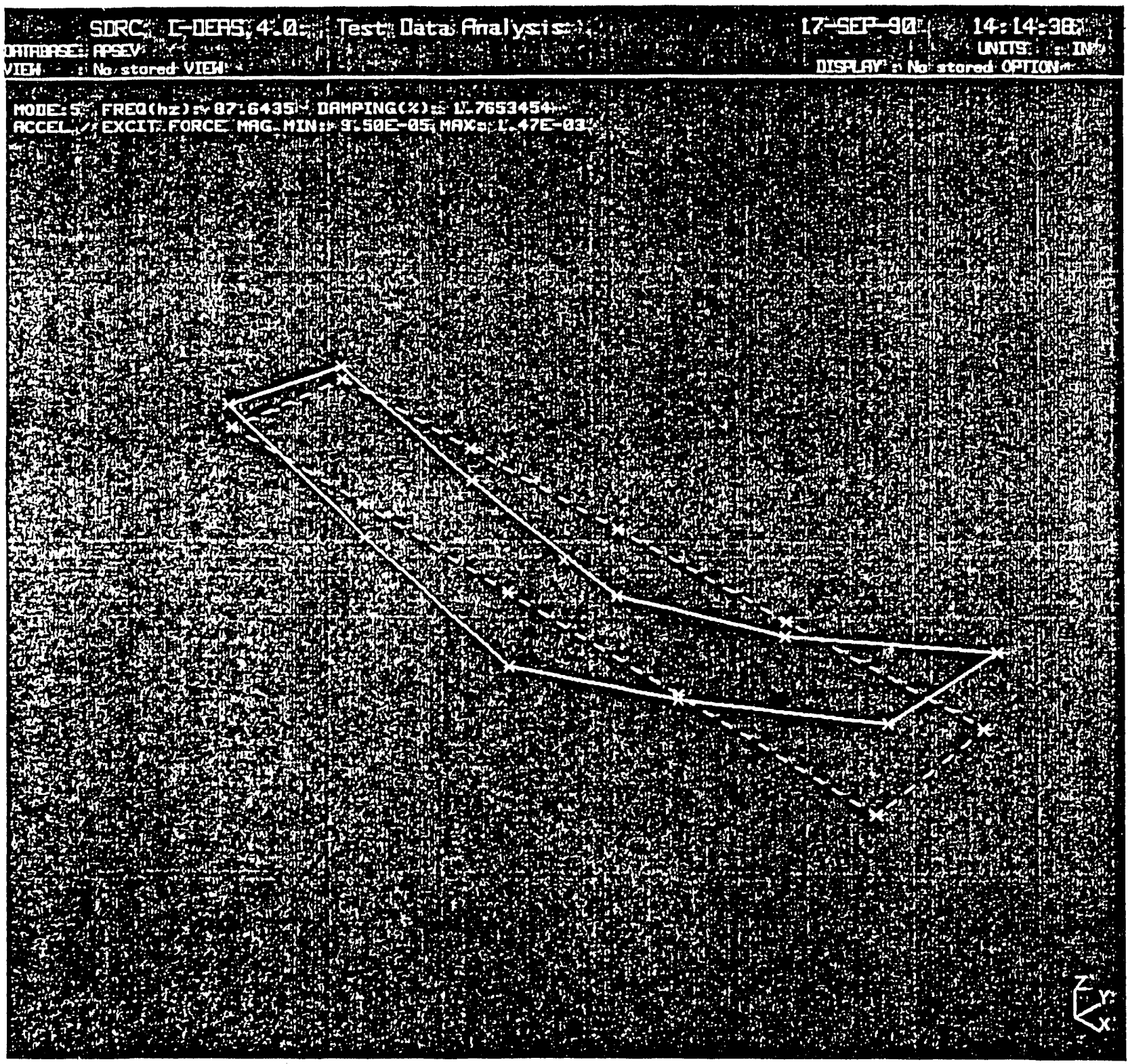




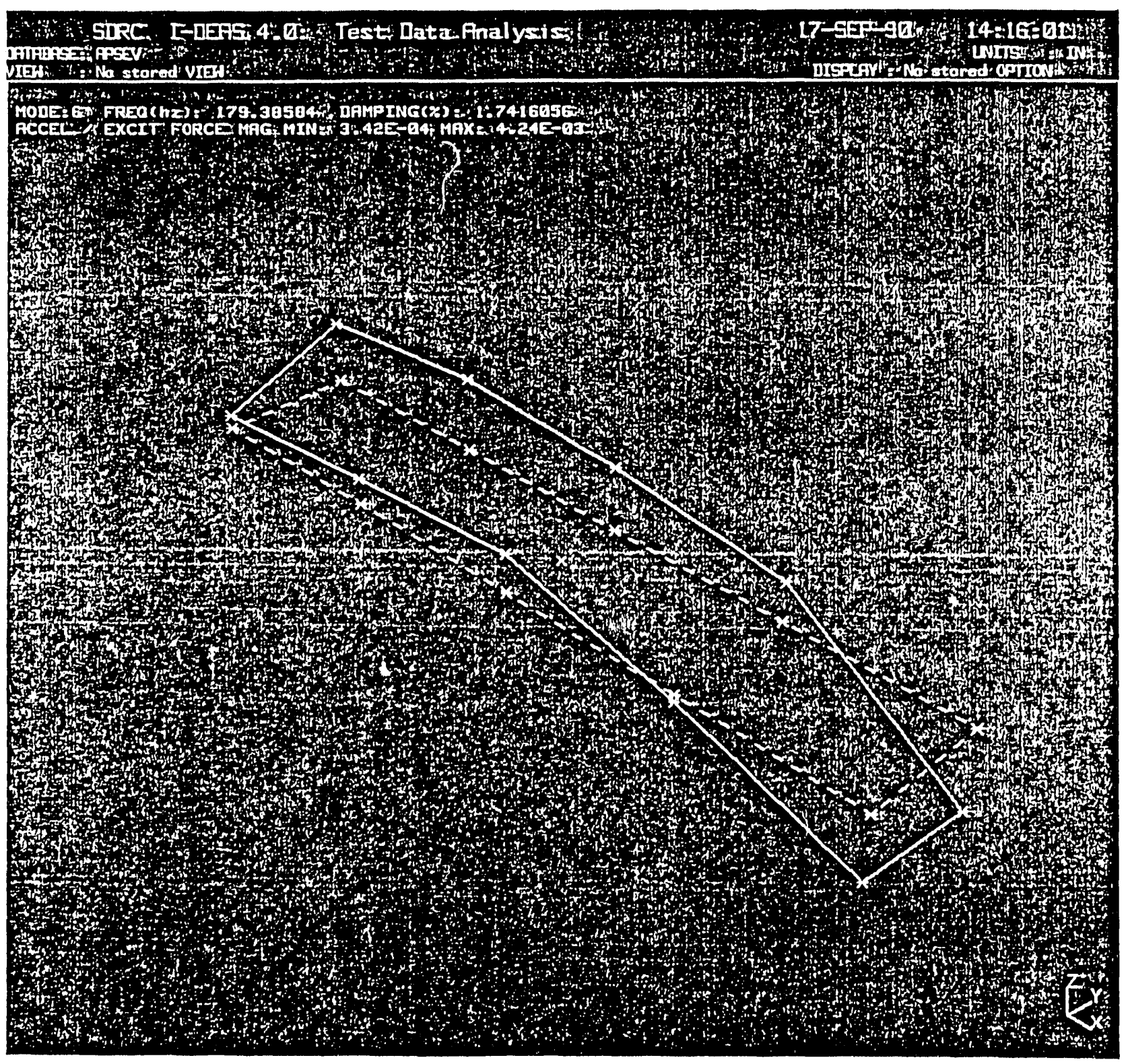




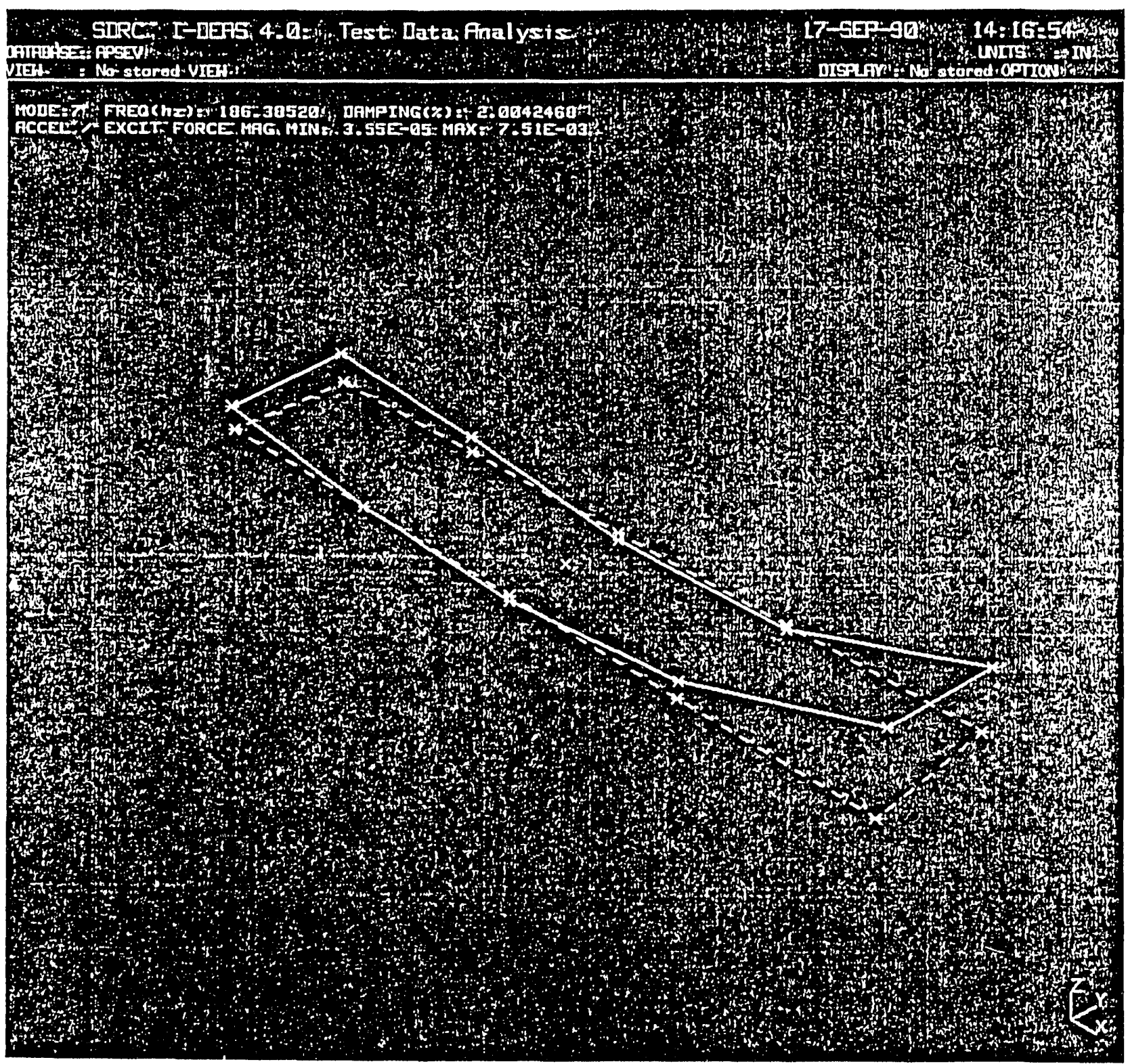




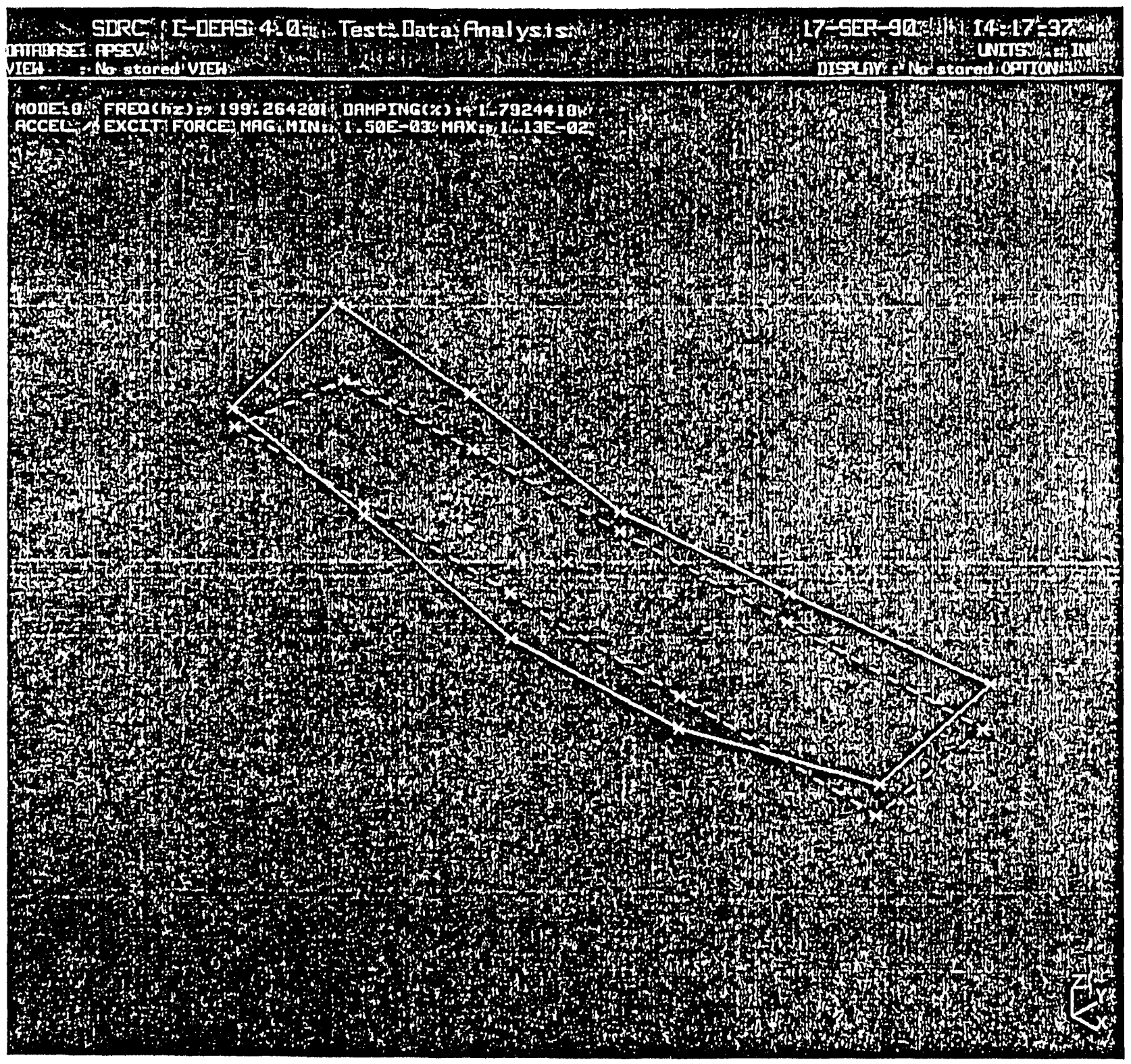




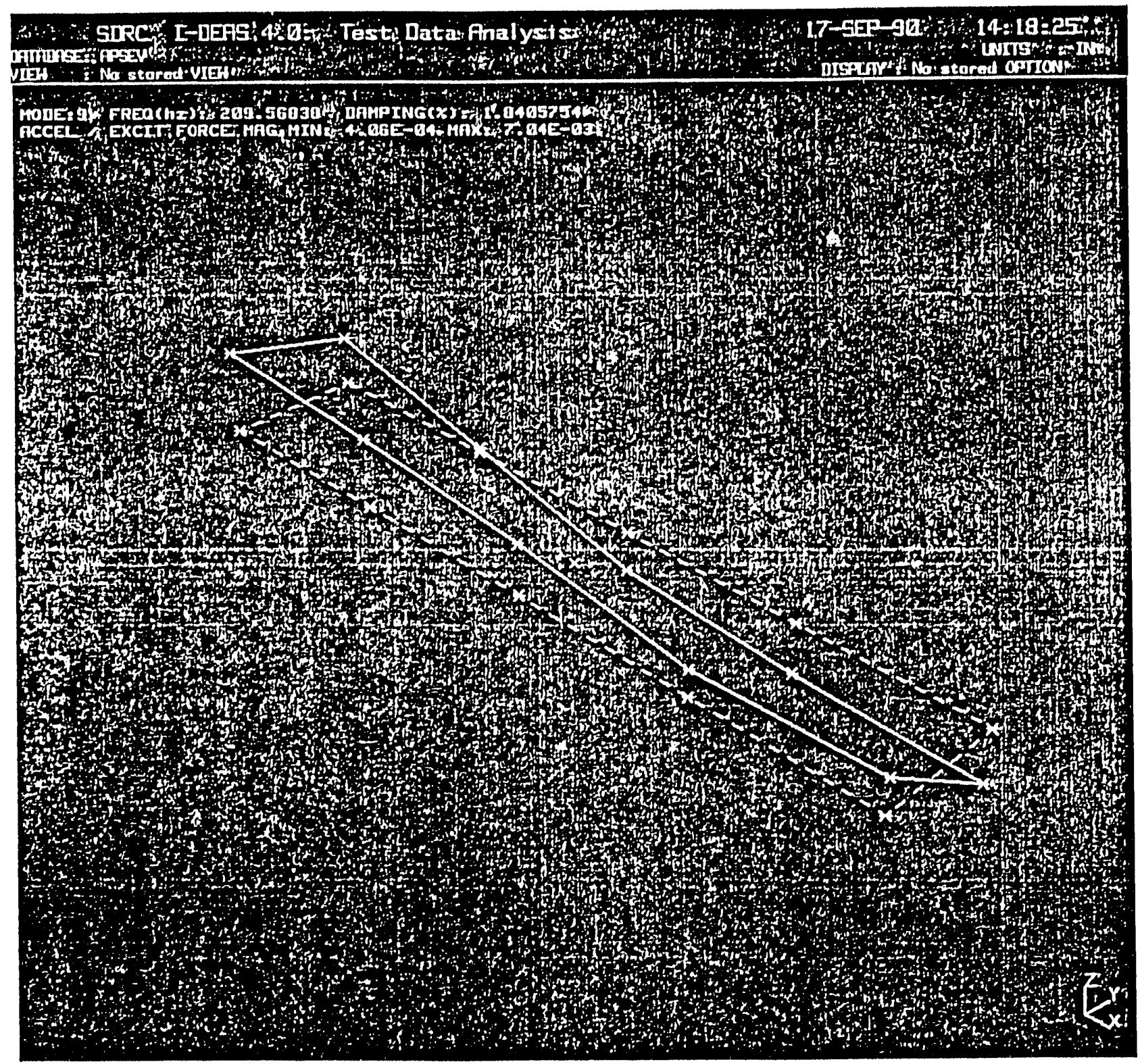




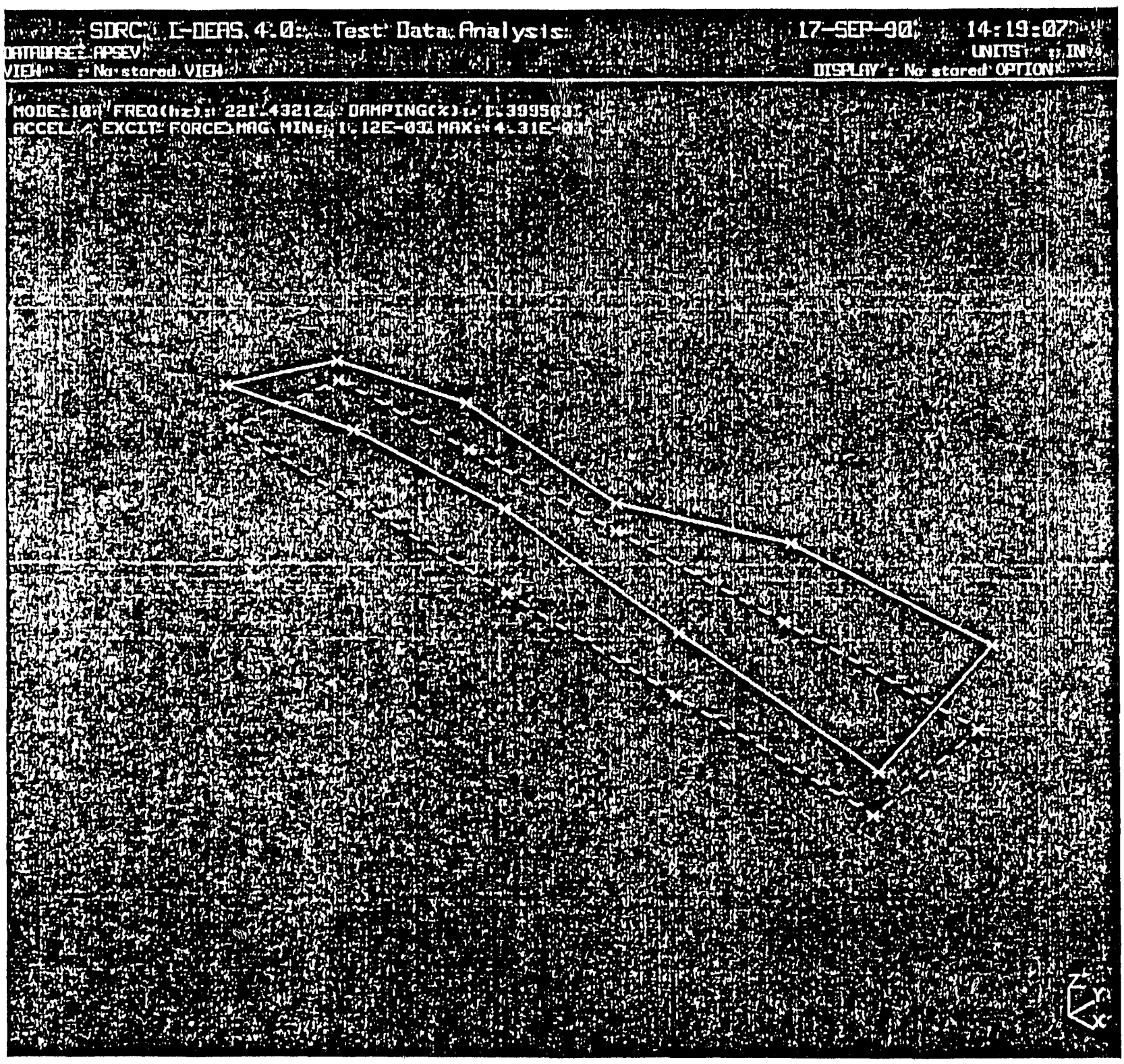




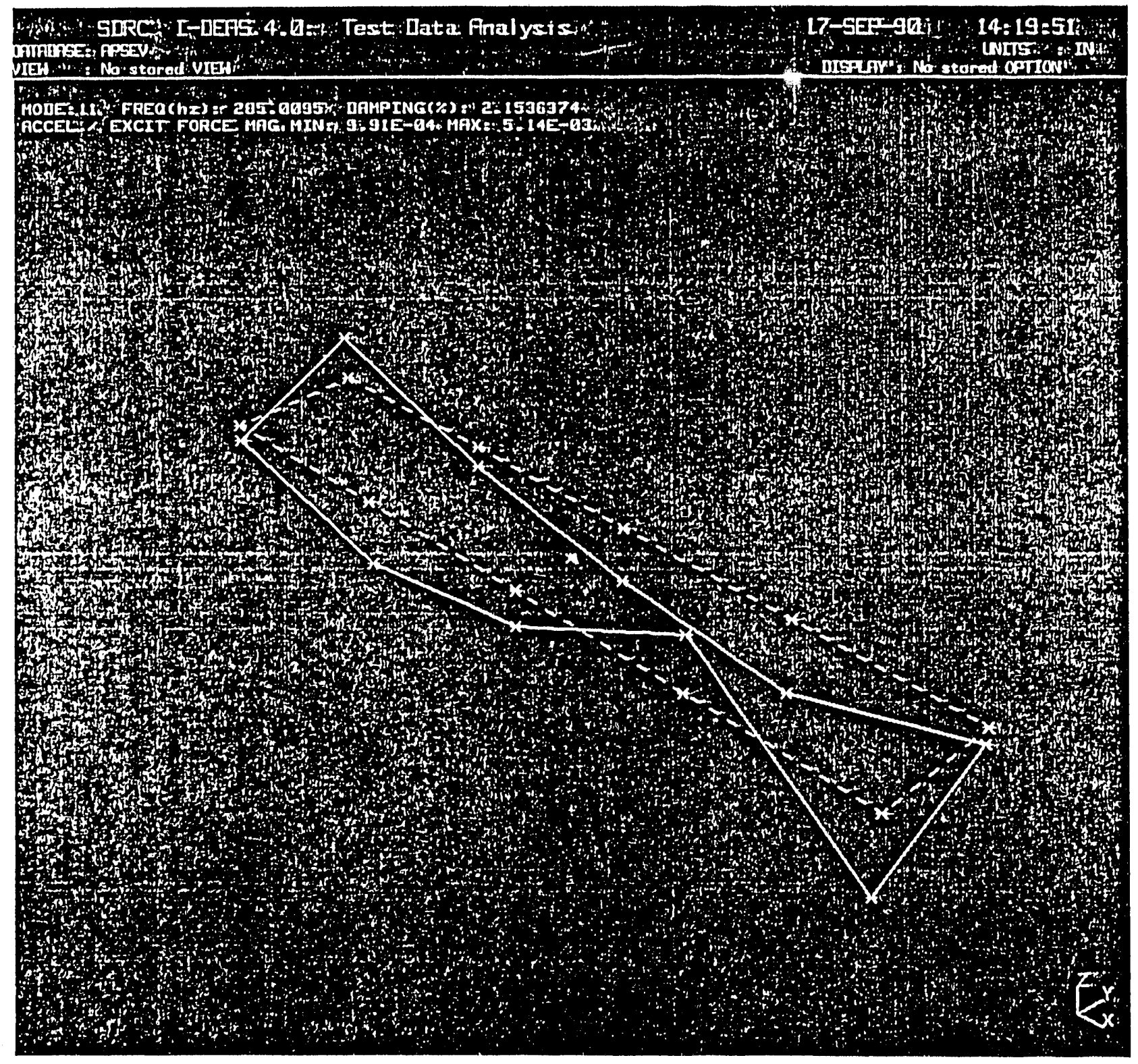




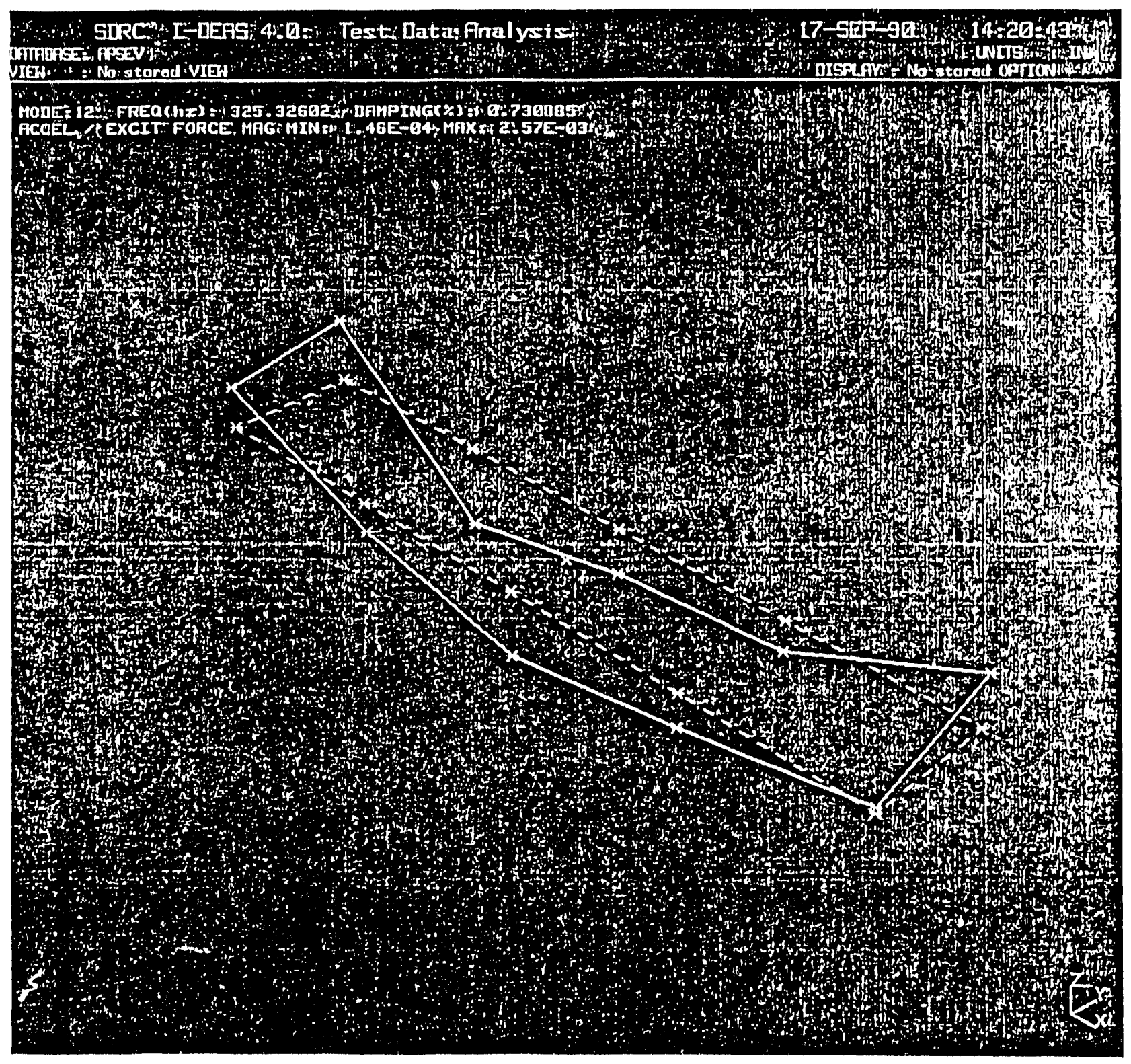




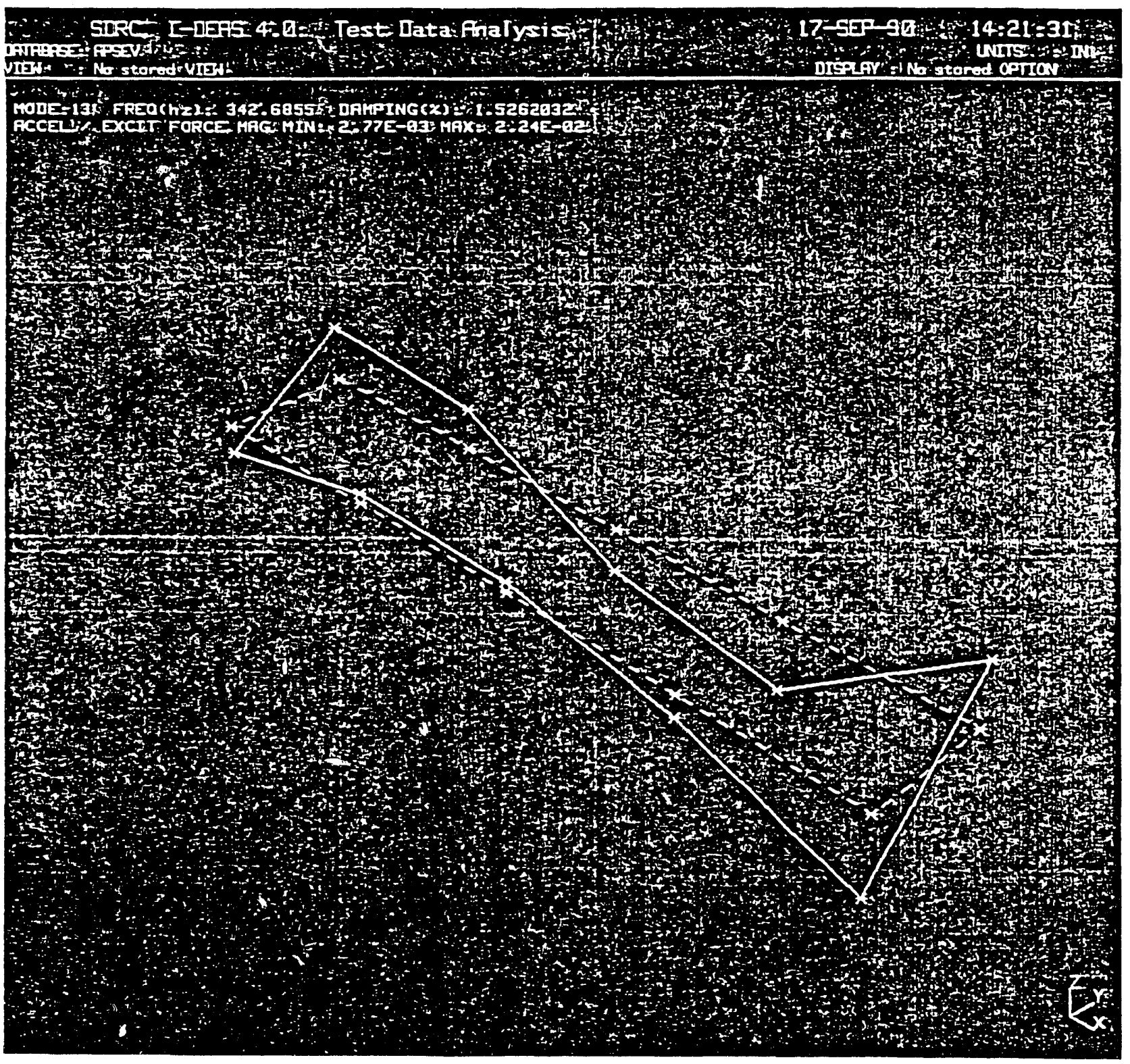




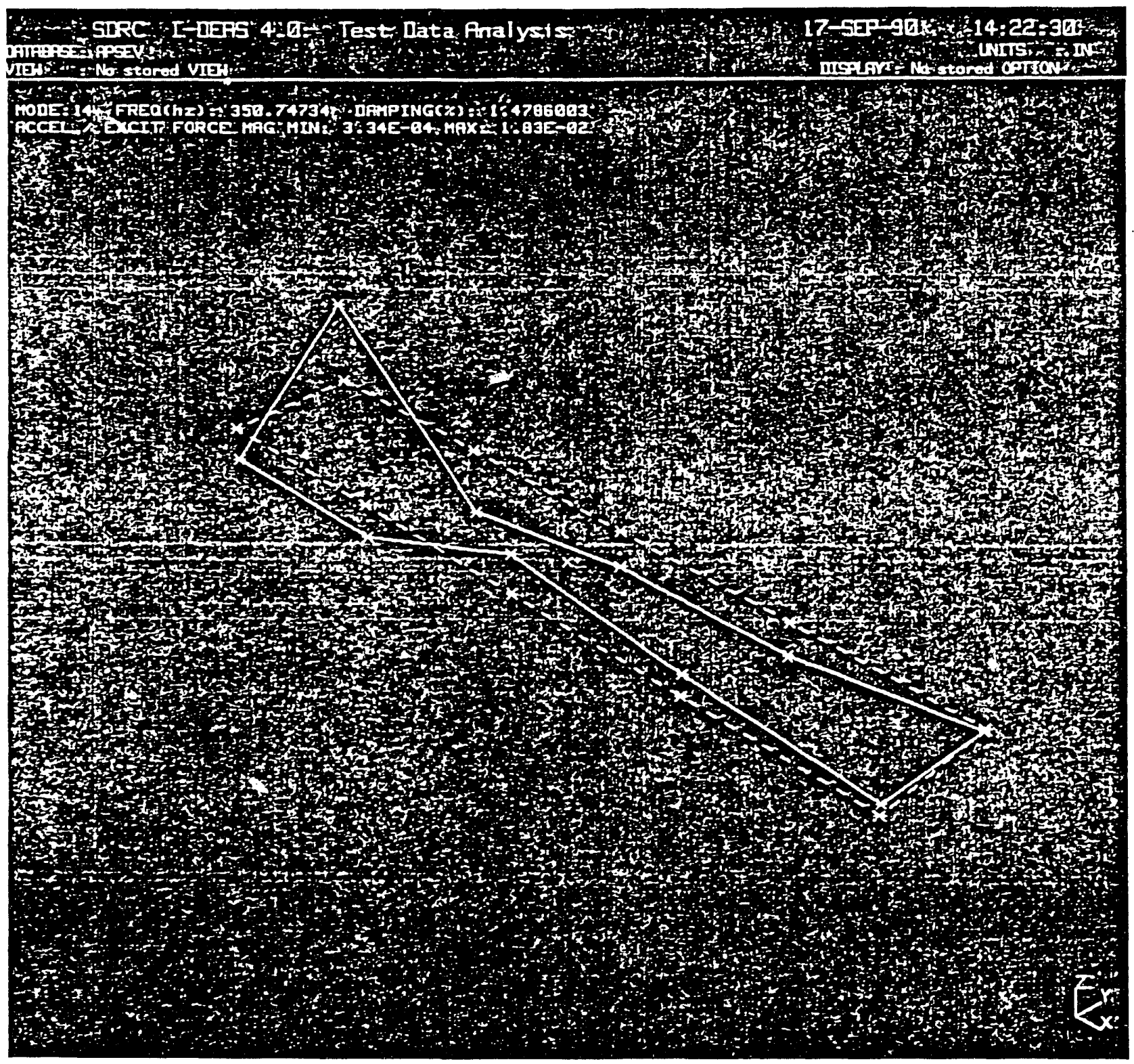




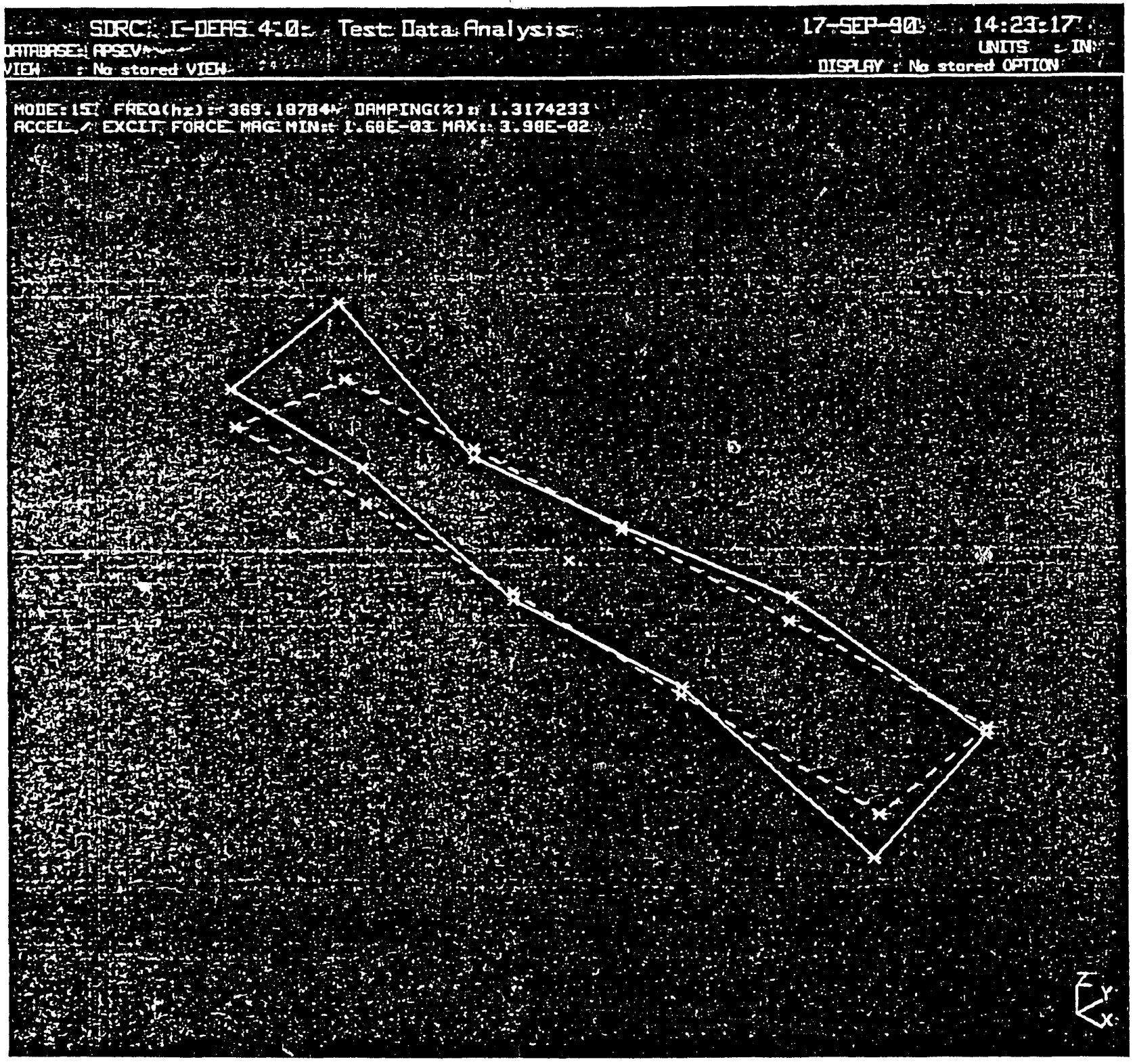



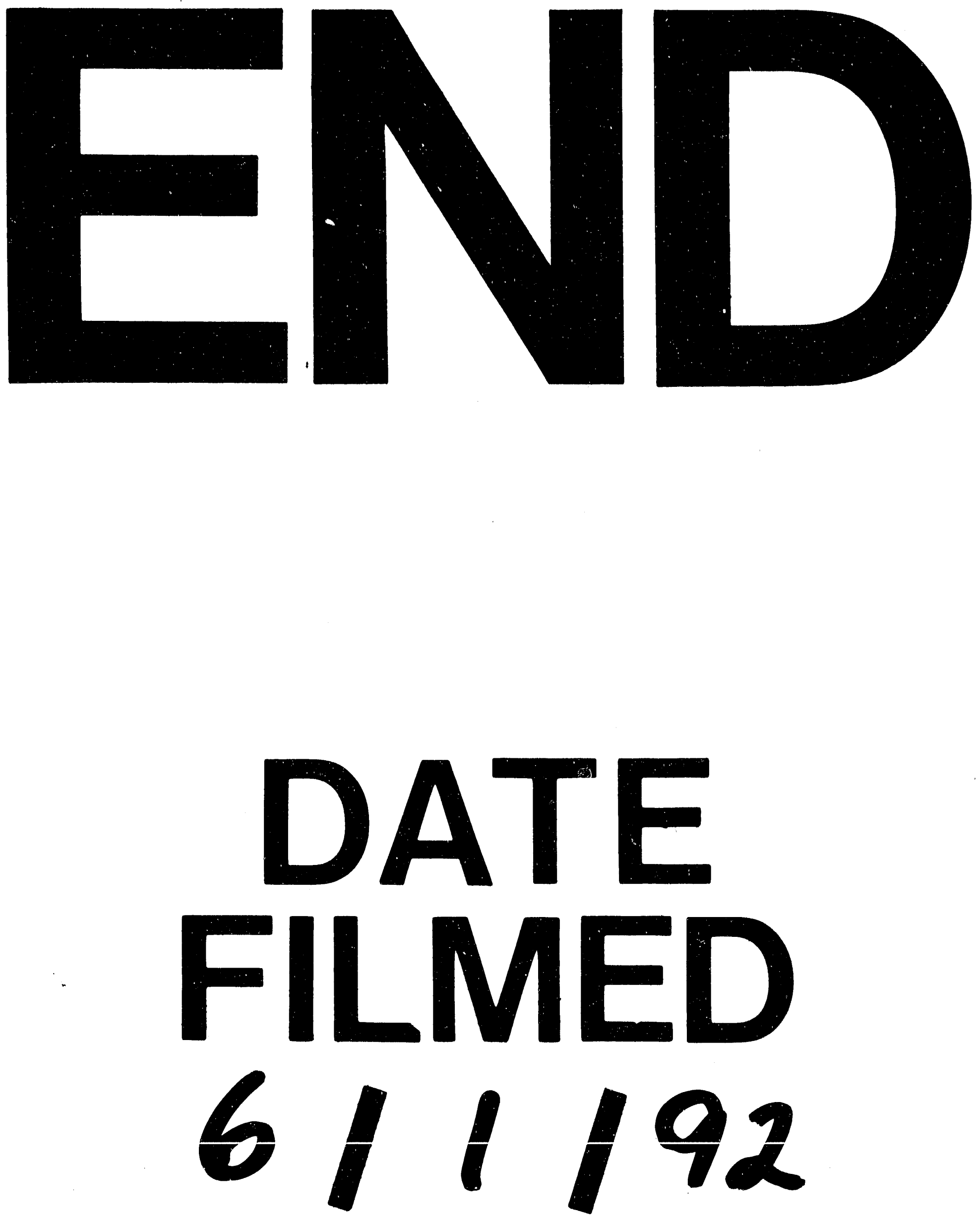
